\title{
Fiscal Year 1999 Battelle Performance Evaluation and Fee Agreement
}

Date Published

September 1998

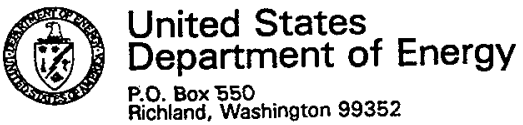

Approved for Public Release 


\section{RELEASE AUTHORIZATION}

Document Number: $\quad$ DOE/RL-98-60, Revision 0

Document Title: $\quad \begin{gathered}\text { Fiscal Year } 1999 \text { Battelle Performance } \\ \text { Evaluation and Fee Agreement }\end{gathered}$

This document, reviewed in accordance with DOE Order 1430.1D, "Scientific and Technical Information Management," and DOE G 1430.1D-1, "Guide to the Management of Scientific and Technical Information," does not contain classified or sensitive unclassified information and is:

APPROVED FOR PUBLIC RELEASE

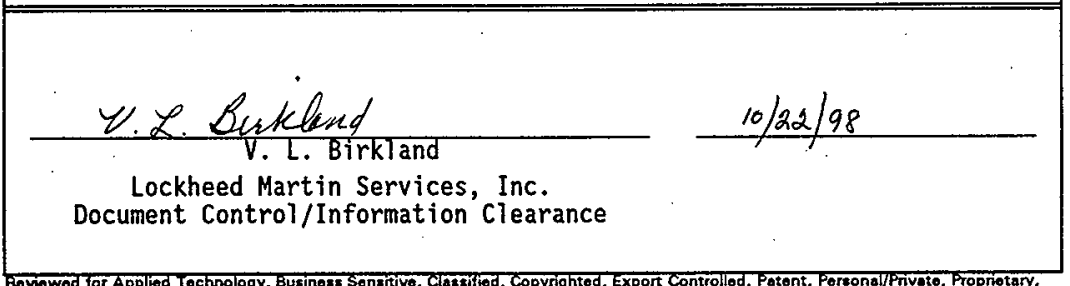

Rovewed for Applied Tochnology, Buriness Sentitive, Chastifed, Copyrighted, Export Controllod, Patant, PersonallPrivato, Propnotary, Protected CRADA, Trademark, Unclastified Controliod Nuclear information.

Tredemark Dicclaimer. Aeference herein to eny specific commercial product, process, or service by trade neme, trademark. manufecturer, of otherwise, does not necessarily constitute or imply its endorsement, recommendation, or favoring by the United States Govemment or any eqency theroof or tis contractore or etbeontractors. The viewe and opinione of authors expresced heroin do not necossarily etate or reflect those of the United States Govemment or any agency thereof. This report has been reproduced from the best avaliable copy.

Printed in the United States of America.

Avallable to the U.S. Department of Energy and its contractors from the U.S. Department of Eneray Office of Sciontlfic and Techical information, P.O. Box 62, Oak Ridgo, TN 37831; Tolophono: 423/576-8401.

Avellable to the publle from the U.S. Department of Commerce Netional Technical information Sorvice, 5285 Port Royal Road, Springfield, VA 22161: Tolephone: 703/487-4650. 
FY 1999

BATTELLE PERFORMANCE EVALUATION AND FEE AGREEMENT

For

Management and Operations of the

Pacific Northwest National Laboratory

This document directly supports the DOE-RL Contract for the Management and Operations of the Pacific Northwest National Laboratory Contract DE-AC0676RLO1830 as referenced within Appendix E of Section J and will be controlled by the DOE-RL Assistant Manager for Science \& Technology, the RL Contracting Officer and the Contractor Legal \& Contracts Directorate.

\section{Revision 0}

September 30, 1998
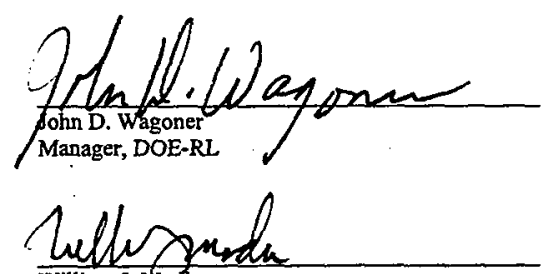

William J. Madia

Director, Pacific Northwest National Laboratory 
I. DETERMINING THE CONTRACTOR'S PERFORMANCE RATING AND PERFORMANCE-BASED FEE

II. AVAILABILITY OF ADDITIONAL PERFORMANCE-BASED FEE

III. CRITICAL OUTCOMES, OBJECTIVES \& PERFORMANCE INDICATORS Background

Performance Expectations

Change Control

Responsibility Matrix

1.0 SCIENTIFIC AND TECHNOLOGICAL EXCELLENCE (55\%)

Objective: Conduct high quality science and technology programs as measured by the following indicators (25\%)

1.1.1 Results of external peer review of relevance and excellence, including Divisional reviews

1.1.2 Recognition by the external scientific and technical community

1.1.3 Number of R\&D 100 and FLC awards

1.1.4 Number of publications in peer reviewed joumals

1.1.5 Number of quality academic/scientific partnerships

1.1.6 Results of DOE-OER Evaluation of the quality of science

1.2 Objective: Deliver Science and Technology Products Relevant to DOE Missions and National Needs (40\%)

1.2.1 Results of DOE-OER's evaluation of the relevance of Battelle's work to DOE Missions and Needs Description: The Director of Energy Research will provide an evaluation to the DOE-RL Contracting Officer as to the relevance of the Contractor's work to DOE missions and needs as primary input for this indicator. The rating will be based on the standard 5 step adjectival rating scale (Outstanding, Excellent, Good, Marginal, or Unsatisfactory).

1.2.2 The results of DOE-OER's evaluation of the Laboratory's programmatic performance 12

1.2.3 Effectively lead the technical aspects of the national Tanks Focus Area 13

1.2.4 Effectively support the Hanford Tanks Privatization Effort 14

1.2.5 Number of innovative technologies and approaches successfully deployed in commercial practice

1.2.6 Provide significant solutions to Hanford problems/needs

1.2.8 Number of solutions and deployments to significant national security problems/issues 20

1.2.9 Customer Feedback on relevance and excellence in National Security 22

1.2.10 Number of energy technologies, systems and technical solutions deployed 22

1.2.11 Customer Feedback on relevance and excellence in Energy 23

1.3 Objective: Successfully operate the Wiley Lab and ARM Facilities (10\%) 24

1.3.1 Successful operation of the Wiley Laboratory 24

1.3.2 Operation of Atmospheric Radiation Measurement (ARM) Extended Research Facilities 25

1.3.3 Results of DOE-OER's evaluation of the quality of the Laboratory's User Facilities 27

1.4 Objective: Demonstrate leadership and excellence in program planning and management for critical outcomes (25\%)

1.4.1 Demonstrate programmatic leadership within Fundamental Science 27

1.4.2 Demonstrate programmatic leadership in Environmental Quality . 28

1.4.3 Effectively lead the technical aspects of the Groundwater and Vadose Zone efforts 29

1.4.4 Customer Feedback on Leadership for key National Security Programs 29

1.4.5 DOE customer feedback on technical and managerial leadership in the Energy thrust areas

1.4.6 Number of formal agreements (e.g., CRADAs, MOUs, non-government contracts, and other formal agreements and expressions of interest) established between October 1, 1998 and September 30, 1999 with private sector entities 
2.1 Objective - Sustain and enhance operational excellence in safety and health, and environmental protection. (67\%)

2.1.1 Worker involvement, knowledge, and culture relative to ES\&H (30\%)

2.1.2 ES\&H training commensurate with assigned responsibilities (30\%)

2.1.3 Material Control (30\%)

2.1.4 ES\&H Lagging Performance Indicators (10\%)

2.2 Objective: Increase mission capabilities through enhancement and effective use of Laboratory facilities and assets. (33\%)

2.2.1 Facilities (Buildings): Utilization of space is commensurate with science and technology mission needs (60\%)

2.2.2 R\&D Equipment Utilization (10\%)

2.2.3 Facilities and Services Integration: An increased level of interaction with other Hanford Site contractors supporting facility infrastructure and services. (30\%)

$3.0^{\circ}$ LEADERSHIP AND MANAGEMENT (20\%)

3.1 Objective - Battelle will provide leadership and management to foster a work environment that optimizes staff satisfaction and individual contribution. (30\%)

3.1.1 Staff separations rate

3.1.2 Personal/Professional Development

3.2 Objective - Battelle Leadership provides effective management systems to drive improvements enabling DOE to optimize oversight activities. (40\%)

3.2.1 Contractor's independent annual averaged rating of the Divisions/Directorates self-a ssessment program performance

3.2.2 DOE's satisfaction with the implementation of the Contractor's self-assessment process

3.2.3 Staff satisfaction with internal products and services from the management systems. 86

3.3 Objective - Battelle leadership and management promote open and effective business operations. (30\%)

3.3.1 Research/support staff labor ratio

3.3.2 Average cost per research FTE

3.3.3 DOE's evaluation of overall Contractor performance in the business management functional areas.

4.1 Objective - Battelle will continue/establish partnerships with local and regional organizations to enhance science, mathematics, and technology education reform efforts in schools. (15\%)

4.1.1 The impact of Laboratory-sponsored programs for teachers of science, mathematics, and technology education in partner school districts.

4.2 Obiective - Battelle will put technology to work in the Tri-Cities and Pacific Northwest to create and sustain a diversified and strong economy. (50\%)

4.2.1 Number of primary sector jobs created within the local area over the five fiscal years beginning with FY 1998 and ending with FY 2002.

4.3 Objective - Battelle will serve the communities to further enhance the Laboratory's status as a valued corporate citizen of the Northwest region. (35\%)

4.3.1 Successfully deploy a community volunteerism program

4.3.2 The percentage increase in the hiring rate of minorities in mid-level professional feeder job groups.

4.3.3 Successful deployment of campaigns to increase awareness of Laboratory capabilities applicable to issues and industries of regional significance. 


\section{INTRODUCTION}

Fiscal Year 1999 represents the third full year utilizing a results-oriented, performance-based evaluation for the Contractor's operations and management of the DOE Pacific Northwest National Laboratory (here after referred to as the Laboratory). However, this is the first year that the Contractor's fee is totally performance-based utilizing the same Critical Outcomes. This document describes the critical outcomes, objectives, performance indicators, expected levels of performance, and the basis for the evaluation of the Contractor's performance for the period October 1, 1998 through September 30, 1999, as required by Clauses entitled "Use of Objective Standards of Performance, Self Assessment and Performance Evaluation" and "Performance Measures Review" of the Contract DE-AC06-76RL01830. Furthermore, it documents the distribution of the total available performance-based fee and the methodology set for determining the amount of fee eamed by the Contractor as stipulated within the clauses entitled "Estimated Cost and Annual Fee," "Total Available Fee" and "Allowable Costs and Fee." In partnership with the Contractor and other key customers, the Department of Energy (DOE) Headquarters (HQ) and Richland Operations Office (RI) has defined four critical outcomes that serve as the core for the Contractor's performance-based evaluation and fee determination. The Contractor also utilizes these outcomes as a basis for overall management of the Laboratory.

As stated above four critical outcomes have been established for FY 1999. These outcomes are based on the following needs identified by DOE and other customers of the Laboratory. The DOE desires quality and relevant science, effective utilization of user facilities, and efficient programmatic performance. All our customers (EM, NN, ER, \& EE) want technology developed, demonstrated, and deployed to soive environmental cleanup, national security, energy, and fundamental science issues. Furthermore the DOE wants improved leadership/management, cost-effective operations, and maintenance of a work environment which fosters innovative thinking and high morale. The Department also desires compliance with environment, safety and health (ES\&H) standards and disciplined conduct of operations for protection of the worker, environment, and the public. As with all of Hanford, DOE expects contribution of the Laboratory to the economic development of the Tri-Cities community, and the region, to build a new local economy that is less reliant on the Hanford mission, as well as enhancing the status of the Laboratory as a valued corporate citizen of the Northwest Region. The Critical Outcome system focuses all of these customer desires into specific objectives and performance indicators, with supporting measures to track and foster continued improvement in meeting the needs (outcomes) of the Laboratory's customers.

For FY 1999 the Critical Outcomes will be utilized to determine the amount of the total available fee of $\$ 7,100,000.00$ eamed by the Contractor within the two areas specified within the contract clauses "Allowable Costs and Fee." Battelle shall receive a performance-based fee of up to $\$ 5,700,000.00$ based on the overall rating of all the four critical outcomes. Furthermore, the contractor may be eligible for additional performance-based fee of up to $\$ 1,400,000.00$ if the Scientific and Technological Excellence Outcome is rated at Excellent or above.

Note: All fee is assigned at the Critical Outcome level and no fee has been delegated to the objective or performance indicator levels throughout this document. Although the indicators within each Outcome shall be the primary means for determining to what extent the Contractor has met each Outcomes, the DOE-RL Contracting Officer may consider any other information available to him/her which relates to the Contractor's performance of all other contract requirements set forth in the Statement of Work, Work Authorization Directive, or similar document in final determination of fee earned as stipulated within the clause entitled "Conditional Payment of Fee" within the contract DE-AC06-76RL01830.

\section{Performance-based Fee Allocation Strategy}

The fee allocation strategy for the Battelle contract with DOE RL, for the management and operation of the Laboratory, is based on the principle that performance-based fee should be viewed as a benefit to DOE; that if the contractor performs well, more fee should be earned. This is consistent with contract reform and the Functional Cost Reporting System formulated by the Financial Management System Improvement Council. This principle leads to a strategy of incrementally rewarding exemplary performance rather than 
incentivizing particular activities and deliverables. Such a strategy transcends a narrow focus on outputs and elevates the performance discussion to the level of outcomes aligned with the mission and agenda of the institution.

Thus, while remaining performance-based, fee allocation may be seen as a strategic investment into certain areas, or portfolios, critical to the DOE and its Laboratory. Each allocation represents the collective wisdom of the senior strategic decision-makers within the DOE Operations Office, the DOE Headquarters institutional steward, and the Contractor. In the case of the Pacific Northwest National Laboratory, these investment portfolios for Fiscal Year 1999 are the four Critical Outcomes identified below. Since management fee is inherently beneficial, the performance-based fee is allocated according to the key decision-makers' judgement of the perceived relative benefit of each Outcome as indicated by the weightings assigned to each. This is true for the overall performance-based fee as well as the additional performance-based fee.

As the primary mission of the Laboratory is science and technology, exemplary achievement in this area is paramount. Similarly, safe effective, efficient operations, leadership, and management outcomes are of equal strategic importance to each other, but of lesser importance than the primary mission. Finally, while sensitivity and responsiveness to community expectations and overall corporate citizenship are essential to institutional success, this outcome is judged to be of the least strategic benefit-worthy of reward, but in smaller amount.

This allocation strategy is aligned with the DOE Strategic Plan, the DOE Laboratory Mission Plan, the Hanford Strategic Plan, as well as the Institutional Plan for the Laboratory. It represents the collective wisdom, formed in partnership, of the senior leadership of DOE Headquarters, the Operations Office, and the Contractor. The strategy rewards the Contractor and benefits DOE for optimizing overall performance against critical outcomes rather than inviting focus on a few outputs to the detriment of others. The following sections detail the process whereby the fee allocation strategy is implemented and the fees eamed are actually determined.

Section I provides information on how the overall performance rating for the Contractor, as well as how the performance-based fee earned (if any) will be determined.

Section II provides information on how the additional available performance-based fee earned (if any) shall be determined utilizing the Scientific and Technological Excellence Critical Outcome as the gateway for additional fee earnings.

Section III provides the detailed information concerning critical outcomes, objectives, performance indicators and expectations of performance, along with the matrix for determining the amount of additional performance-based fee eamed (if any) for each outcome.

Section IV describes the commitments for documenting and reporting the Laboratory's self-evaluation. 
The FY 1999 Battelle performance evaluation rating will be determined using a process wherein progress against each Performance Indicator will result in a corresponding point value. The point values of each Performance Indicator will be taken from the associated Contingency Diagram. Points for each Performance Indicator will be added to determine a numeric rating for the corresponding Objective.

The sum of the points for each Objective supporting a Critical Outcome will then be weighted according to this agreement and added to determine the point value for the Critical Outcome. The point value for each Critical Outcome will determine an adjectival rating in accordance with the corresponding table for each Critical Outcome. The adjectival rating and corresponding point value for each Critical Outcome will be weighted in accordance with the Table A, below, and will be added to determine the Contractor's point total. The total points will be compared to the scale in Table B, below; to determine an overall Contractor adjectival rating and the amount of performance-based fee earned.

This technique carries raw points and weighted points forward through the entire process. A detailed explanation is provided below.

Performance Indicator Score Development: Raw scores for each Performance Indicator are determined by plotting year-end performance along the $\mathrm{x}$-axis of the associated Contingency Diagram and adding the Effectiveness points accumulated along the $Y$-axis and translating that level to the appropriate number value using the scales for each indicator found in this document.

Evaluation of Objectives: Point scores for each Objective are determined by adding the individual Effectiveness scores for each Performance Indicator from the associated Contingency Diagram. The totals of each of the Objectives are then converted to the 5 point scale utilized by DOE $(1.0-5.0)$ utilizing the normalization table for each Objective. Each Objective is then weighted according to the weightings provided in each Critical Outcome section.

Critical Outcome Evaluation: Numeric Critical Outcome scores are weighted as defined in Table A below and are summed to determine the Contractor's overall weighted evaluation score.

Determining the Overall Contractor Adjectival Rating: The total Critical Outcome score is compared to an adjectival rating scale, see Table B below, to determine the overall Contractor rating for Fiscal Year 1999.

Determining the Amount of Performance-Based Fee Eamed; The total Performance-Based Fee eamed is determined based on the over all Contractor adjectival rating for Fiscal Year 1999 as indicated within Table $B$ below (an Excellent rating and above earns $100 \%$ of the available performance-based fee, a Good rating provides $80 \%$ of the available performance-based fee, a Marginal and below performance earns $0 \%$, of the available performance-based fee).

Note: All numeric values that have been normalized to the 5 point scale specified in this document will be rounded to the nearest tenth of a point using the standard rounding convention of $x .49$ and less rounds down to the nearest tenth, while $x .50$ and greater rounds up to the nearest tenth. Rounding will be performed at each calculation level. 


\begin{tabular}{|c|c|c|c|c|}
\hline 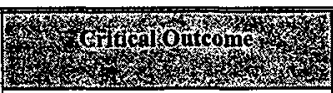 & 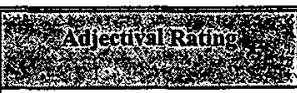 & (5) & Moth & Hojo \\
\hline $\begin{array}{l}\text { Scientific and Technological } \\
\text { Excellence }\end{array}$ & & . & $55 \%$ & \\
\hline Operational Excellence & & & $20 \%$ & \\
\hline Leadership \& Management &. & & $20 \%$ & \\
\hline Community Relations & & & $5 \%$ & \\
\hline 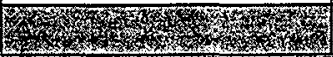 & W & (1) & 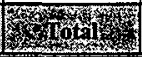 & \\
\hline
\end{tabular}

Table A. FY 1998 Contractor Evaluation Score Calculation

\begin{tabular}{|l|c|c|c|c|c|}
\hline Total Score & $5.0-4.5$ & $4.4-3.5$ & $3.4-2.5$ & $2.4-1.5$ & $<1.5$ \\
\hline Final Rating & Outstanding & Excellent & Good & Marginal & Unsatisfactory \\
\hline $\begin{array}{l}\text { Performance- } \\
\text { Based Fee }\end{array}$ & $\$ 5,700,000.00$ & $\$ 5,700,000.00$ & $\$ 4,560,000.00$ & $\$ 0.00$ & $\$ 0.00$ \\
\hline
\end{tabular}

Table B. Overall Contractor Adjectival Rating and Performance-Based Fee Scale

\section{AVAILABILITY OF ADDITIONAL PERFORMANCE-BASED FEE}

A total available additional performance-based fee of $\$ 1,400,000.00$ has been allocated among the critical outcomes for Fiscal Year 1999 as specified within Table C below. However, the additional performancebased fee is only available to be earned by the Contractor if the Scientific and Technological Excellence Critical Outcome is rated at Excellent or above. If this gateway is achieved, then the Contractor shall be eligible to claim the otherwise additional performance-based fee earned for each critical outcome as specified within the Available Performance-Based Fee Matrix designated with each outcome (see tables $1.4,2.11,3.4$, and 4.4$)$.

\begin{tabular}{|c|c|}
\hline Critical Outcome $\mathrm{W}$ W $\mathrm{S}$, & 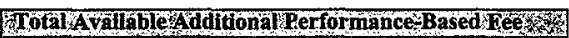 \\
\hline Scientific and Technological Excellence & $\$ 770,000.00$ \\
\hline Operational Excellence & $\$ 280,000.00$ \\
\hline Leadership and Management & $\$ 280,000.00$ \\
\hline Community Relations & $\$ 70,000.00$ \\
\hline
\end{tabular}




\section{CRITICAL OUTCOMES, OBJECTIVES \& PERFORMANCE INDICATORS}

\section{Background}

To ensure both the short and long-term ability of the Pacific Northwest National Laboratory to meet DOE missions and provide high-value products and services to the DOE and other customers, the DOE-HQ and $R L$, in partnership with the Contractor, evaluated DOE and other customer needs and current operating environments to develop the Laboratory's four Critical Outcomes. While they are validated anmually the Critical Outcomes typically have a 3-5 year time horizon.

The outcome-oriented approach focuses the evaluation of the Contractor's performance against these Critical Outcomes. Progress against these outcomes is measured through the use of specific performance indicators (objective and subjective) that primarily focus on end-results or impact and not on processes or activities. These measures are embodied within the formal contract through Appendix E and F of Section J.

\section{Performance Expectations}

The four Critical Outcomes and their objectives, as agreed to by DOE-HQ, RL, and the Contractor, provide the framework for evaluation and fee determination for Fiscal Year 1999. With this framework DOE-RL and Contractor staff have teamed to develop mutually-agreed upon performance indicators. In addition, considerable effort has been devoted to developing an understanding of the performance expectations associated with each of the objective and subjective performance indicators. The specific performance expectations and associated performance ratings and performance-based fee are contained within this document.

\section{Change Control}

While the Critical Outcomes described herein represent the current set for the Contractor they can also be changed as prevailing scientific, and/or economic factors change. When this happens, the objectives and the resulting performance indicators will also be altered to ensure movement of the Laboratory in a direction consistent with the expectations of its customers. The content of this document will be managed via formal change control. Changes to the FY 1999 Performance Evaluation and Fee Agreement will be documented by completing the Change Control Tracking Sheet (see Appendix A). The sheet is selfexplanatory and require the concurrence of both RL and the Contractor Critical Outcome Owners as well as a documented description of the proposed modification and a documented rationale for the modification to include what effects (if any) the change may have on the ability for the Contractor to earn performancebased fee.

Once the Critical Outcome Owners have concurred with the modification, RL staff should forward the form with the prescribed attachments to Terry L. Davis at mail stop K8-50. Contractor staff should forward the change control form, with attachments, to Randy R. LaBarge at mail stop K1-30. They shall ensure that all required information has been provided and that both Critical Outcome Owners have concurred in the modification. The modification will then be logged in and final RL and Contractor approvals obtained as necessary to include Contracting Officer approval. Once approved the document will be updated through RL Document Control and revised pages will be issued.

The above process is the preferred method for incorporating changes to this document, however, if the Parties cannot reach agreement on the changes to critical outcomes, objectives, performance indicators, and/or expected levels of performance, the Contracting Officer shall have the right to unilaterally establish changes as referred to within the clause entitled "Total Available Fee" within the contract DE-AC0676RL01830. 


\section{Responsibility Matrix}

Appendix B identifies the RL and Contractor Critical Outcome Owners and points-of-contact for each of the objectives and performance indicators.

\section{Critical Outcomes, Objectives, and Performance Indicators}

The following sections describe the Critical Outcomes; their supporting objectives, and associated performance indicators for FY 1999 as well as the matrix for additional performance-based fee for each outcome. 


\subsection{SCIENTIFIC AND TECHNOLOGICAL EXCELLENCE (55\%)}

\section{Critical Outcome}

\section{Battelle will conduct high quality, externally recognized, scientific research and development programs.}

Modification: The objectives, indicators and expected levels of performance identified below have been developed based on the best information available at the time. Should circumstances arise which require modifications to any of the objectives, indicators and/or expected levels of performance within this outcome it shall be accomplished through the approved change control process described within this document. If the Parties cannot reach agreement on the changes the Contracting Officer shall have the right to make reasonable changes as specified within the contract DE-AC06-76RLRL01830.

1.1 Objective: Conduct high quality science and technology programs as measured by the following indicators $(25 \%)$

1.1.1 Resuits of external peer review of relevance and excellence, including Divisional reviews

Description: The results from Research Division Review Committees (none of whom are Battelle employees) and DOE program offices are evaluated to determine performance against this indicator.

A) Division Review Committee Evaluations: Division reviews (performed by Research Division Review Committees) will be provided to the Director of the Laboratory. Research Division reviews shall follow the guidance provided in the Laboratory Subject Area entitled, "Peer Review". The results from these reviews, including performance levels and trends and Laboratory response, also will be summarized into an overall evaluation and performance rating based on the standard 5 point scale.

The following Division reviews are planned:

- Environmental and Health Sciences Division

- Environmental Technology Division

- Energy Technology Division

- National Security Division

B) DOE Program Office Reviews: DOE Program Offices determine those peer reviews to be conducted in any given year. DOE Program reviews can include an evaluation of the following:

- Quality of Science and technology

- Relevance to DOE missions or national needs

- Effective and efficient program management

- Success in construction and operation of facilities.

DOE-HQ Program reviews currently anticipated for FY 1999 include the following:

- Atmospheric Radiation Measurements Program: OBER/JASONS-Environmental Sciences Division

- Chemical Sciences Program: OBES-Chemical Sciences Division

- Materials Science Program: OBES-Materials Sciences Division 
Baseline Information: Results of all Division and Program reviews are evaluated and a composite score is assigned. In FY 1997 the Laboratory achieved a rating of outstanding. Although the FY 1998 ratings have not yet been received $R L$ does not expect a marked change in this area.

Performance Expectation Related Assumptions: Specific Program reviews are determined by DOE Program offices and are therefore subject to change. During Research Division Review closeout meetings, a DOE-RL Science and Technology Program Division representative will attend Division Committee closeout meeting with the Associate Laboratory Director and the Division Review Committee chairman.

Performance: Composite of all scheduled peer reviews.

Target: $\quad$ Outstanding

Neutral: $\quad$ Good

Minimum: Unsatisfactory

1.1.2 Recognition by the external scientific and technical community

Description: The three types of "recognition" information that are gathered include: Awards, Invited Talks, and Committee Service. A standard of quality and/or significance has been developed for each recognition type from which to judge the recognition for inclusion in this performance indicator. Each of the following categories has three standards of quality/significance. Point rankings will be assigned to each $[3,2$, and 1$]$ for quantifying the performance measure.

Awards

3 points: highest honors/recognition from an external professional society or organization; adjunct faculty; fellows

2 points: long-term achievement/service awards from major state, national, or international scientific and technical bodies

1 point: general external professional recognition (e.g., assisting in event, authoring special publication, or special distinction from a professional organization)

Invited Talks

3 points: Invited keynote speaker, course teacher, or critical event organizer for a major professional organization or event

2 points: Invited presenter at or active contributor to a major professional organization or event

1 point: general invited participant to a professional organization or event

Committee Service

3 points: highest external service/appointment recognition by a state, national, or international level professional community (e.g., directorships, editorial boards, major strategic alliance assignments with scientific agencies or industry)

2 points: long-term recognition from or invited membership to a major scientific or technical body (e.g., state, national, or international committees, boards, and panels)

1 point: short-term external professional service/appointment assignments (e.g., supporting key event or meeting)

The following is planned:

- Category scopes and numbers in each category have been established (Awards, Invited Talks, and Committee Service) and included based upon meeting the standard of quality mentioned above. 
- Recognition data will continue to be gathered in FY 1999, with the FY 1999 performance indicator target being established relative to the average of the sum total of the recognition categories for FY1997 and FY 1998.

- By FY 2000, data will exist to establish a three-year rolling average measurement basis for Recognition by the Scientific and Technical Community.

Baseline Information: FY 1997 (Awards-24, Invited Talks-24, Committee Service-27).

Performance Expectation Related Assumptions: Evaluation for FY 1999 is a comparison to the average of FY 1998 and FY 1997.

Performance: Percentage change in total points

Target: $\quad 10 \%$ increase in awards

Neutral: $\quad 0 \%$ increase in awards

Minimum: $\quad 10 \%$ decrease in awards

\subsubsection{Number of R\&D 100 and FLC awards}

Description: The indicator will be based on a 3 year rolling average of the number of R\&D 100 and FLC Awards received by the Laboratory each year.

R\&D Awards are submitted in the early spring for a summer notification.

FLC Awards are submitted in September for December notification.

Baseline Information: Laboratory historical performance data is indicated below:

\begin{tabular}{|c|c|c|c|c|c|c|c|}
\hline & FY92 & FY93 & FY94 & FY95 & FY96 & FY97 & FY98 \\
\hline R\&D 100 & 3 & 2 & 2 & 3 & 5 & 3 & 7 \\
\hline FLC & 3 & 4 & 3 & 3 & 3 & 4 & 3 \\
\hline Total & 6 & 6 & 5 & 6 & 8 & 7 & 10 \\
\hline
\end{tabular}

Performance Expectation Related Assumptions: The Laboratory is allowed a maximum of four FLC submissions.

Performance:

Target: Three-year average of 8.0 or better

Neutral: $\quad$ Three-year average of 7.33

Minimum: Three-year average of 6.66 or less

1.1.4 Number of pubiications in peer reviewed journais

Description: This indicator represents the number of publications by staff in peer reviewed technical journals or publications, resulting from activities completed while employed by the Laboratory. "Peer reviewed," means joumals which are self-reported or refereed in either EBSCO Serials Directory or Ulrich's International Periodical Directory. The number of publications by staff will be determined by a search of the following commercially available databases for authors employed by the Laboratory:

- Chemical Abstracts (Chemistry)

- SciSearch

- Social SciSearch (Social Sciences) 
- BIOSIS Previews (Life Sciences)

- INSPEC (Physics/Electronics/Electrical Engineering)

- Ei Compendex*Plus (Engineering)

- EMBASE (Biomedical)

- MEDLINE (Biomedical)

Note: For the purposes of benchmarking, an additional search was conducted spanning FY $1995-$ FY 1997 in the SciSearch database, comparing the raw numbers of publications from Pacific Northwest National Laboratory, Oak Ridge, Emest Orlando Lawrence Berkeley, Brookhaven, and Argonne National Laboratories, and the percentage of change over that time frame. This data will be collected again at the end of FY 1998, and can be used for the basis of further discussion on setting performance expectations in the future. The data currently has not been normalized against the number of researchers at each laboratory or any other factors such as funding levels and sources. This data (from the SciSearch database only) is presented below. Any change will be incorporated via approved change control.

\begin{tabular}{lrrrrrrr}
\hline Laboratory Name & FY95 & FY96 & FY97 & \% change & \% change & \% change \\
\hline & & & & FY95-FY96 & FY96-FY97 & FY95-FY97 \\
& & & & & & & \\
Pacific Northwest National Laboratory & 407 & 399 & 439 & $-2 \%$ & $10 \%$ & $8 \%$ \\
Oak Ridge National Laboratory & 1116 & 1022 & 1158 & $-8 \%$ & $13 \%$ & $4 \%$ \\
Ernest Orlando Lawrence Berkeley Laboratory & 1139 & 1085 & 1179 & $-5 \%$ & $9 \%$ & $4 \%$ \\
Brookhaven National Laboratory & 726 & 660 & 666 & $-9 \%$ & $1 \%$ & $-8 \%$ \\
Argonne National Laboratory & 980 & 801 & 955 & $-18 \%$ & $19 \%$ & $-3 \%$ \\
\hline
\end{tabular}

Baseline Information: Battelle staff had 485 publications published in 30 peer-reviewed joumals in FY97(data from all 8 databases previously mentioned).

Performance Expectation Related Assumptions: None

Performance:

Target:

Neutral:

525 publications published

Minimum:

500 publications published

425 publications published

1.1.5 Number of quality academic/scientific partnerships

Description: This indicator consists of two parts. The first measures the number of quality strategic partnerships between the Laboratory and colleges, universities, and other academic support organizations that link institutional goals, interests, and capabilities so that substantive collaborations may occur that enhance the research and education missions of the partners. The second part drives the development of mechanism to measure the number of strategic partnerships between the Laboratory and other national laboratories and industry.

1.1.5.1 Battelle. will continue and/or establish strategic research/education partnerships with colleges, universities, and other academic support organizations that enhance the Laboratory's science/technology mission and are consistent with the relevant provisions of the Department of Energy's Strategic Plan. These partnerships will:

1. develop/enhance strategic research/education partnerships with Northwest colleges, universities, and other academic organizations that strengthen specific core technical 
capabilities of the Laboratory, enhance the Laboratory's science/technology mission, and support the research and education missions of Laboratory partners, and

2. develop/enhance integrated research/education partnerships and collaborations with colleges, universities, and other academic organizations that augment/strengthen the Laboratory's mission and broad set of core technical capabilities, enhance the Laboratory's science/technology mission, and support the research and education missions of Laboratory partners.

Progress during FY 1999 will be tracked and based on the following measures:

The number of partners that meet the Laboratory's quality criteria for research/education partnerships in 3 areas: informal/formal agreements, appointments, and substantive interactions/collaborations. Approximately 20 separate criteria are used to quantify the extent and quality of the academic/scientific relationships under this indicator. Institutions demonstrating commitment and accomplishment in at least 12 of those 20 measures are deemed "Robust" partners. Those with at least 9 criteria fulfilled are "Developing" partners. And those with as least 6 are "Emerging" partners. (Colleges or universities with fewer than 6 facets of interaction with the Laboratory are not counted as partners.)

Baseline Information: In FY 1997, there were a total of 47 partners representing colleges/universities.

Performance Expectation Related Assumptions: Ability to meet this indicator is heavily influenced by funding.

Performance:

$\begin{array}{ll}\text { Target: } & 80 \text { partners } \\ \text { Neutral: } & \text { 55 partners } \\ \text { Minimum: } & \text { 25 partners }\end{array}$

1.1.5.2 The Laboratory will develop a mechanism to permit measurement of our ability to establish strategic research partnerships with other national laboratories, industry, and other national or international scientific organizations that enhance the Laboratory's science/technology mission. The data collected in FY99 will be used to establish a baseline for future years.

Baseline Information: No baseline is currently available. The baseline will be established during FY99.

Performance Expectation Related Assumptions: The proposed mechanism(s) for collecting data will need to be finalized early in the first quarter of FY99 to ensure an accurate baseline can be captured.

Performance Expectation: Success against this indicator will be measured by:

- Definition of what will be measured completed in Q1FY99.

- Tracking mechanism established and agreed upon in Q1FY99.

- Baseline established by the end of FY99.

Performance Expectation: Does not contribute to score. 


\subsubsection{Results of DOE-OER Evaluation of the quality of science}

Description: The Director of Energy Research will provide an evaluation to the DOE-RL Contracting Officer as to the quality of science conducted by the Contractor as input for this indicator. The rating will be based on the standard 5 step adjectival rating scale (Outstanding, Excellent, Good, Marginal, or Unsatisfactory).

Baseline: In FY97 the Contractor received a rating of "Outstanding" from the DOE Office of Energy Research in the area of Quality of Science. Although FY 1998 ratings have not yet been received RL does not expect a marked changed in this area.

Performance Expectation Related Assumptions: None

Performance:

Target: Outstanding

Neutral: Good

Minimum: Unsatisfactory

1.2 Objective: Deliver Science and Technology Products Relevant to DOE Missions and National Needs (40\%)

\section{Fundamental Science}

1.2.1 Results of DOE-OER's evaluation of the relevance of Battelle's work to DOE Missions and Needs

Description: The Director of Energy Research will provide an evaluation to the DOE-RL Contracting Officer as to the relevance of the Contractor's work to DOE missions and needs as primary input for this indicator. The rating will be based on the standard 5 step adjectival rating scale (Outstanding, Excellent, Good, Marginal, or Unsatisfactory).

Baseline: In FY97 the Contractor received a rating of outstanding from the DOE Office of Energy Research in the area of Relevance. Although FY 1998 ratings have not yet been received RL does not expect a marked changed in this area.

Perfonnance Expectation Related Assumptions: None

Performance Rating:

Target: Outstanding

Neutral: Good

Minimum: Unsatisfactory

1.2.2 The results of DOE-OER's evaluation of the Laboratory's programmatic performance

Description: The Director of Energy Research will provide an evaluation as to the Contractor's scientific programmatic performance to the DOE-RL Contracting Officer as primary input for this indicator. The rating will be based on the standard 5 step adjectival scale (Outstanding, Excellent, Good, Marginal, or Unsatisfactory).

Baseline: In FY97 the Contractor received a rating of excellent from the DOE Office of Energy Research in the area of programmatic performance. Although FY 1998 ratings have not yet been received $R L$ does not expect a marked changed in this area. 
Performance Expectation Related Assumptions: None

Performance:

Target: Outstanding

Neutral: Good

Minimum: Unsatisfactory

\section{Environmental Quality}

1.2.3 Effectively lead the technical aspects of the national Tanks Focus Area

This Performance Indicator is a composite of three Performance Sub-indicators, designed to provide an overall evaluation of the Laboratory's effectiveness in leading the national Tank Focus Area.

Performance Expectations:

Target: $\quad 225$

Neutral: $\quad 0$

Minimum: $\quad-250$

1.2.3.a Effective definition of technical solutions across the DOE complex

This performance indicator will measure the effectiveness of the TFA Technical Team in working with site users, technical advisors, and DOE-HQ to develop technology development recommendations that are responsive to the sites needs. The TFA Technical Team's multiyear technical response to site needs will be the subject of evaluation. The evaluation will take place after the technical response evaluation and prioritization meeting to be held in the mid-year time frame. The DOE TFA Management Team will evaluate the TFA Technical Team performance by means of a 10-point scale survey designed to enhance the resolution of performance evaluation (10 being the optimal score). The user will directly evaluate the technical team's performance on specific technology development processes. The subject survey will be developed jointly by DOE-RL and the TFA Technical Team. DOE-RL will issue and receive the results of the survey for analysis. The relationship between the survey scoring system and performance indicator expectations will be discussed and approved by $R I$ prior to the issuance of the survey. The survey will be issued during the fourth quarter.

1.2.3.b Adequate technology delivery to solve complex-wide problems

DOE-EM has set overall performance metrics for high-level waste for FY 1999-2001. The TFA supports these measures by providing technical solutions to the key problems associated with meeting these metrics. This performance indicator will include the accomplishment of demonstrations, deployments, and delivery of data needed to solve key site problems. The TFA has identified a number of site problems to be addressed in fiscal years 1999-2001. In addressing each problem, the TFA has planned activities in 1999 that will include either a demonstration of a technology, deployment of a technology, or delivery of data from testing.

A successful demonstration is defined as the completion of an activity that provides sufficient performance and cost data to enable the user to evaluate the technology against alternatives and to support a decision as to viability for deployment. A deployment is defined as testing of a new technology in the working environment. Data delivered refers to data from hot or cold demonstrations or laboratory testing that is used directly by sites 
to meet either regulatory, privatization, or design requirements. A listing of 20 equally weighted demonstrations, deployments or data to be delivered in FY 99 has been prepared; agreed to, and will be maintained by DOE-RL and the Contractor.

Performance will be measured by percent of completion of planned demonstrations, deployments, and delivery of test data at end of year (example 18 completions out of $20=$ $90 \%$ ). Demonstrations, deployments and delivery of test data will each be identified by Technical Task Plan (TTP) number and by milestone identification number. Milestone completion will be confirmed through concurrence letter to the site for whom the work was conducted.

When a potential demonstration, deployment or data to be delivered has been placed on the list, it cannot be removed from the list unless funding is cancelled or user schedule or commitment has changed. These changes will be captured through normal change control procedures.

\subsection{3.c Adequate tracking of technical progress to baseline}

The TFA is concerned with and actively manages the cost and schedule performance of its technical activities. Technical progress as assessed by the TFA Technical Team is often the first indication of cost and schedule issues. The TFA Technical Team will identify technical issues that have cost and schedule impact, propose corrective actions, and coordinate corrective actions that will result in total carryover of less than $10 \%$. This indicator will be measured by TFA FY 1999 year-end carryover. It is recognized that to meet this performance indicator that DOE-RL and the Laboratory will work as parmers to carry out required changes.

\subsubsection{Effectively support the Hanford Tanks Privatization Effort}

This Performance Indicator is a composite of three Performance Sub-indicators, designed to provide an overall evaluation of the Laboratory's effectiveness in supporting the Hanford Tanks Privatization Effort.

\section{Performance:}

$\begin{array}{lr}\text { Target: } & 250 \\ \text { Neutral: } & 0 \\ \text { Minimum: } & -300\end{array}$

1.2.4.a Provide leadership support for the successful implementation of the Phase I TWRS privatization through timely and high quality review and evaluation of BNFL, Inc. deliverables.

Description: An extended design phase for the Tank Waste Remediation System (TWRS) BNFL, Inc. contract has been negotiated. This design phase will commence in August 1998 and extend for 24 months. During this period, BNFL, Inc. will submit a number of deliverables that will be reviewed by DOE to determine if BNFL, Inc. is performing adequately and is likely to reach a satisfactory conclusion at the end of the design phase. The Laboratory will play a leading role in assisting DOE in the timely evaluation of the BNFL, Inc. deliverables by: defining the type of review/evaluation; planning and preparing for the review; conducting the review and evaluation; and documenting the evaluation results. The set of BNFL, Inc. deliverables upon which the Laboratory will be evaluated will be established by November 1, 1998.

This performance indicator will measure the effectiveness of the Laboratory's technical leadership in the evaluation of BNFL, Inc.'s deliverables. 
Performance Evaluation: Up to ten major deliverables may be identified and agreed upon. in FY1999 by the Waste Integration Team (WTT) and Waste Disposal Division (WDD) for this indicator, pending final negotiation of the scope and budget for FY 1999. These deliverables are significant to understand BNFL, Inc.'s technical, regulatory and business approach and assuring that BNFL, Inc. is completing the Part B-1 work as planned. Work to be formed by BNFL; Inc. during Part B-1 is: 1) optimize the Low Activity Waste (LAW) and High Level Waste (HLW) treatment and immobilization system, mitigate risk, and reduce contingencies in the waste treatment and immobilization system defined by BNFL, Inc. in Part A; 2) revise the technical, operational, regulatory, and financial elements of the waste treatment services and immobilization system; 3) provide firm fixed-unit prices for waste treatment services; and 4) perform all activities necessary to reach financial closure for privatized facilities. An assessment questionnaire will be developed to be completed by the WDD manager to provide the data for WIT's performance against this indicator. This questionnaire will be completed by the WDD manager at mid-year and at the end of the year. For each deliverable, the questionnaire will address the following topics:

- Effectiveness of the planning/structuring of the deliverable evaiuation;

- Effectiveness of the evaluation in supporting development of the final terms and conditions in the BNFL, Inc. Contract;

- Usefulness, completeness, and timing of evaluation results in influencing DOE's final negotiation of the Contract;

- Quality of documentation of any evaluation results; and

- DOE judgment of the importance and overall effectiveness of the Laboratory role in the evaluation of the major Part B-1 deliverables.

A scoring system will be developed for the questionnaire and agreed upon by WDD and WIT. Each deliverable will be evaluated on a $0-10$ scale. The average will be calculated and multiplied by 10 to provide a $0-100$ rating scale.

1.2.4.b Effectively support DOE's decision making by ensuring that key decisions are identified and analyzed, and that appropriate information is provided to DOE decision makers in a timely manner.

Description: For DOE to continue successfully with TWRS Privatization, a number of key decisions must be made during the design phase (approximately two years beginning August 1998). During FY 1999 key decisions are expected to include: technical optimization decisions; decisions as to the appropriate mix of financing; decisions regarding the development of methods needed for Contract $H$ clauses (e.g., cost and schedule contingency effects on price, price adjustment mechanisms, etc.); and decisions pertaining to the selection of an alternative(s) for development into an executable alternative to the Privatization Contract for treating tank waste.

This performance indicator will measure the Laboratory's ability to establish an appropriate decision process for DOE, provide thorough analysis of the decision, and ensure the availability of the information needed for DOE to make the decisions.

Performance Evaluation: Up to 10 key decisions to be made in FY 1999 may be identified and agreed upon by WIT and WDD for this indicator, pending final negotiation of scope and budget for FY 1999 by the end of the $1^{\text {st }}$ quarter FY 1999. These decisions will be ones of high importance to $\mathrm{DOE}$ and ones in which the Laboratory plays a key role. An assessment questionnaire will be developed to be completed by the WDD manager to provide the data for this performance indicator. This questionnaire will be completed by the WDD manager at mid-year and at the end of the year. The questionnaire will address, for each decision support activity, the following topics: 
- Clearly articulating the decision to be made and effectiveness of the planning/structuring of the decision process;

- Effectiveness of analyses and information gathering performed to support the decision;

- Usefulness, completeness, and timing of information provided to DOE for making the decision;

- Appropriateness of any reviews of the analyses, information, and decision making process;

- Adequacy of the documentation of the decision; and

- DOE judgment of the importance and overall effectiveness of the Laboratory role in the decision.

A scoring system will be developed for the questionnaire and agreed upon by WDD and WIT. Each deliverable will be evaluated on a $0-10$ scale. The average will be calculated and multiplied by 10 to provide a $0-100$ rating scale.

1.2.4.c Effectively support DOE in their effort to respond to unanticipated issues and informational requests on the TWRS Privatization Program.

Description: TWRS Privatization is a multi-billion doilar project and therefore receives a significant amount of scrutiny from various government agencies, regulators, stakeholders and other special interest groups as well as DOE-HQ. DOE is continually faced with responding to unanticipated inquiries regarding the program. These inquiries may require responses ranging from a phone call responding to the inquiry to completion of an analysis and preparation of a detailed report or presentation. The Contractor's performance will be evaluated based on their ability to respond to unanticipated requests in a timely and high quality manner.

Performance Evaluation: Each half of the fiscal year, DOE-RL and Battelle may select up to two high-importance requests for which the Laboratory will be evaluated under this performance indicator with final approval by DOE-RL, pending final negotiation of scope and budget for FY 1999 by the end of the $1^{\text {st }}$ quarter FY 1999. An assessment questionnaire will be developed for completion by the WDD manager to provide the data for Battelle's performance relative to these two requests plus Battelle's overall performance relative to responding to unanticipated requests. The questionnaire will address the following topics:

- Ability to allocate appropriate staff and subcontractor resources to responding to the requests;

- Effectiveness of anaiyses and information gathering performed in support of the response preparation;

- Timeliness of the response; and

- Adequacy of the documentation of the response, and DOE's judgement of the importance of the request and the overall effectiveness of the Contractor's role in responding to the request.

A scoring system will be developed and agreed upon by WDD and WIT to score each response on a $0-10$ scaie.

1.2.5 Number of innovative technologies and approaches successfully deployed in commercial practice 
Definitions:

A successful deployment is defined as inclusion of the innovative technology as part of the user's baseline.

Commercial practice is defined as use by industry, DOE contractors, DOD contractors, or other licensees in routine practice as a part of their baseline suite of tools.

Innovative technologies are defined as technologies, approaches, or systems that demonstrate a significant advance in the state of the art or represent a new application of existing technology to a method or process with the result of improved cost, schedule, safety, and/or effectiveness. A project that contains or has the potential to contain one or more of the following attributes (without adversely effecting the others) shall meet the criteria for innovative technology: $25 \%$ reduction in life cycle cost, $25 \%$ reduction in schedule, significant safety enhancement, and/or significant program risk reduction, and/or other criteria as defined by the user or their representative.

Innovative technologies held or offered "on the shelf" but not utilized in active practice are not acceptable under this definition.

A funded deployment is defined as inclusion of the innovative technology in a baseline activity that has been funded at a level agreeable to both the user and the Laboratory for performance of the task, for the full duration of the expected period of performance.

Establishment or a change to the baseline is defined as when an innovative technology deployment causes the user to change the existing baseline plan as a result of the deployment. A change to the baseline plan may occur a year or more after the completion of a deployment.

Description: This indicator will measure the transfer to a user of hardware, software, and methodologies for actual use in their field of application. This will measure the end resuit of a technically sound, user driven program.

Baseline Information: Battelle historical performance was estimated using the above definitions. The number and location of innovative technology deployments are being used to evaluate performance in the absence of definitive information regarding the impact of an innovative technology deployment.

Performance Expectation Related Assumptions: This indicator measures activities that have a significant time lag, that is, the deployments in FY 1999 will have been in process for 3-5 years in various stages of development. There will be an attribution of value for the activity. The relative value of deployments is reflected in the point system described below.

Performance Evaluation: The outcome of included activities will be documented in the "Milestone Status / Activity Acceptance and Completion" report format, which will inciude a brief description of the deployment, and the cost/economic and other benefits, that may be derived from its use. For EM-50 funded deployments, and where funds are provided, a report shall be prepared describing the innovative technology and the deployment and to convey results to other potential users. The report will also contain a life cycle cost benefit assessment; data from this analysis would be considered in the event incentive fee is earned as a result of the deployment (incentive fee must not exceed benefit to the government resulting from activity). 
A point system will be used to evaluate performance against this indicator:

- Two points will be awarded for each time an innovative technology or approach is deployed at Hanford or another DOE site or on a particular DOE waste stream at other locations (e.g., Privatization contractors).

- One point will be awarded each time an innovative technology or approach is deployed at separate non-DOE government sites or at commercial or private sites.

- Two additional points will be awarded each time a technology deployment results in the user's establishment of a new baseline plan at Hanford or another DOE site.

- Maximum lifetime points awarded for a specific technology will be 10 for Hanford or DOE site deployments, and five for non-DOE government sites or commercial sites, for a total maximum of 15 points.

- Different applications of the same technology or approach for different source problem will constitute a separate deployment.

- Business Sensitive deployments will be verified with the customer under the appropriate nondisclosure agreement.

Performance:

$\begin{array}{lr}\text { Target: } & 16 \text { Points } \\ \text { Neutral: } & 6 \text { Points } \\ \text { Minimum } & \text { 0 Points }\end{array}$

\subsubsection{Provide significant solutions to Hanford problems/needs}

Description: This indicator will measure and enhance the focus of Contractor activities in addressing Hanford science needs and technical gaps conducted at the request of the client. First, the Contractor will evaluate the science and technology needs at Hanford as developed by the ERC, PHMC, and Site Technoiogy Coordination Group (STCG) to identify the basic research, applied research, advanced development, demonstration requirements, and deployment opportunities. This information will be used to address OER, EM, NAS, Focus Area, etc., questions on Hanford Science and Technology needs, identify critical research areas needing investigation, and to provide an opportunity for partnerships with DOE-RL, industry, and academia. Contractor activities in support of PHMC, ERC, DOE and STCG technology assessment, evaluation, and insertion will be applied to this performance indicator. Activities undertaken are to be of a technical nature rather than purely administrative and may include technical and engineering services, studies and consultations. The resulting products may be engineered solutions, new approaches to addressing existing problems, new technologies, improvements to existing approaches or technologies, and adaptations and/or applications of technologies or approaches developed elsewhere. Problems that may be addressed by Hanford .technical solutions are not limited to environmental restoration or waste management, but may include any of the scientific, technical, and engineering issues facing DOE-RL and its contractors. These activities may be those that: 1) reduce technical uncertainty, 2) address safety questions, 3) provide process improvement, 4) identify, evaluate and recommend innovative technologies, 5) provide technology assessments, 6) submit proposals that address the STCG, EM programmatic, and EM science needs at Hanford.

Baseline Information: Battelle historical performance was estimated using the above definitions. The Contractor shall identify all activities conducted to address Hanford needs on a quarterly basis and shall provide the information to DOE-RI for review/validation.

Performance Expectation Related Assumptions: Currently, the Laboratory is solving Hanford problems in a number of areas; however, DOE-RL wants the Laboratory to continue the emphasis on Hanford technical solutions. 
Performance Evaluation: The number of expected activities will be established and discussed with DOE-RL. The main focus of this metric should be on Laboratory technical input to Hanford operating elements such as engineering requests, etc. The resuits of the activities performed to meet the required performance will be documented, by providing DOE-RL the following information:

- Identification of a specific DOE-RI or contractor client

- A description of the problem or need being addressed

- A description of the approach/activities the Contractor undertook to address the need or problem

A point system will be used to evaluate performance against this indicator. Based on DOE-RI's review, points will be awarded as follows:

- One point will be allocated for each project completed for Hanford clients that produce a technical product such as a report or other technical deliverable during the year. One point will also be awarded each new EM-50 task that addresses one or more Hanford needs, and $1 / 2$ point will be awarded for each continuing EMSP task that addresses one or more Hanford needs.

- Proposals prepared by the Contractor, where required to address Hanford problems and environmental technology needs, will be allocated $1 / 2$ point each.

- DOE-RL may award additional credit for completion of particularly significant activities as deemed appropriate by DOE-RL; however, the maximum points awarded for one activity will be 5 .

- No items will be included on this list that are also included as a deployment.

Performance:

$\begin{array}{ll}\text { Target: } & 75 \text { Points } \\ \text { Neutral: } & 35 \text { Points } \\ \text { Minimum: } & \text { 0 Points }\end{array}$

1.2.7 Customer Feedback on relevance and excellence in Environmental Quality

Description: Customer feedback from program managers who fund work at the Laboratory will be obtained through the use of a survey. The survey is designed to solicit feedback along two dimensions: a) the strategic value of the work to the customer, and b) project performance, i.e., how well the Laboratory is performing work on the project. The Laboratory Sub-sector Leaders, Account Managers and Product Line Managers will identify the set of projects to be surveyed in the mission area of Environmental Quality. DOE-RL Director of Science \& Technology Programs will approve the list of critical projects.

The survey will be sent to the customer jointly by the RL Assistant Manager for Science and Technology and the Laboratory Director. Surveys will be returned to the Contractor with a copy provided to $R L$ upon request.

The survey will use a 5 point rating scale along each dimension and will also provide the customer with the opportunity to provide written comments. The indicator will be reported in terms of average score (rounded to the nearest 0.1 ) for each of the two dimensions (i.e., strategic value and project performance) for all projects surveyed within each of the three mission areas with the points summed for both dimensions. In order to obtain the highest possible response rate, customers who do not initially return the survey will be contacted.

Baseline Information: A survey conducted in FY 1997 provides a relative baseline to assist in setting performance expectations by mission area: 


$\begin{array}{lcc} & \begin{array}{c}\text { Value } \\ \text { Dimension }\end{array} & \begin{array}{c}\text { Performance } \\ \text { Dimension }\end{array} \\ \text { Environmental Quality } & 4.0 & 4.1 \\ \text { National Security } & 4.0 & 4.0 \\ \text { Energy } & 4.2 & 4.5\end{array}$

FY 1998 performance data will be available after October 1, 1998 and depending on the results of that survey, changes may be expected on FY 1999 target values.

Performance Expectation Related Assumptions: None

Performance:

Target: $\quad 9$

Neutral: $\quad 6$

Minimum: 5

\section{National Security}

\subsubsection{Number of solutions and deployments to significant national security problems/issues}

Description: It is the objective of the National Security Division to provide deployable solutions that meet a variety of national and international security needs. The pathway to accomplishing this first involves the ability to develop solutions to problems identified by the client. The solutions provided then form the pool from which deployments can be made at either a "local" level, or the national/international "global" level.

The scope identified for this Performance Indicator is to achieve any combination of contributions at the solution or deployment (local or global) level. Those deployments that solve national / international security problems would contribute more than deployments at a local level, and local deployments would contribute more than non-deployed solutions.

Definitions:

Solution: Activities undertaken are to be of a technical or policy-making nature, rather than administrative, and may inchude technical and engineering services, studies and consultations. The resulting products may be: knowledge provided to make a decision, engineered solutions, new approaches to addressing existing problems, new technologies, improvements to existing approaches / technologies, and adaptations \&/or applications of technologies or approaches developed elsewhere. These activities may be those that reduce technical uncertainty, address safety questions, provide process improvements, identify, evaluate and recommend innovative technologies, provide technology/policy assessments, and must meet a defined client need or requirement.

Deployment: Inclusion of the solution as part of the user's system.

(Deployment) Local: A solution applied at, typically, a single site/location to address the client's originally-identified and focused problem. Local deployments may be: knowledge provided to make a decision, services or reports provided which results in a change in the way client does business, deployments significant to local/state security issues, or are a significant achievement in a project's lifecycle. The number of "local" deployments will be more numerous than giobal deployments.

(Deployment) Global: A solution applied at, typically, multiple sites/locations to address national / international issues/needs. Note: the number of "global" deployments to national security 
problems in any year will be quite small - these projects can take anywhere from 3-10 years work to achieve results at the national/international level, and these will be worth significantly more points for purposes of this performance indicator.

Baseline Information: Data from FY98 focused on the "global" level of contributions and examples included:

- the Automated Radioxenon Sampler / Analyzer (ARSA) unit for ultrasensitive analysis of four xenon isotopes in near real-time that permits high-sensitivity remote detection of nuclear detonations and used for the requirements of the Comprehensive Test Ban Treaty, and

- Safe storage and ultimate disposition of irradiated fuel - a pivotal provision of an international agreement to end Democratic Peoples Republic of Korea (DPRK) plutonium production.

- Under the performance indicator for FY99, it is assumed that achieving two global deployments in a single year is as "outstanding" a performance as possible. It is also assumed that achieving one "global" deployment, in addition to the expected mix of solutions and local deployments still places NSD performance in the "outstanding" range.

Performance Expectation Related Assumptions: The two "global" deployments from FY98 alone are insufficient to establish an adequate baseline for the expanded scope of the measure in FY99. "Local" deployments and solutions in FY98 were investigated in order to establish a target and expected goal for FY99. However, this year should be considered the first in establishment of a baseline for this augmented measure compared with FY98.

Process: The process will be interactive and iterative between the DOE-RL and Contractor contacts.

An "Activity Acceptance and Completion Form" must be filled out for each technology, policy/service and technical solution to be considered for solution/deployment, and submitted to DOE-RL for concurrence. This form will contain identification of the client, a brief description of the solution / deployment and the approach and activities used to develop the solution / deployment, the client need or requirement, and a description of the benefits that may be derived from its use. This form will be initially submitted to DOE-RI for concurrence that the solution/ deployment proposed meets the definitions as outlined in this performance indicator. The final submittal of this form will occur when the solution/ deployment has been completed, for DOERL's concurrence and awarding of points.

A point system will be used to evaluate performance against this indicator:

- One point will be awarded for each time a proposed solution meets a client need or requirement.

- A total of three points will be awarded for a local deployment (Two additional points will be awarded for each time a solution results in a local deployment.)

- And a maximum of seven points will be awarded for a global deployment (Four additiona] points will be awarded for each time a local deployment gains global deployment status, or six points for a solution reaching global deployment status without first reaching local deployment status.)

- No more than seven points possible for any deployment.

Different applications of the same technology or approach for different source problems wili constitute a separate deployment.

Performance:

Target: $\quad 38$

Neutral: $\quad 18$

Minimum: $\quad 0$ 


\subsubsection{Customer Feedback on relevance and excellence in National Security}

Description: Customer feedback will be obtained through the use of a survey. The survey is designed to solicit feedback along two dimensions: a) the strategic value of the work to the customer, and b) project performance, i.e., how well the Laboratory is performing work on the project. The Laboratory Sub-sector Leaders, Account Managers and Product Line Managers will identify the set of projects to be surveyed in the mission areas of National Security. DOE-RL Director of Science \& Technology Programs will approve the list of critical projects.

The survey will be sent to the customer jointly by the RL Assistant Manager for Science and Technology and the Laboratory Director. Surveys will be returned to the Contractor with a copy provided to $\mathrm{RL}$ upon request.

The survey will use a 5 point rating scale along each dimension and will also provide the customer with the opportunity to provide written comments. The indicator will be reported in terms of average score (rounded to the nearest 0.1 ) for each of the two dimensions (i.e., strategic value and project performance) for all projects surveyed within each of the three mission areas with the points summed for both dimensions. In order to obtain the highest possible response rate, customers who do not initially return the survey will be contacted.

Baseline Information: A survey conducted in FY 1997 provides a relative baseline to assist in setting performance expectations by mission area. FY 1998 performance data will be available after October 1, 1998 and depending on the results of that survey, changes may be expected on FY $1999^{\circ}$ target vaiues.

Performance Expectation Related Assumptions: Consistent level of performance across the laboratory.

Performance:

$\begin{array}{ll}\text { Target: } & 9 \\ \text { Neutral: } & 6 \\ \text { Minimum: } & 5\end{array}$

\section{Energy Resources}

1.2.10 Number of energy technologies, systems and technical solutions deployed

Description: Moving technology, systerns, and technical solutions from the laboratory to ultimate deployment is a critical part of furthering the programmatic and strategic objectives of DOE (ST22). This performance objective focuses on moving energy-related technology to practice and will count the number of energy-related technologies, systems, and technical solutions (software, analytic tools, and methodologies) ultimately deployed. Performance will be measured by counting the number of deployments (defined below) achieved.

For a deployment to be counted against this indicator, the following conditions must be met:

- An "Activity Acceptance and Completion Form" must be filled out for each technology, system and technical solution that is to be considered as deployed, and submitted to DOE-RL for concurrence. This form will define the following as applicable: the technology being deployed, the deployment partner, the deployment vehicle, the application, and conditions/circumstances of deployment.

- Have an Energy-related application, which generally supports the DOE Energy Resources missions. 
Deployment mechanisms that will be counted are the following:

- Signed government use agreement

- Signed commercial nonexclusive license agreement

- Signed commercial exclusive license agreement

- Signed commercial license agreement with an equity position

- Assignment/assumption of title for technology (e.g., direct sale of technology)

- Technology used in Government Facilities

- Technology field tested/demonstrated in Government Facilities

Baseline Information: There were no deployments of energy related technologies meeting the above conditions and definitions in FY98, or FY97.

Performance Expectation Related Assumptions: None

Performance: The total number of deployments achieved will result in the following rating for this performance indicator.

$\begin{array}{lc}\begin{array}{l}\text { Performance } \\ \text { Level }\end{array} & \begin{array}{c}\text { Number of } \\ \text { Deployment }\end{array} \\ { } } & 3 \\ \text { Neutral: } & 1 \\ \text { Minimum: } & 0\end{array}$

\subsubsection{Customer Feedback on relevance and excellence in Energy}

Feedback will be obtained through the use of a survey designed to solicit feedback along two dimensions: a) the strategic value of the work to the customer, and b) project performance (i.e., how well the Laboratory is performing work on the project). Laboratory Sub-sector Leaders, Account Managers and Product Line Managers will identify the set of projects to be surveyed in the mission areas of Environmental Quality, National Security, and Energy Resources. DOE-RL Director of Science \& Technology Programs will approve the list of critical projects.

The survey will be sent to the customer jointly by the RL Assistant Manager for Science and Technology and the Laboratory Director. Surveys will be returned to the Contractor with a copy provided to RL upon request. In order to obtain the highest possible response rate, customers who do not initially return the survey will be contacted.

The survey will use a 5 point rating scale and will also provide the customer with the opportunity to provide written comments. The indicator will be reported in terms of average score (rounded to the nearest 0.1 ) summed for each of the two dimensions (i.e., strategic value and project performance) for all projects surveyed within the Energy Resources mission area. Performance targets are as follows:

Baseline Information: None

Performance Expectation Related Assumptions: None

Performance:

Target: $\quad 9$

Neutral: $\quad 6$

Minimum: 5 
1.3 Objective: Successfully operate the Wiley Lab and ARM Facilities (10\%)

\subsubsection{Successful operation of the Wiley Laboratory}

This performance indicator reflects the mission of the Wiley Laboratory as a user facility; the research mission of the Wiley Laboratory is addressed in other sections of Critical Outcome 1.0. The indicator is a composite of three sub-indicators of equal weight. The sub-indicators will be rolled up into a final rating based upon a continuous scale of 1 to 5 as follows:

- 5.0 represents the target performance level

- 3.0 represents the neutral performance level

- 1.0 represents the minimum performance level

\subsubsection{Number of users of the Wiley Lab.}

Description: This performance indicator measures the number of non-EMSL organization staff users of the Wiley Lab in FY99 relative to baseline data measured in FY98. The data will be reported as number of local, regional, national or international users from academic institutions, government laboratories or private industry. The data on users will be summarized in the quarterly critical outcome presentations. A final report for the appropriate DOE/HQ program managers will also be prepared for their information and action.

Baseline Information: The number of non-EMSL users in FY98 will be used as the baseline from which the performance measure is made for FY99.

Performance Expectation Related assumptions: The number of non-EMSL users is expected to exhibit significant growth relative to FY98.

Performance Expectation: Growth in the number non-EMSL users by $20 \%$ will count towards an outstanding performance level and resulting in $100 \%$ of available score, growth of $15 \%$ will be worth $90 \%$ (excellent), growth of $10 \%$ will be worth $50 \%$ (good), growth of $5 \%$ will be worth $0 \%$ (marginal); and growth less than $5 \%$ will be worth $-50 \%$ (unsatisfactory).

1.3.1.2 Number of peer-reviewed publications from use of the Wiley Lab by non-PNNL staff.

Description: This performance indicator measures the number of peer reviewed publications in FY99 resulting from use of the Wiley Laboratory in FY99 or previous years. Data will be collected on peer-reviewed publications resulting from collaborative or independent use of the Wiley Lab. Comparison of publications by type of user will be summarized in the quarterly critical outcome presentations. A final report for the appropriate DOE/HQ program managers will also be prepared for their information and action.

Baseline Information: A publication baseline will be established using FY98 available data. Baseline data will not be used in the comparison of publications by type of user.

Performance Expectation Related Assumptions: The number of peer reviewed publications in FY99 resulting from use of the Wiley Lab by non-PNNL staff is expected to exhibit growth relative to FY98. However; since the number of peer-reviewed publications depends on activities in previous years, we anticipate that the growth in peer-reviewed publications will be slower than growth in number of users and programmatic funding. 
Performance Expectation: Growth in the number of peer-reviewed publications with non-EMSL authors by $15 \%$ will count towards an outstanding performance level $(100 \%$ of available score), growth of $10 \%$ will be worth $90 \%$ (excellent), growth of $5 \%$ will be worth $80 \%$ (good), growth of $0 \%$ will be worth 0 (marginal), and growth less than $0 \%$ will be worth $-50 \%$ (unsatisfactory).

\subsubsection{User satisfaction.}

Description: This performance indicator measures the level of satisfaction of users of the Wiley Lab. A User Satisfaction Survey was developed in FY98 and sent to all non-EMSL staff who used the Wiley Lab in FY98. This data will be analyzed in the $1^{\text {st }}$ quarter of FY99 and an action plan will be prepared describing actions to be taken to address those areas where users indicated dissatisfaction. The analysis and the action plan will be presented at the $1^{\text {st }}$ quarter critical outcome presentation. A final report will be prepared for the appropriate DOE/HQ program managers for their information and action in the $2^{\text {nd }}$ quarter of FY99. If necessary, the survey will be modified in the 3rd quarter of FY99 with participation and approval by DOE and any changes will be reported at the 3rd quarterly critical outcome presentation. The FY99 User Satisfaction Survey will be sent to all non-EMSL staff who used the Wiley Lab in FY99 before the end of FY99 and the necessary steps will be taken to ensure survey results will be available by November 1 , 1999 for DOE-RL use in the FY99 performance evaluation.

Baseline Information: A user satisfaction baseline for FY00 will be established in FY99 using data from FY98 available data.

\section{Performance Expectation Related Assumptions: N/A}

Performance Expectation: Completion of all activities described above will serve as a gateway to positive scoring for this indicator (a score of 0 will be earned if any of the above activities are not completed).

In addition to essay questions, the survey will utilize customer feedback questions addressing satisfaction with aspects of their experience at/with the Wiley Lab. These feedback questions will have 5 ranges of response: very satisfied, satisfied, neither satisfied nor dissatisfied, dissatisfied, very dissatisfied. The results of the user survey will determine score provided there is completion of gateway activities. If the review of user responses to survey questions reveals the majority (greater than $50 \%$ ) of question responses indicate satisfied or very satisfied and further, greater than $17 \%$ indicate very satisfied, this will earn an outstanding rating of $100 \%$ of available score. If the majority of responses indicate satisfied or very satisfied but $17 \%$ or less indicate very satisfied, this would earn a rating of $90 \%$ of available score (excellent). If greater than $50 \%$ of the question responses do not indicate dissatisfaction, this will earn a rating of $50 \%$ of available score (good). If $50 \%$ or greater of the question responses indicate dissatisfaction, this will earn a rating of 0 (marginal).

\subsubsection{Operation of Atmospheric Radiation Measurement (ARM) Extended Research Facilities}

The Contractor manages the day to day operations of three ARM Extended Research Facilities for the Department of Energy. These facilities observe a variety of atmospheric variables for the purpose of improving the performance of global climate models. Measurement strategies are designed to meet the specific needs of ARM Science Team Members, whose role is to meet the scientific objectives of the ARM Program. Science Team Members are funded through a competitive process run by the ARM Program Manager who is located in Germantown, Maryland. The ARM Program Manager determines the number of Science Team projects, and it is based on the quality of proposals received in response to periodic solicitations and on available funding. In addition, ARM data are available to non-ARM funded researchers through the ARM Data Archive 
located at Oak Ridge National Laboratory. The indicator is a composite of two sub-indicators. Each sub-indicator will be rolled up into a final rating based upon a scale of 1 to $S$ as follows:

- 5.0 represents the Target performance level

- 3.0 represents the Neutral performance level

- 1.0 represents the minimum performance level

\subsubsection{Number of peer-reviewed publications based on ARM data}

Description: The purpose of ARM is to advance understanding of radiative energy transfer in the atmosphere (and particularly the role of clouds, water vapor, and aerosols on this process) and how changes in this process effect atmospheric dynamics. A principal goal is to translate this new knowledge into improved parameterization schemes for climate models.

Number of non-PNNL peer-reviewed publications based on ARM data: An important measure of ARM performance is its scientific productivity in terms of papers appearing in peer-reviewed scientific journals that are based on or use ARM data and the influence ARM science is having on process parameterizations in climate models. ARM scientific productivity is an indirect measure of Battelle's performance in managing the day to day operations thus Battelle's performance in this area will be measured as the productivity of all ARM Science Team projects.

Baseline Information: Using FY 1998 data, a publication baseline consisting of the number of all publications by ARM Science Team members based on ARM data will be established. This data will be used to measure FY 1999 performance.

Performance Expectations: For FY 1999, an annual publication growth rate of greater than or equal to $110 \%$ as compared to FY 1998 will be counted as outstanding performance (5), greater than or equal to $100 \%$ will represent excellent performance (4), greater than or equal to $90 \%$ good (3), greater than or equal to $80 \%$ marginal (2), and less than $80 \%$ per year will qualify as unsatisfactory performance (1).

\subsubsection{User satisfaction.}

Description: This performance indicator measures the level of satisfaction of ARMfunded users of the ARM Facility. A user baseline will be established to determine appropriate survey recipients. A User Satisfaction Survey will be developed and sent to all non-PNNL members of the ARM Science Team who used the facility in FY99. The survey will be developed and submitted for DOE approval by the end of the $2^{\text {nd }}$ quarter of FY99. The User Satisfaction Survey will be sent to all non-PNNL members of the ARM Science team before the end of FY99 and the necessary steps will be taken to ensure survey results will be available by November 1, 1999 for DOE-RL use in the FY99 performance evaluation.

Baseline Information: A user satisfaction baseline for FY00 will be established using FY99 data.

Performance Expectation Related Assumptions: Completion of all activities described above will serve as a gateway to scoring for this indicator (a score of 0 will be earned if any of the above activities are not completed).

Performance: The survey will utilize customer feedback questions addressing satisfaction with the ARM facility. These feedback questions will have 5 ranges of response: very satisfied, satisfied, neither satisfied nor dissatisfied, dissatisfied, very dissatisfied. The results of the user survey will determine score provided there is completion of gateway activities. If the review of user responses to survey questions 
reveals the majority (greater than $50 \%$ ) of question responses indicate satisfied or very satisfied and further, greater than $17 \%$ indicate very satisfied, this will earn an outstanding rating (5). If the majority of responses indicate satisfied or very satisfied but $17 \%$ or less indicate very satisfied, this would eam a rating of excellent (4). If greater than $50 \%$ of the question responses do not indicate dissatisfaction, this will earn a rating of good (3). If $50 \%$ or greater of the question responses indicate dissatisfaction, this will earn a rating of marginal (2).

\subsubsection{Results of DOE-OER's evaluation of the quality of the Laboratory's User Facilities}

Description: The Director of Energy Research will provide an evaluation as to the quality of the Contractor's operations of Laboratory User Facilities to the DOE-RL Contracting Officer as primary input for this indicator. The rating will be based on the standard 5 step adjectival scale (Outstanding, Excellent, Good, Marginal, or Unsatisfactory).

Baseline: In FY97 the Contractor received a rating of outstanding from the DOE Office of Energy Research in the area of user facilities. Although FY 1998 ratings have not yet been received RL does not expect a marked changed in this area.

Performance Expectation Related Assumptions: DOE-HQ overall evaluations were not a specific part of the Battelle Critical Outcomes in the past, although those evaluations were considered when assigning a final rating to the Contractor.

Performance Rating:

Target: Outstanding

Neutral: Good

Minimum: Unsatisfactory

1.4 Obiective: Demonstrate leadership and excellence in progxam planning and management for critical outcomes (25\%)

\section{Fundamental Science}

\subsubsection{Demonstrate programmatic leadership within Fundamental Science}

Description: The Environmental and Health Sciences Division of the Laboratory provides leadership to the following six major initiatives:

- EMSL- Wiley User Facility

- NABIR

- ARM

- JCI- Joint Catalysis Institute

- CCPP/ACPI- the Accelerated Climate Prediction Initiative (within the Climate Change Prediction Program)

- SSI- Strategic Simulation Initiative

This indicator is designed to provide a feedback mechanism regarding Battelle's ability to demonstrate strong and effective leadership to the initiatives it manages.

Approach: A program composite will be developed based upon interviews with those responsible for overall program oversight and direction (i.e., directed at a level above Program management 
for each initiative). The interviews will address the following critical questions relating to, or indicating dimensions of, leadership (includes weighting for each dimension).

- How would you rate the quality of leadership provided by Battelle? ( $40 \%$ of final rating),

- How would you rate Battelle's ability to effectively team with other laboratories and universities? ( $20 \%$ of final rating),

- How would you rate the degree of Laboratory Institutional (management, administration, funding, etc.) support to leadership of these programs? (20\% of final rating), and

- How would you rate the overall program quality? ( $20 \%$ of final rating).

A representative from EHSD and DOE-RL will conduct joint interviews. The questions presented above, are designed to elicit feedback on both the positive aspects of leadership demonstrated as well as those areas that warrant improvement if a sound relationship with the customer is to continue. By the end of the first quarter of FY99, the Laboratory and DOE-RL, will jointly:

- Identify customers to be interviewed in advance of conducting any interviews.

- Develop a general interview schedule for the year.

- Develop the interview protocol and evaluation scheme for each interview and for consolidating these into a single rating.

Baseline Information: None

Performance Expectation Reiated Assumptions: The final rating along each dimension will be rated on a scale of 1 to 5 , with 5 representing outstanding performance. Both DOE-RL and EHSD will determine these ratings with final approval by DOE-RL.

Performance:

The final composite rating across all dimensions will be as follows:

- 5.0 represents the target performance level

- 3.0 represents the neutral performance level

- 1.0 represents the minimum performance level

\section{Environmental Quality}

1.4.2 Demonstrate programmatic leadership in Environmental Quality

Description: The Environmental Technologies Division of the Laboratory provides leadership to the following major initiatives:

- EM S\&T Roadmapping

- Long-Range Stewardship and Risk-Based Decision Making

This indicator is designed to provide a feedback mechanism regarding Battelle's ability to demonstrate strong and effective leadership to the initiatives it manages.

Approach: A program composite will be developed based upon interviews with those responsible for overall program oversight and direction (i.e., directed at a level above Program management for each initiative). The interviews will address the following critical questions relating to, or indicating dimensions of, leadership (includes weighting for each dimension).

- How would you rate the quality of leadership provided by Battelle? ( $40 \%$ of final rating),

- How would you rate Battelle's ability to effectively team with other laboratories and universities? ( $20 \%$ of final rating), 
- How would you rate the degree of Laboratory Institutional (management, administration, funding, etc.) support to leadership of these programs? ( $20 \%$ of final rating), and

- How would you rate the overall program quality? ( $20 \%$ of final rating).

A representative from ETD and DOE-RL will conduct joint interviews. The questions presented above are designed to elicit feedback on both the positive aspects of leadership demonstrated as well as those areas that warrant improvement if a sound relationship with the customer is to continue. By the end of the first quarter of FY99, the Laboratory and DOE-RL will jointly:

- Identify customers to be interviewed in advance of conducting any interviews.

- Develop a general interview schedule for the year.

- Develop the strategic objectives emphasizing the development and up-front planning of the programs.

- Develop the interview protocol and evaluation scheme for each interview and for consolidating these into a single rating.

Baseline Information: None

Performance Expectation Related Assumptions: The initiatives evaluated will be based upon availability of the target agreed upon interviewers and interviewees.

The final rating along each dimension will be rated on a scale of 1 to 5 , with 5 representing outstanding performance. Both DOE-RI and ETD will determine these ratings with final approval by DOE-RL.

Performance:

The final composite rating across all dimensions will be as follows:

- 5.0 represents the target performance level

- 3.0 represents the neutral performance level

- 1.0 represents the minimum performance level

1.4.3 Effectively lead the technical aspects of the Groundwater and Vadose Zone efforts

1.4.3.a Develop scientific and technology roadmaps for key gaps

Definition and assumptions to be developed once funding and workscope have been defined for FY99 and will be incorporated via approved change control.

\subsubsection{B PROVIDE LEADERSHIP FOR PARTICIPATION OF OTHER NATIONAL LABORATORIES}

Definition and assumptions to be developed once funding and workscope have been defined for FY99 and will be incorporated via approved change control.

\section{National Security}

1.4.4 Customer Feedback on Leadership for key National Security Programs

Description: The National Security Division of the Laboratory provides leadership and key technical contributions to the following DOE national security strategic goals:

- Ensure and enhance protection of nuclear materials, sensitive information and facilities. 
- Provide DOE-related intelligence and threat assessment support to members of the national security community.

- Reduce inventories of surplus weapons-usable fissile materials worldwide in a safe, secure, transparent, and irreversible manner.

- Strengthen the nuclear nonproliferation regime through support of treaties and international agreements.

- Work with the states of the former Soviet Union and others to minimize the risks of proliferation

- Advance nonproliferation technology.

- Assist countries in reducing the risks from Soviet-designed nuclear power plants and implement a self-sustaining nuclear safety improvement program capable of reaching internationally accepted safety practices.

- Assist in the multi-national effort to shut down Chornobyl Units 1,2, and 3 in the Ukraine and reduce the risk of possible collapse of the Unit 4 sarcophagus.

The Laboratory National Security Division Associate Laboratory Director and DOE-RL will conduct joint interviews of key DOE customers in the above programmatic areas to collect feedback on Battelle's performance in demonstrating technical and managerial leadership. By the end of the first quarter of FY99, the Laboratory and DOE-RL will jointly:

- Identify customers to be interviewed in advance of conducting any interviews.

- Develop a general interview schedule for the year.

- Develop interview questions around the strategic goals to be achieved in advance of the interviews.

- Develop the interview protocol and evaluation scheme for each interview and for consolidating these into a single rating.

Baseline Information: None

Performance Expectation Related Assumptions:

The initiatives evaluated will be based upon availability of the agreed upon interviewers and interviewees.

The final rating will be based on a scale of 1 to 5 , with 5 representing outstanding performance. Both DOE-RL and NSD will determine these ratings with final approval by DOE-RL.

Performance: The final composite rating across all dimensions will be as follows:

- 5.0 represents the target performance level

- 3.0 represents the neutral performance level

- 1.0 represents the minimum performance level

\section{Energy Resources}

1.4.5 DOE customer feedback on technical and managerial leadership in the Energy thrust areas

Description: A representative from the Laboratory Energy Division and DOE-RL will conduct joint interviews of key DOE customers in the four Energy thrust areas (i.e., Efficient Vehicles and Automotive Structures; Intelligent Building Systems; Engineering Simulation and Modeling Virtual Prototyping; Fuel Systems Technology) to collect feedback on Battelle's performance in demonstrating technical and managerial leadership. By the end of the first quarter FY 1999, the Laboratory and DOE-RL will jointly: 
- Identify customers to be interviewed in advance of conducting any interviews.

- Develop the interview schedule for the year.

- Develop interview questions around the strategic objectives to be achieved in the thrust areas in advance of the interviews.

- Develop the interview protocol/script and evaluation scheme for each interview and for consolidating these into a single rating.

Baseline Information: None

Performance Expectation Related Assumptions:

The initiatives evaluated will be based upon availability of the agreed upon interviewers and interviewees.

The final rating will be based on a scale of 1 to 5 , with 5 representing outstanding performance. Both DOE-RL and NSD will determine these ratings with final approval by DOE-RL.

Performance: The final composite rating across all dimensions will be as follows:

- 5.0 represents the target performance level

- 3.0 represents the neutral performance level

- 1.0 represents the minimum performance level

1.4.6 Number of formal agreements (e.g., CRADAs, MOUs, non-government contracts, and other formal agreements and expressions of interest) established between October 1, 1998 and September 30, 1999 with private sector entities

Description: Formal agreements must meet the following criteria to be accepted as performance against this indicator:

- Agreements directly address one of the four thrust areas described above (Efficient Vehicles and Automotive Structures, Intelligent Building Systems, Engineering Simulation and Modeling - Virtual Prototyping, and Fuel Systems Technology).

- Technical scope of the agreement must be focused on a specific objective with clearly defined deliverables.

- The agreement partner must contribute at least $25 \%$ of the total dollar value of the relationship either as funding or in-kind contributions.

Agreements that existed prior to October 1, 1998 that are renewed, extended, or otherwise amended in terms of scope, level of effort, commitment of resources, or deliverabies for performance in FY99 may count under this indicator as long as DOE-RL and the Laboratory concur that they meet the above criteria, and are substantially revised.

Baseline Information: The number of agreements meeting the above criteria and conditions were 7 in FY97, and 12 in FY98. FY98 performance was unusually high, and because of business conditions and the multi-year nature of the agreements put in place, the potential for putting new agreements in place for FY99 will be limited.

Performance Expectation Related Assumptions: None 
Performance: Number of Agreements meeting the above conditions.

\begin{tabular}{|c|c|}
\hline $\begin{array}{c}\text { Performance } \\
\text { Level } \\
\end{array}$ & $\begin{array}{l}\text { Number of } \\
\text { Agreements }\end{array}$ \\
\hline Target: & 9 \\
\hline Neutral: & 5 \\
\hline Minimum: & 1 \\
\hline
\end{tabular}

Critical Outcome Performance Rating and Additional Performance-Based Fee

Figures $1 \mathrm{~A}, 1 \mathrm{~B}, 1 \mathrm{C}, 1 \mathrm{D}, 1 \mathrm{E}$ and $1 \mathrm{~F}$ document the associated agreements on performance expectations in the form of contingency functions. The overall performance rating for this outcome will be determined by summing the effectiveness scores for all Objectives as depicted in Tables 1.1 through 1.4, normalizing the scores using Table 1.5 and comparing the normalized sum to the rating scale in Table 1.6. Additional performance-based fee earned (if any) for this outcome is determined by comparing the overall outcome score $(5.0-3.5)$ to the amount available within Table 1.7 . 
Figure 1A, Scientific \& Technological Excellence Objective 1.1, Contingency Diagram

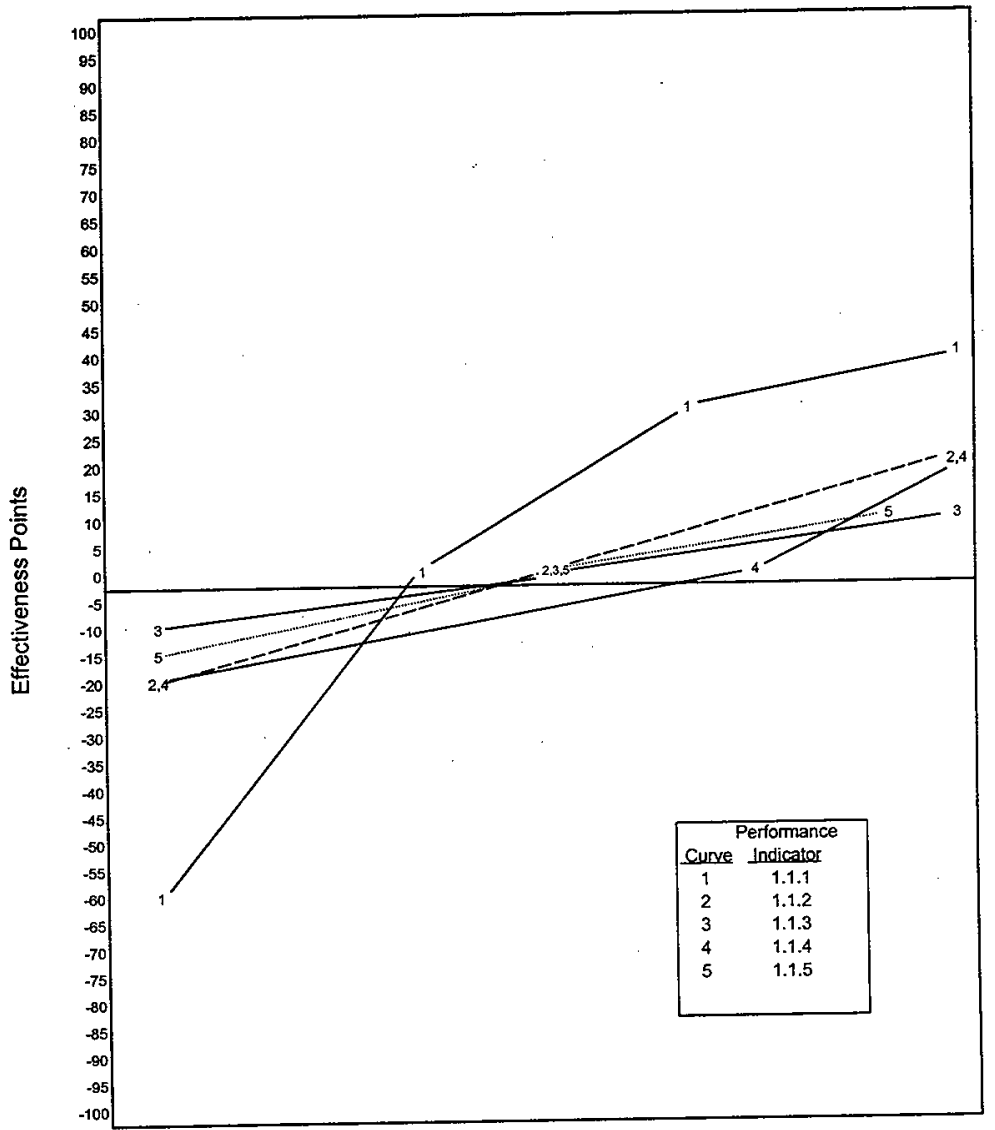

Performance Indicator

1 Extemal Peer Review

2 Recog by Sci Committee

3 R\&D $100 /$ FLC Awards

4 Publications in Joumals

5 Acad/Sci Partnerships
SCALES

\begin{tabular}{|c|c|c|c|c|c|c|c|c|c|c|c|c|c|c|c|c|c|c|c|c|c|c|c|c|c|}
\hline & $\mathrm{M}$ & & & & & & & & $\mathrm{G}$ & & & & & & & & $\mathrm{E}$ & & & & & & & & 0 \\
\hline & .90 & & & & & & $5 \%$ & & & & & & $0 \%$ & & & & & & $5 \%$ & & & & & & $10 \%$ \\
\hline 6.0 & & & & & & 6.5 & & & & & & 7.0 & & & & & & 7.5 & & & & & & 8.0 \\
\hline & 425 & & & & & & 450 & & & & & & 475 & & & & & & 500 & & & & & & 525 \\
\hline
\end{tabular}


Figure 1B, Scientific \& Technological Excellence Objective 1.2, Contingency Diagram

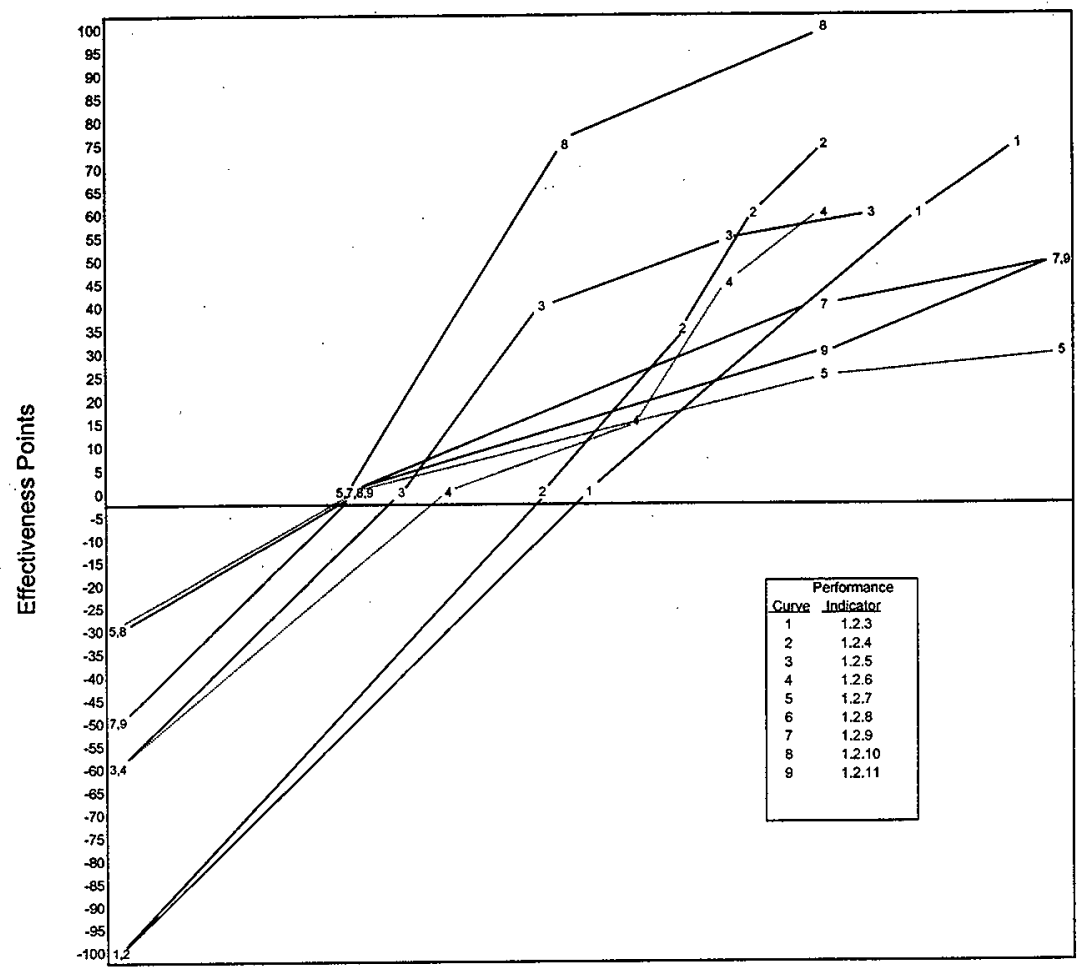

Perfomance Indicator

1 EQ-TFA Corrposite

2 EQ-PIiv Composite

3 EO-Tech Deploys

4 EQ- Hantord Solns

5 EQ-Cust Feedback

6 NS-Solnsideploys

7 NS - Cust Feedback

g Energy - Tech Deploys

9 Energy - Cust Fdbk

SCALES

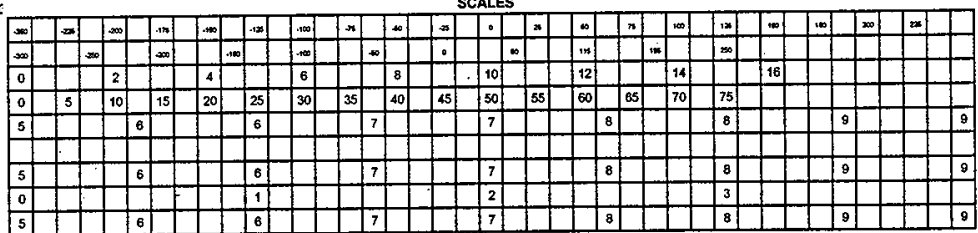


Figure 1C, Scientific \& Technological Excellence Objective 1.2, Indicator 1.2.3,

\section{Contingency Diagram}

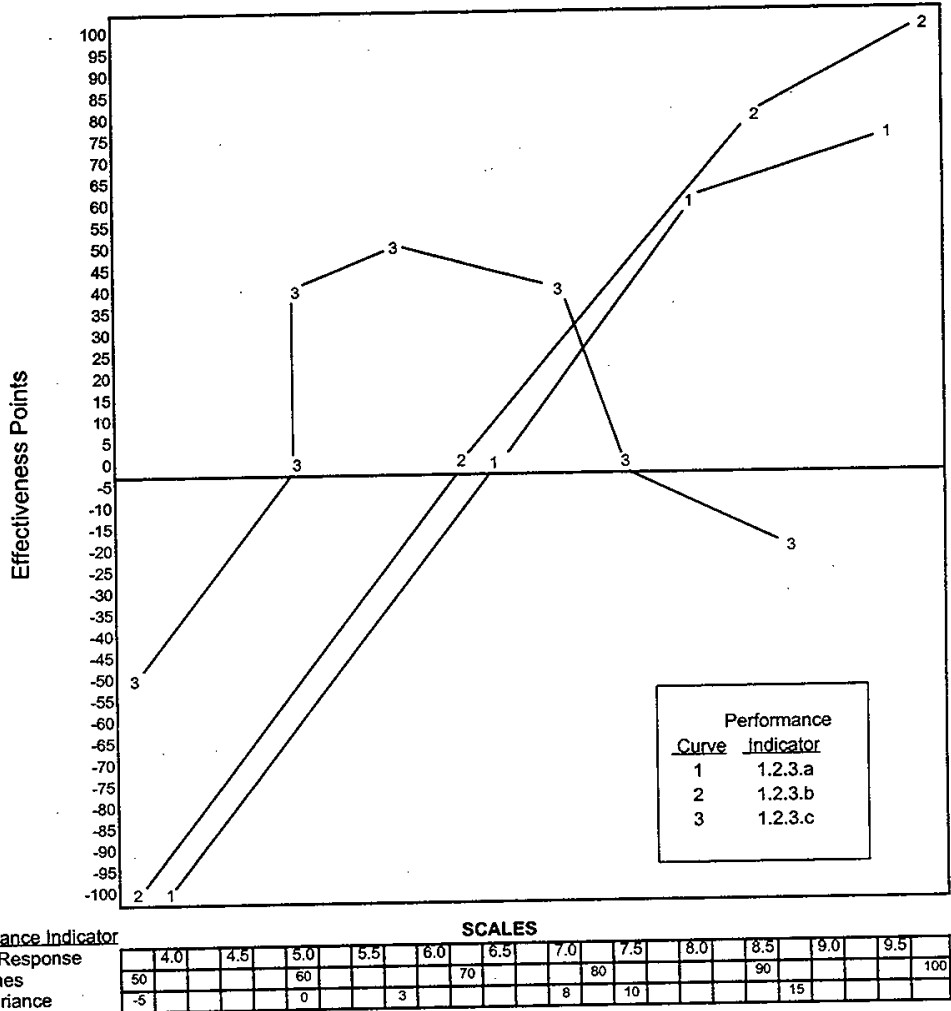

1 Survey Response

2 Milestones

3 Cost Variance

\begin{tabular}{|c|c|c|c|c|c|c|c|c|c|c|c|c|c|c|c|c|c|}
\hline & 4.0 & 4.5 & 15.0 & 5.5 & & 6.0 & & 6.5 & 7.0 & & 7.5 & 8.0 & 8.5 & & 9.0 & 9.5 & \\
\hline 50 & & & 60 & & & & 701 & & & 80 & & & 90 & & & & 100 \\
\hline 5 & & & $\overline{0}$ & & 3 & & & & 8 & & \begin{tabular}{|c|}
10 \\
\end{tabular} & & & 15 & & & \\
\hline
\end{tabular}


Figure 1D, Scientific \& Technological Excellence Objective 1.2, Indicator 1.2.4, $-\therefore$

Contingency Diagram

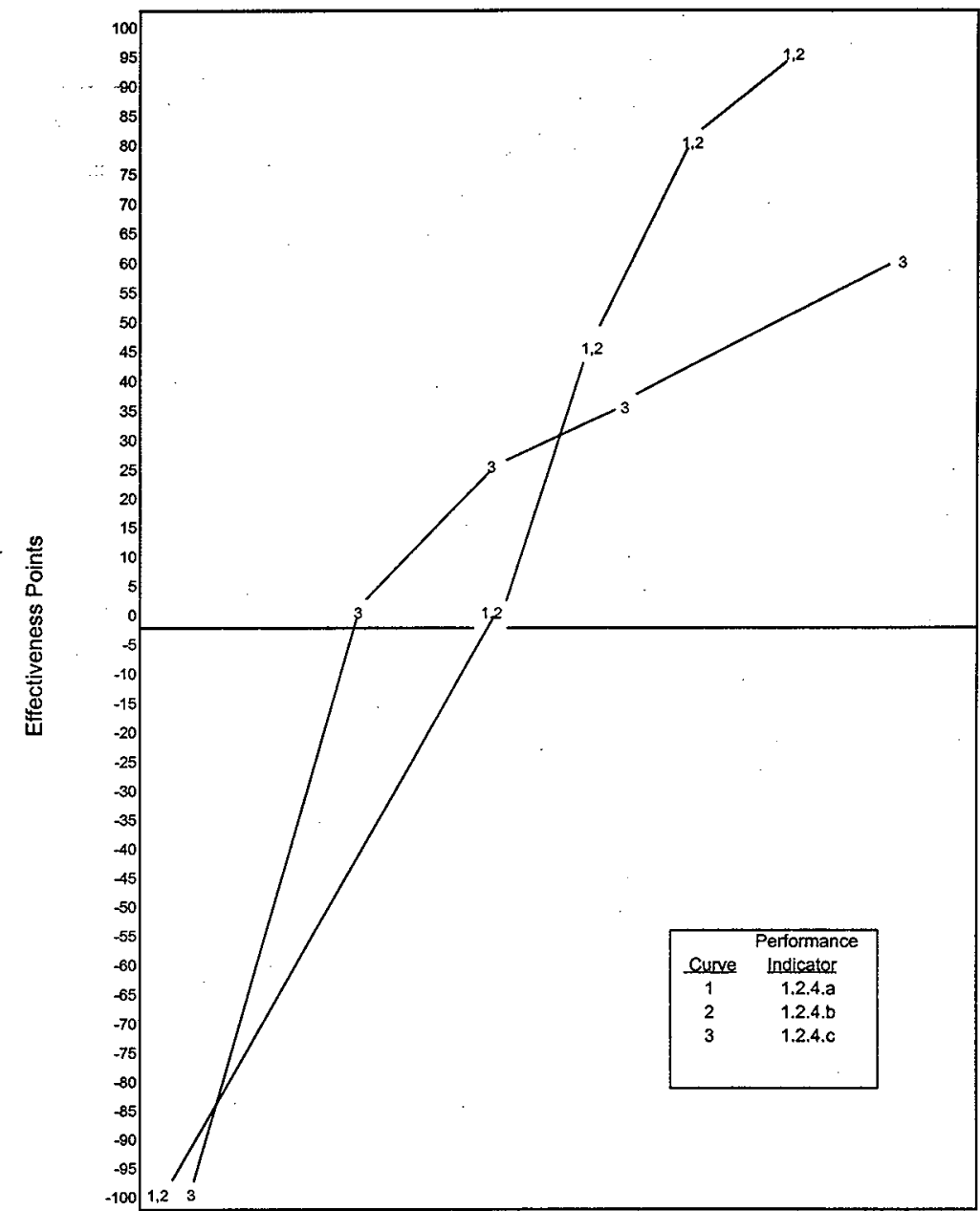

Perfomance Indicator

SCALES

1 BNFL Deliverables

2 Strategic Decisions

3 Issue Response.

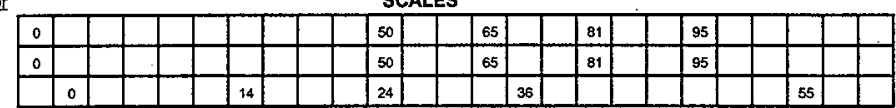


Figure 1E, Scientific \& Technological Excellence, Objective 1.3 Contingency Diagram

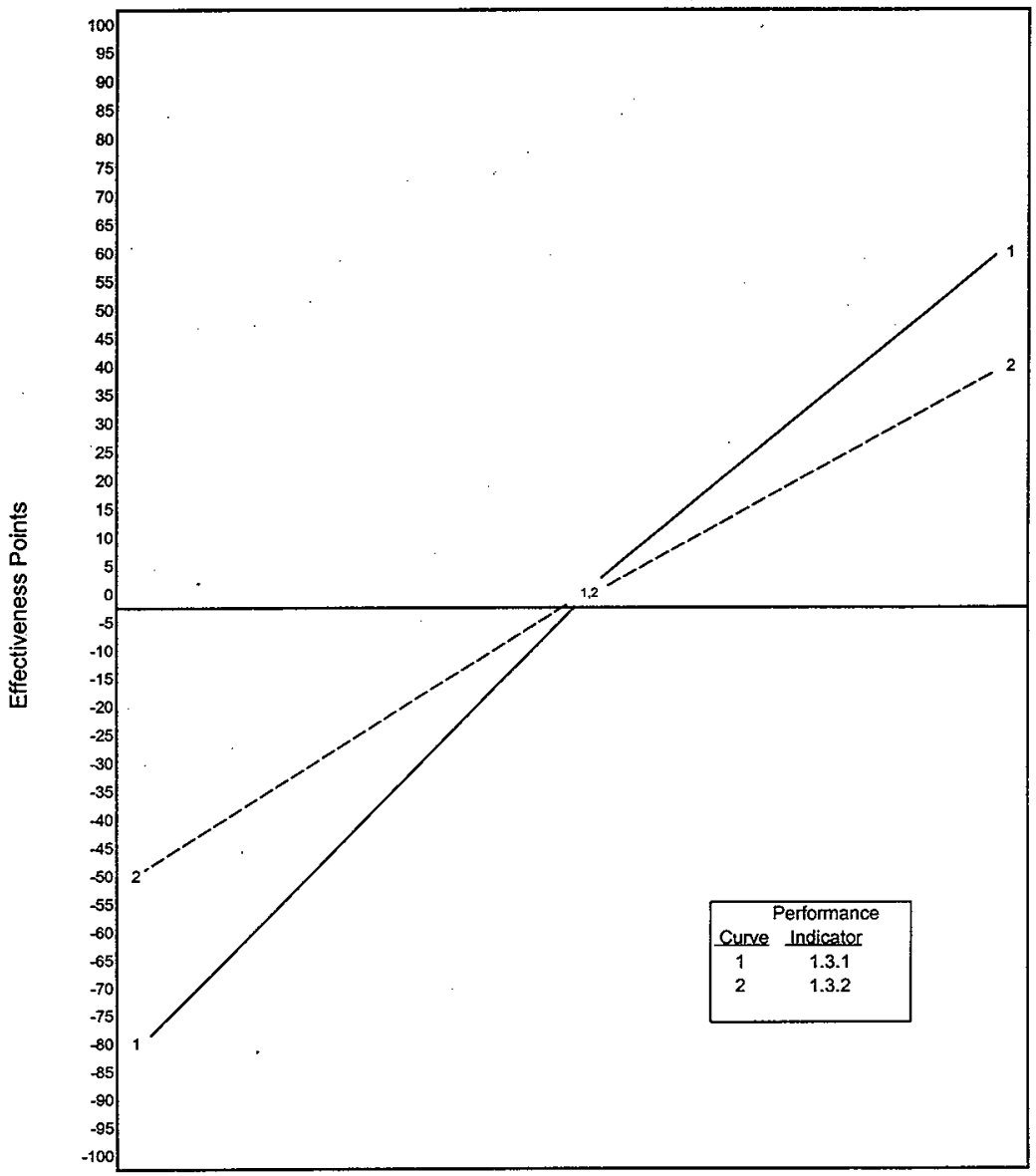

Performance Indicater

1 EMSL Facilities

SCALES

2 ARM Facilities

\begin{tabular}{|l|l|l|l|l|l|l|l|l|l|l|l|l|l|l|l|l|l|l|l|l|l|l|l|l|l|}
\hline & 1 & & & & & & 2 & & & & & & 3 & & & & & & 4 & & & & & & 5 \\
\hline 1 & & & & & & 2 & & & & & & 3 & & & & & & 4 & & & & & \\
\hline
\end{tabular}


Figure 1F, Scientific \& Technological Excellence, Objective 1.4 Contingency Diagram

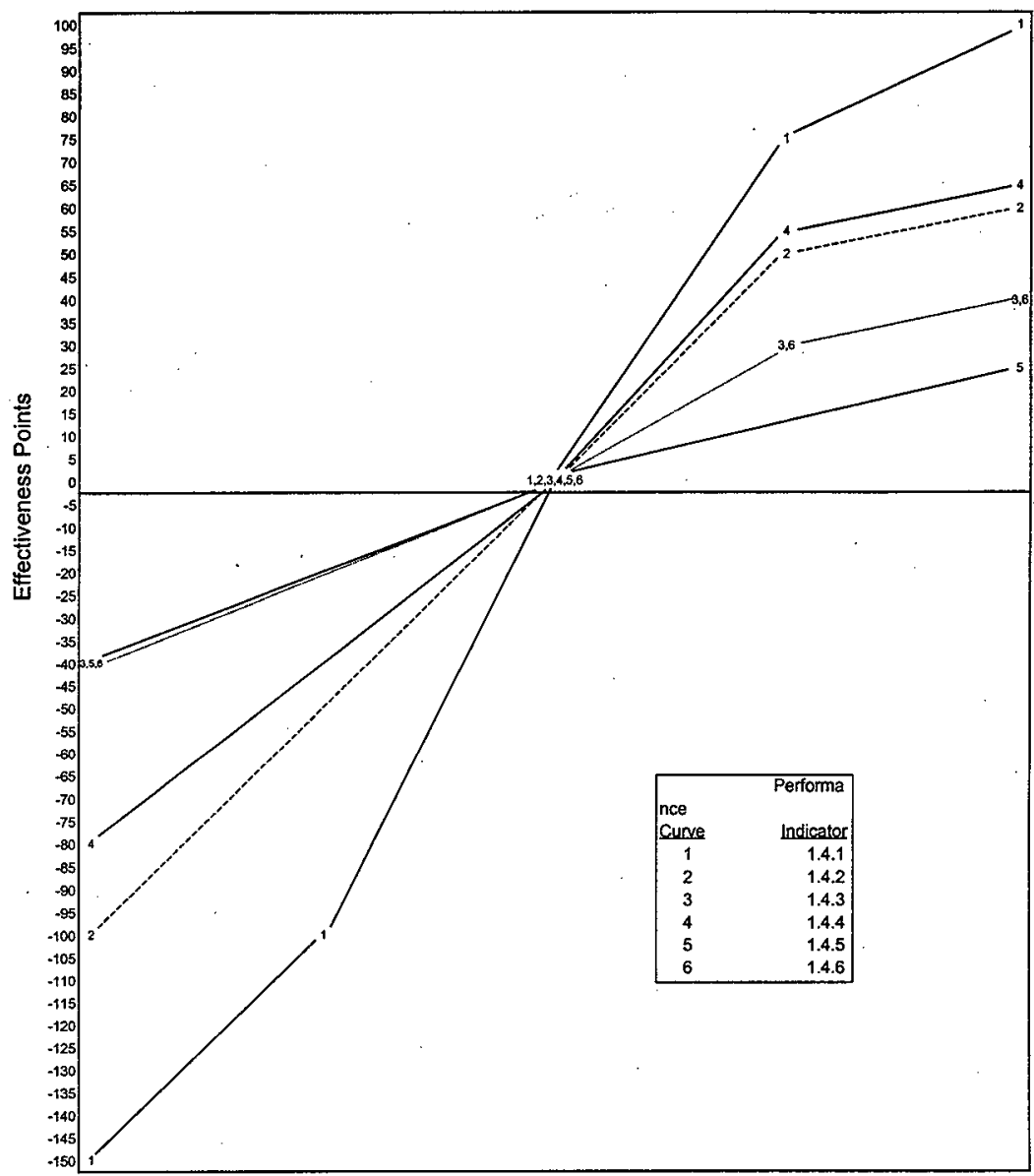

Rerfogmance-ladicator

1 OER Leaderstip

2 EQ-Leacership

3 EQ-Vadosa Zone

4 NS - Leadership

5 Energy -Leadership

6 Enery patnerships

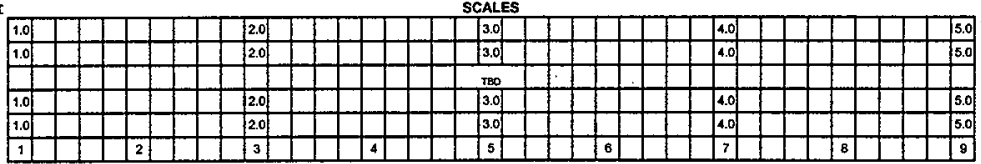




\begin{tabular}{|c|c|c|c|c|c|}
\hline WELEMENT & $\begin{array}{c}\text { Performance } \\
\text { Level }\end{array}$ & $\begin{array}{c}\text { Effectiveness } \\
\text { Score }\end{array}$ & $\begin{array}{l}\text { Value } \\
\text { Points } \\
\end{array}$ & Weight & $\begin{array}{l}\text { Weighted } \\
\text { Points }\end{array}$ \\
\hline $\begin{array}{l}\text { 1.1 Conduct high quality S\&T } \\
\text { programs }\end{array}$ & & & $\therefore$ & & \\
\hline $\begin{array}{l}1.1 .1 \text { Results of external peer review of } \\
\text { relevance and excellence, including } \\
\text { Divisional reviews }\end{array}$ & & & & & \\
\hline $\begin{array}{l}\text { 1.1.2 Recognition by the external } \\
\text { scientific and technical community }\end{array}$ & & & & & \\
\hline $\begin{array}{l}\text { 1.1.3 Number of R\&D } 100 \text { and FLC } \\
\text { awards }\end{array}$ & & & & & \\
\hline $\begin{array}{l}\text { 1.1.4 Number of publications in peer } \\
\text { reviewed journals }\end{array}$ & & & & & \\
\hline $\begin{array}{l}\text { 1.1.5 Number of quality } \\
\text { academic/scientific partnerships }\end{array}$ & & & & & \\
\hline W & Total form & & & $50 \%$ & \\
\hline W & 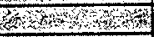 & 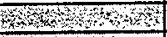 & का सक & Xros & wow \\
\hline $\begin{array}{l}\text { 1.1.6 Results of DOE-OER Evaluation } \\
\text { of the quality of science }\end{array}$ & ming & 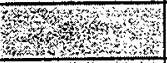 & & $50 \%$ & \\
\hline & $\begin{array}{l}\text { Obj } 1.1 \\
\text { Total }\end{array}$ & Whon & 20 & कto & \\
\hline
\end{tabular}

Table 1.1 - Objective 1.1 Performance Rating Development 


\begin{tabular}{|c|c|c|c|c|c|}
\hline 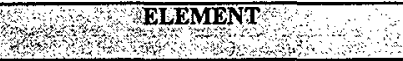 & $\begin{array}{l}\text { Performance } \\
- \text { Level }\end{array}$ & $\begin{array}{l}\text { Effectiveness } \\
\text { Score }\end{array}$ & $\begin{array}{l}\text { Value } \\
\text { Points }\end{array}$ & Weight & $\begin{array}{c}\text { Weighted } \\
\text { Points }\end{array}$ \\
\hline $\begin{array}{l}1.2 \text { Deliver S\&T products relevant to } \\
\text { DOE missions and national needs }\end{array}$ & $\mathrm{x}$ & & & & \\
\hline $\begin{array}{l}\text { 1.2.1 Results of DOE-OER's evaluation } \\
\text { of the relevance of Battelle work to DOE } \\
\text { Missions and Needs }\end{array}$ & (x) & Why & & $10 \%$ & \\
\hline $\begin{array}{l}\text { 1.2.2 The results of DOE-OER's } \\
\text { evaluation of the Laboratory's } \\
\text { programmatic performance }\end{array}$ & whon & 3nt & & $10 \%$ & \\
\hline r & Whong & 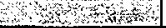 & $\omega^{2}$ & a & \\
\hline $\begin{array}{l}1.2 .3 \text { Effectively lead the technical } \\
\text { aspects of the national Tanks Focus Area }\end{array}$ & & & & & \\
\hline $\begin{array}{l}\text { 1.2.4 Effectively support the Hanford } \\
\text { Tanks Privatization Effort }\end{array}$ & & & & $\theta_{0}$ & \\
\hline $\begin{array}{l}1.2 .5 \text { Number of innovative technologies } \\
\text { and approaches successfully deployed in } \\
\text { commercial practice }\end{array}$ & & & & & \\
\hline $\begin{array}{l}\text { 1.2.6 Provide significant solutions to } \\
\text { Hanford problems/needs }\end{array}$ & & & & & \\
\hline $\begin{array}{l}1.2 .7 \text { Customer Feedback on relevance } \\
\text { and excellence in Environmental Quality }\end{array}$ & & & & & \\
\hline $\begin{array}{l}1.2 .8 \text { Number of solutions and } \\
\text { deployments to significant national } \\
\text { security problems/issues }\end{array}$ & & & & & \\
\hline $\begin{array}{l}1.2 .9 \text { Customer Feedback on relevance } \\
\text { and excellence in National Security }\end{array}$ & & & & & \\
\hline $\begin{array}{l}1.2 .10 \text { Number of energy technologies, } \\
\text { systems and technical solutions } \\
\text { deployed }\end{array}$ & & & & . & \\
\hline $\begin{array}{l}1.2 .11 \text { Customer Feedback on relevance } \\
\text { and excellence in Energy }\end{array}$ & & & & & \\
\hline & \begin{tabular}{r|} 
Total.form \\
Curves
\end{tabular} & & & $80 \%$ & \\
\hline & $\begin{array}{r}\text { Obj 1.2 } \\
\text { Total } \\
\end{array}$ & & & $\sqrt{3}$ & \\
\hline
\end{tabular}

Table 1.2 - Objective 1.2 Performance Rating Development 


\begin{tabular}{|c|c|c|c|c|c|}
\hline $4,4 \%$ ELEMENT & $\begin{array}{r}\text { Performance } \\
\text { Level }\end{array}$ & $\begin{array}{l}\text { Effectiveness } \\
\text { S Score }\end{array}$ & $\begin{array}{l}\text { Value } \\
\text { Points }\end{array}$ & Weight & $\begin{array}{l}\text { Weighted } \\
\text { Points }\end{array}$ \\
\hline $\begin{array}{l}\text { 1.3 Successfully operate the Wiley Lab } \\
\text { \& ARM Facilities }\end{array}$ & 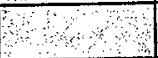 & & & & \\
\hline $\begin{array}{l}\text { 1.3.1 Successful operation of the Wiley } \\
\text { Laboratory }\end{array}$ & & & & & \\
\hline $\begin{array}{l}\text { 1.3.2 Operation of ARM Extended } \\
\text { Research Facilities }\end{array}$ & & & & & \\
\hline W W & Wotal form & & & $50 \%$ & \\
\hline $\begin{array}{l}\text { 1.3.3 Results of DOE-OER's evaluation } \\
\text { of the quality of the Laboratory's User } \\
\text { Facilities }\end{array}$ & $\frac{1}{4 x+3}$ & 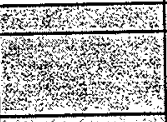 & & $50 \%$ & \\
\hline Wyon & Syobj & & $\overline{4}$ & 5 & \\
\hline
\end{tabular}

Table 1.3 - Objective 1.3 Performance Rating Development 


\begin{tabular}{|c|c|c|c|c|c|}
\hline Ww, & $\begin{array}{l}\text { Performance } \\
\text { Level }\end{array}$ & $\begin{array}{l}\text { Efrectiveness } \\
\text { Score }\end{array}$ & $\begin{array}{l}\text { Value } \\
\text { Points }\end{array}$ & Weight & $\begin{array}{l}\text { Weighted } \\
\text { Points }\end{array}$ \\
\hline $\begin{array}{l}\text { 1. Scientific and Technological } \\
\text { Excellence }\end{array}$ & sis & & & 3 & \\
\hline $\begin{array}{l}\text { 1.1 Conduct high quality S\&T } \\
\text { programs }\end{array}$ & $\begin{array}{r}\text { Obj } 1.1 \\
\text { Total }\end{array}$ & Wrow & & $25 \%$ & \\
\hline When & 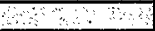 & ysing & & & \\
\hline $\begin{array}{l}\text { 1.2 Deliver S\&T products relevant to } \\
\text { DOE missions and national needs }\end{array}$ & $\begin{array}{r}\text { Obj } 1: 2 \\
\text { Total }\end{array}$ & Why & & $40 \%$ & \\
\hline$x_{\mathrm{t}} \mathrm{s}, \mathrm{\alpha}, \mathrm{a}$ & 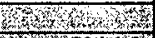 & S 5 , & 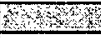 & 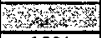 & Whys \\
\hline $\begin{array}{l}\text { 1.3 Successfully operate the Wiley Lab } \\
\text { \& ARM Facilities }\end{array}$ & 3. & 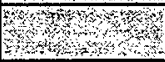 & & $10 \%$ & \\
\hline W & $\because$ & 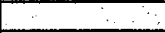 & 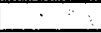 & $\therefore$ & \\
\hline $\begin{array}{l}\text { 1.4Demonstrate leadership \& } \\
\text { excellence in program planning \& } \\
\text { management ... }\end{array}$ & & & & & \\
\hline $\begin{array}{l}\text { 1.4.1 Demonstrate programmatic } \\
\text { leadership within Fundamental Science }\end{array}$ & & & & & \\
\hline $\begin{array}{l}\text { 1.4.2 Demonstrate programmatic } \\
\text { leadership in Environmental Quality }\end{array}$ & & & & & \\
\hline $\begin{array}{l}1.4 .3 \text { Effectively lead the technical } \\
\text { aspects of the Groundwater and Vadose } \\
\text { Zone efforts }\end{array}$ & & & & & \\
\hline $\begin{array}{l}\text { 1.4.4 Customer Feedback on Leadership } \\
\text { for key National Security Programs }\end{array}$ & & & & & \\
\hline $\begin{array}{l}\text { 1.4.5 DOE customer feedback on } \\
\text { technical and managerial leadership in } \\
\text { the Energy thrust areas }\end{array}$ & & & & & \\
\hline $\begin{array}{l}1.4 .6 \text { Number of formal agreements ... } \\
\text { with private sector entities }\end{array}$ & & & & $25 \%$ & \\
\hline . & $\begin{array}{r}\text { Obj } 1.4 \\
\text { Total } \\
\end{array}$ & & & Total & \\
\hline
\end{tabular}

Table 1.4 - Scientific and Technological Excellence Critical Outcome Performance Rating Development 


\begin{tabular}{|c|c|c|c|c|}
\hline Objective 1.1 & Objective 1.2 & Objective 13 & Objective 1.4 & Value Points \\
\hline F & $626000^{\circ}$ & (1) & $3 x_{2}$ & 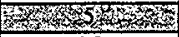 \\
\hline 96.0 & 575.5 & 95.0 & 322.6 & 4.9 \\
\hline 92.0 & 551.0 & 90.0 & 315.1 & 4.8 \\
\hline 88.0 & $\overline{526.5}$ & 85.0 & 307.7 & 4.7 \\
\hline 84.0 & 502.0 & 80.0 & 300.2 & 4.6 \\
\hline 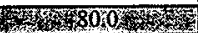 & 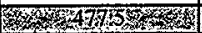 & 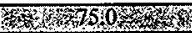 & 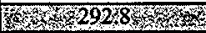 & 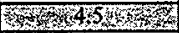 \\
\hline 76.0 & 449.4 & 70.0 & 285.3 & 4.4 \\
\hline 72.0 & 421.5 & 65.0 & 277.9 & 4.3 \\
\hline 68.0 & 393.4 & 60.0 & 270.4 & 4.2 \\
\hline 64.0 & 365.3 & 55.0 & 263.0 & 4.1 \\
\hline 60.0 & 337.4 & 50.0 & 255.5 & 4 \\
\hline 54.0 & 309.3 & 45.0 & 230.0 & 3.9 \\
\hline 48.0 & 281.2 & 40.0 & 204.4 & 3.8 \\
\hline 42.0 & 253.3 & 35.0 & 178.9 & 3.7 \\
\hline 36.0 & 225.2 & 30.0 & 153.3 & 3.6 \\
\hline 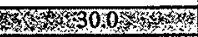 & 6rom $1971 \%$ & $3025.00 \%$ & W $1278, \mathrm{w}$ & 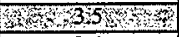 \\
\hline 24.0 & 157.8 & 20.0 & 102.2 & 3.4 \\
\hline 18.0 & 118.3 & 15.0 & 76.7 & 3.3 \\
\hline 12.0 & 78.8 & 10.0 & 51.1 & 3.2 \\
\hline 6.0 & 39.5 & 5.0 & 25.6 & 3.1 \\
\hline 0.0 & 0.0 & 0.0 & 0.0 & 3 \\
\hline-9.3 & -28.0 & -6.5 & -25 & 2.9 \\
\hline-18.5 & -56.0 & -13.0 & -50 & 2.8 \\
\hline-27.8 & -84.0 & -19.5 & -75 & 2.7 \\
\hline-37.0 & -112.0 & -26.0 & -100 & 2.6 \\
\hline $46463 \mathrm{~m}$ & कान14000 & $62,325 \%-4$ & $40-125$ & 255 \\
\hline-55.5 & -168.0 & -39.0 & -150 & 2.4 \\
\hline-64.8 & -196.0 & -45.5 & -175 & 2.3 \\
\hline-74.0 & -224.0 & -52.0 & -200 & 2.2 \\
\hline-83.3 & -252.0 & -58.5 & -225 & 2.1 \\
\hline-92.5 & -280.0 & -65.0 & -250 & 2 \\
\hline-95.8 & -308.0 & -71.5 & -270 & 1.9 \\
\hline-99.0 & -336.0 & -78.0 & -290 & 1.8 \\
\hline-102.3 & -364.0 & -84.5 & -310 & 1.7 \\
\hline-105.5 & -392.0 & -91.0 & -330 & 1.6 \\
\hline 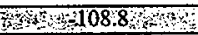 & $4 \times 42000 \%$ & 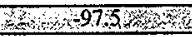 & 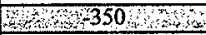 & $20+115$ \\
\hline-112.0 & -448.0 & -104.0 & -370 & 1.4 \\
\hline-115.3 & -476.0 & -110.5 & -390 & 1.3 \\
\hline-118.5 & -504.0 & -117.0 & -410 & 1.2 \\
\hline-121.8 & .532 .0 & -123.5 & -430 & 1.1 \\
\hline $5 \times 1,125,0 \times 40$ & $+x+560.0 \%$ & $40=130.08 \%$ & Wh $4450 \mathrm{ge}, \mathrm{n}$ & F, 1 \\
\hline
\end{tabular}

Table 1.5 - Scientific and Technological Excellence Critical Outcome Score Normalization Table 


\begin{tabular}{|c|c|c|c|c|c|}
\hline Total Score & $5.0-4.5$ & $4.4-3.5$ & $3.4-2.5$ & $2.4-1.5$ & $1.4-1.0$ \\
\hline Final Rating & Outstanding & Excellent & Good & Marginal & Unsatisfactory \\
\hline
\end{tabular}

Table 1.6 - Scientific and Technological Excellence Critical Outcome Final Ráting

\begin{tabular}{|c|c|c|}
\hline Outcome Rating & Score & $\begin{array}{l}\text { Pentomance-based } \\
\text { Fee }\end{array}$ \\
\hline \multirow{6}{*}{ Outstanding } & 5.0 & $\$ 770,000$ \\
\hline & 4.9 & $\$ 721,875$ \\
\hline & 4.8 & $\$ 673,750$ \\
\hline & 4.7 & $\$ 625,625$ \\
\hline & 4.6 & $\$ 577,500$ \\
\hline & 4.5 & $\$ 529,375$ \\
\hline \multirow{9}{*}{ Excellent } & 4.4 & $\$ 481,250$ \\
\hline & 4.3 & $\$ 433,125$ \\
\hline & 4.2 & $\$ 385,000$ \\
\hline & 4.1 & $\$ 336,875$ \\
\hline & 4.0 & $\$ 288,750$ \\
\hline & 3.9 & $\$ 240,625$ \\
\hline & 3.8 & $\$ 192,500$ \\
\hline & 3.7 & $\$ 144,375$ \\
\hline & 3.6 & $\$ 96,250$ \\
\hline Good or Less & 3.5 & $\$ 48,725$ \\
\hline & 3.4 & $\$ 0$ \\
\hline
\end{tabular}

Table 1.7 - Scientific and Technological Excellence Critical Outcome Additional Performance-Based Fee Matrix 


\subsection{OPERATIONAL EXCELLENCE (20\%)}

\section{Critical Outcome}

Battelle will conduct work and operate Laboratory facilities with distinction, fully supportive of and integrated with the Laboratory's science and technology mission and fully protective of workers, the public and the environment.

Modification: The objectives, indicators and expected levels of performance identified below have been developed based on the best information available at the time. Should circumstances arise which require modifications to any of the objectives, indicators and/or expected levels of performance within this outcome it shall be accomplished through the approved change control process described within this document. If the Parties cannot reach agreement on the changes the Contracting Officer shall have the right to make reasonable changes as specified within the contract DE-AC06-76RLRL01830.

2.1 Objective - Sustain and enhance operational excellence in safety and health, and environmental protection. (67\%)

\section{Performance Indicators}

2.1.1 Worker involvement, knowledge, and culture relative to ES\&H (30\%)

Description: This Performance Indicator is a composite of three Performance Subindicators, designed to provide an overall evaluation of worker involvement, knowledge, and culture relative to ES\&H and the expectations of DOE and Battelle.

2.1.1.1 Management interactions with workers to ensure staff involvement in work planning, knowledge of requirements and attitude/culture relative to ES\&H.

Measure: This indicator provides a measure of appropriate management and staff interaction to ensure staff involvement in work planning, knowledge of requirements, and appropriate worker attitude/culture relative to ES\&H. The performance will be determined by observing work and performing a minimum of 175 interviews.

Description: Each Contractor R\&D division and the Contractor ES\&H and Facilities and Operations (F\&O) directorates will perform in-field assessments of staff behavior, knowledge, and opinion using a standardized evaluation tool reviewed and approved by DOE RL. The evaluation tool will measure specific staff members and will be a basis for Laboratory improvement in the following areas:

- Involvement in work planning

- Knowledge of applicable requirements

- Behaviors relevant to ES\&H

- Opinion of the adequacy of their involvement and the value of ES\&H controls in their work

The tool will be used by objective staff (e.g. management, management representatives, Safety and Health Representatives, or selected bargaining unit staff for some of F\&O evaluations) during routine field activities (such as self-assessment walkthroughs). Staff who are selected to participate in the evaluations will be asked to verbally answer quantifiable questions and provide comments or other information. 
Based on verbal responses by staff, observation of work being performed, and other information as necessary the manager/staff performing the evaluation will make a rating determination relative to the bullets above. The results generated by these evaluations will be included in the assessing organization's self-assessment results and used in accordance with their self-assessment program, which is measured within the Leadership and Management Critical Outcome.

Each Contractor R\&D division and the Contractor ES\&H and F\&O directorates will identify those organizations that perform potentially hazardous work (organizational elements that perform only paper studies will be excluded). At least one hundred and seventy-five assessments (interactions) will be conducted by the participating organizations and rolled-up at the Lab level. During self-assessment walkthroughs of lab-intensive areas or other routine field activities as appropriate, evaluators will identify staff who are working and who will be asked to participate in the evaluations under this PI.

Data will be collected and reported on a quarterly basis. The following table represents the suggested number of assessments per quarter by organization. The number of assessments shall, without material deviation, be spread over participating organizations as represented below.

\begin{tabular}{|c|c|c|c|c|c|c|c|}
\hline & \multicolumn{6}{|c|}{ Assessments by Organization } & \\
\hline FY-99 & EHSD & Energy & ES\&H & ETD & $\mathrm{F} \& \mathrm{O}$ & NSD & Total \\
\hline Q1 & की & 7 & 5 & और 8 & 88 & $x-7$ & 44 \\
\hline Q2 & 9 & 7 & 5 & 8 & 8 & 7 & 44 \\
\hline $\mathrm{Q} 3$ & 8 & 7 & 5 & 9 & 8 & 7 & 44 \\
\hline$Q 4 \times$ & 8 & 7 & 5 & 8 & 9 & 6 & 43 \\
\hline Total & 34 & 28 & 20 & 33 & 33 & 27 & 175 \\
\hline
\end{tabular}

Performance:

Target: $\quad 175$ evaluations performed in FY99 and the results used in the selfassessment Program

Neutral: $\quad 150$ evaluations performed in FY99 FY99 and the results used in the self-assessment Program

Minimum: $\quad 125$ evaluations performed in FY99 FY99 and the results used in the self-assessment Program

Background: This performance indicator has been developed along the lines of classic Voluntary Protection Program (VPP) measures. VPP emphasizes worker involvement in the decision.making process. This measure counts the number of interactions between management/leadership and the worker. The lack of such interactions has been identified as a contributing factor in recent accidents at other DOE sites.

Benefit: As identified in ISM Verification worker involvement was weak. It is necessary in order to have excellent ES\&H at the laboratory that the workforce have confidence in their training, knowledge of their job and responsibilities, and be involved in the work planning. Interactions between management and the work force is the first step in ensuring improvements in this area.

\subsubsection{Dose Index}

Measurement: This indicator provides a direct measurement of the accuracy of estimating dose for activities during radiological work planning process. 
Description: The ratio of the sum of actual doses received as recorded in ACES or REX, as appropriate, divided by the sum of all collective dose estimates required by RCP3.1.01, Exhibit 1. Radiological Engineers must have a better understanding of work activities and job scope while work planners must have a better understanding of radiological ALARA practices to be successful on this indicator. This indicator will include only those activities requiring entry into Radiation Areas, and High Radiation Areas. This indicator will be tracked for those activities with an estimated dose for an individual greater than 100 mrem or an estimated dose greater than 1000 mrem collective for a group.

Assumptions: There will be no significant change in scope of radiological work within the Laboratory

Baseline Information: The ratio of actual dose to estimated dose for the FY98 Dose Index PI was 0.67 on August 31, 1998.

Performance:

Target: Between and including 0.8-1.2 (delta $\leq 0.2)$

Neutral: Between $0.4-0.8$ or $1.2-1.6$ (delta $\leq 0.4$ )

Minimum: Below 0.4 or above and including 1.6 (delta $>.6$ )

Benefits: Success on this indicator will result in Radiological Engineers having a better understanding of work activities and job scope while work planners will have a better understanding of radiological ALARA practices.

\subsubsection{User involvement in SBMS Subject Area development}

Measure: This indicator provides a measure of worker involvement in development of Laboratory-level procedures (i.e., SBMS Subject Areas). This is one aspect of worker involvement within the Contractor organizations and also demonstrates management's commitment to the principle of worker involvement.

Description: The percentage of user involvement in the development of new SBMS Subject Areas either as part of a development team or by providing comments to early drafts during the development stage. The total number of new Subject Areas issued during FY99 will be the base (denominator) and the number with user involvement (as defined above) the numerator. The performance will be based on cumulative performance throughout the fiscal year and reported monthly. The indicator will include all new Subject Areas issued via SBMS during the fiscal year.

The sunsetting of A-Manuals will serve as a gate for this portion of the Worker Involvement performance indicator. For this subindicator to be counted in the overall evaluation of performance for the 2.1 objective, $60 \%$ of the chapters/sections of the AManuals that exist at the beginning of the fiscal year must be eliminated from the on-line system by the end of fiscal year 1999 .

Assumptions: The following are basic assumptions for this indicator:

- User involvernent is not necessary in $100 \%$ of new or revised Subject Areas.

- User involvement is designated by the line organization (R\&D division or functional directorate) based on their need to participate.

- User involvement is characterized as participation before review of the final draft of a Subject Area. 
- Line organizations may designate individuals to represent them that are assigned from functional organizations (e.g., Quality or ES\&H). These designees are counted as "users."

- Subject Mater Experts.(SMEs) and/or management system owners will provide a list of users to the SBMS manager, as evidence of worker involvement in the development of a Subject Area.

- The minimum number of workers that must be involved in the development of a Subject Area to count for this subindicator is one.

- A worker is defined as anyone other than the management system owner and the SME for a particular Subject Area.

- Sunsetting occurs once all the information that needs to be converted to Subject Areas, as concurred with by the Subject Area Development Lead, has been converted and issued as an SBMS Subject Area, as a Program Description, or as another document (e.g., B-Manual).

Baseline Information: Data for this indicator was gathered during FY98 as part of the SBMS self-assessment activities. That baseline provided the following results from the development of 40 Subject Areas:

- Users involved in development of Subject Area: 7

- Users involved in review of Subject Area during development: 5

- Users involved only in review of final draft of Subject Area: 27

- No users involved in development of Subject Area: 1

Performance:

Target: Users involved in $60 \%$ or more of new Subject Areas developed. Neutral: Users involved in $40 \%$ of new Subject Areas developed.

Minimum: Users involved in $30 \%$ or less of Subject Areas developed.

Benefits: Two aspects of this indicator result in increase effectiveness and efficiency:

- User involvement in development of Subject Areas ensures that Lab-level procedures can be implemented and reflect actual operations, thus enhancing compliance with requirements.

- User involvement creates an increased level of "buy-in" on the part of the users and a greater understanding of the need for the requirements. This provides some advocates for the procedures within the line organizations.

2.1.2 ES\&H training commensurate with assigned responsibilities (30\%)

Measure: The PI on ES\&H training commensurate with assigned responsibilities is an indirect indicator that staff competence and level of knowledge throughout the Laboratory is commensurate with assigned responsibilities. The PI will be measured utilizing two subindicators.

Description: The ES\&H required training course list (see 2.1.2.2 below) is based on the following categories of ES\&H training requirements:

- Worker Safety and Health

- Radiological Controls

- Environment and Waste Management

- Emergency Planning 
Assumption: The list of targeted ES\&H required courses for this performance indicator may need to be adjusted during the year for courses that become inactivated or are no longer required. Such changes to the list will be made via approved change control.

Benefit: Continuing this PI drives the institutionalization of a guiding principle of ISM, which is an integral part of sustaining excellence in ES\&H at the Laboratory.

\subsubsection{Completion of SDTP and required ES\&H training}

Measure: This subindicator measures the extent to which staff have identified and completed their ES\&H training requirements. This subindicator is measured in two parts, Part 1 and Part 2. Part 1 and Part 2 are multiplied together to provide a composite score for performance measurement.

Description:

\section{Part 1 - Staff Completion of SDTP}

Part I measures the extent to which regular full time staff have identified their current ES\&H training requirements based on their job assignments using the Staff Development and Training Planning Tool (SDTP). The measure of the percentage of staff who have updated their SDTP is:

$$
\% \text { complete }=\frac{\text { No. of staff with SDTP updated since October } 1,1998}{\text { Total number of regular full }- \text { time PNNL staff }}(\mathrm{x} 100)
$$

The subindicator includes regular full time staff located in all Laboratory facilities (e.g., Sequim, BWO, and Seattie). It also includes other Battelle staff who are currently employed, were employed by Battelle for at least 3 months during the fiscal year, and have access to the SDTP at their location. "SDTP updated" means that the staff member, their manager, and/or training coordinator have developed/reviewed and approved the SDTP, and it has been loaded into the PeopleSoft PNL Student Training Plan database.

Part 2 - Staff Completion of ES\&H Training Requirements:

The second part measures the extent to which staff have completed ES\&H required training requirements:

$$
\% \text { complete }=\frac{\text { No. of staff who have completed all required ES \& } H \text { training }}{\text { No. of staff with SDTP updated since October } 1,1998}\{x 100)
$$

For this subindicator, "Required ES\&H training" is the list of target required ES\&H courses (see 2.1.2.2 below).

\section{Composite Measure of Completed ES\&H Required Training}

The multiplication of the two parts described above results in the percentage of staff who have completed all the targeted ES\&H training based on a current SDTP. As such, it indicates a confidence value for staff ES\&H competence.

Composite $=$ Part $1 \times$ Part $2=\%$

For the subindicator, the year-end values are based on the values as they exist in the PeopleSoft databases on the last working day of the fiscal year, as corrected for year-end errors due to recording delays for completed training. The subindicator is measured monthly in both parts and as a composite. 
Baseline Information: The FY-98 PI 4.1.3 was very similar to this subindicator. For fiscal year 1999, the PI has been expanded to include more staff and additional ES\&H training requirements. The FY98 performance was $77.1 \%$ as of August 31, 1998.

Performance:

Target: $\quad 85 \%$

Neutral: $\quad 80 \%$

Minimum: $\quad 70 \%$

\subsubsection{Completion of ES\&H Training Courses}

Measure: This subindicator measures the extent to which the total number of designated ES\&H courses are completed.

Description:

$$
\% \text { complete }=\frac{\text { Total No. of Required ES \& H Courses }- \text { No. of Courses Past Due }>3 \text { months }}{\text { Total No. of Required ES \& H Courses }}(x 100)
$$

The "Total number of required ES\&H Courses" is the number of instances of training for all the required ES\&H courses listed below. The three-month allowance gives staff 30 days to complete the SDTP and another two months to schedule and take identified ES\&H training courses.

Baseline Information: This indicator is new for FY 1999 therefore baseline information is extremely limited. A similar indicator for small groups within the Laboratory was utilized to set the initial target. Baseline information for this indicator shows a completion rate for training of approximately 90 percent.

Performance:

Target: $\quad 90 \%$

Neutral: $\quad 85 \%$

Minimum: $\quad 70 \%$

ES\&H Course Listing for FY99

\begin{tabular}{|l|l|}
\hline $\begin{array}{l}\text { Course } \\
\text { Code }\end{array}$ & \multicolumn{1}{|c|}{ Course Title } \\
\hline 842 & 16-Hour Hazardous Waste Operations Upgrade Training \\
\hline 837 & 24-Hour Hazardous Waste Operations Training \\
\hline 835 & 40-Hour Hazardous Waste Operations Training \\
\hline 404 & BED Training - 325 Building \\
\hline 403 & BED Training - Laboratory-Type Facilities \\
\hline 402 & BED Training - Office-Type Facilities \\
\hline 407 & BEP - 325 Building \\
\hline 1061 & Building 325 Safety Analysis \\
\hline 694 & Confined Space Entry \\
\hline 379 & Crane/Hoist/Rigging - Initial \\
\hline 967 & Crane/Hoist/Rigging - Requalification \\
\hline 646 & Criticality Safety - 324 FMHs - Classroom \\
\hline 647 & Criticality Safety - 324 FMHs - Testing \\
\hline 648 & Criticality Safety - 325 FMHs - Classroom \\
\hline
\end{tabular}




\begin{tabular}{|c|c|}
\hline $\begin{array}{l}\text { Course } \\
\text { Code }\end{array}$ & Course Title \\
\hline 649 & Criticality Safety -325 FMHs - Testing \\
\hline 640 & \begin{tabular}{|l|l|} 
Criticality Safety -320 Criticality Safety for Cognizant Line Managers -325 Building \\
\end{tabular} \\
\hline 639 & Criticality Safety for Criticality Safety Representatives Testing \\
\hline 638 & \begin{tabular}{|l|} 
Criticality Safety for Criticality Safety Representatives Training \\
\end{tabular} \\
\hline 641 & \begin{tabular}{|l|l|} 
Criticality Satety for Criticality Safety for Isolated Facility Representatives -325 Building \\
Critical
\end{tabular} \\
\hline 1003 & \begin{tabular}{|l|} 
Criticality Safety for 1solatity Safety Program in 325 \\
\end{tabular} \\
\hline 577 & \begin{tabular}{|l|} 
Criticality Safety Program in 325 \\
DOE-Owned Sealed Radioactive Source Custodian Training \\
\end{tabular} \\
\hline 1059 & \begin{tabular}{|l|} 
DOE-Owned Sealed Radoactore sor \\
Electrical Safety for Non-Workers \\
\end{tabular} \\
\hline 1014 & \begin{tabular}{|l|} 
Electrical Safety for Non-workers \\
Electrical Safety for Workers \\
\end{tabular} \\
\hline 695 & \begin{tabular}{|l|} 
Electrical Safety for workers \\
Emergency Safety Showers and Eyewash Stations \\
\end{tabular} \\
\hline 696 & $\begin{array}{l}\text { Emergency Safety Showers and } \\
\text { Emergency Safety Showers and Eyewash Stations On-the-Job Training }\end{array}$ \\
\hline 701 & \begin{tabular}{|l} 
Emergency Satety showers \\
Fall Protection - General \\
\end{tabular} \\
\hline 653 & \begin{tabular}{|l|} 
Fall Protection-General \\
Fire Extinguisher Awareness \\
\end{tabular} \\
\hline 706 & Firearms Custodian/Alternate \\
\hline 699 & \begin{tabular}{|l} 
Firearms Custodian/Alting - Annual \\
Firearms Safety Training -
\end{tabular} \\
\hline 1056 & Floor Over Crane \& Hoists On-the-Job Training \\
\hline 1057 & \begin{tabular}{|l|} 
Floor Over Crane \& Hort On-the-Job Training Evaluation \\
\end{tabular} \\
\hline 381 & \begin{tabular}{|l|} 
Forklift On-the-Job I raining \\
Forklift Operation - Initial \\
\end{tabular} \\
\hline 968 & \begin{tabular}{|l|} 
Forklift Operation - initual \\
Forklift Requalification \\
\end{tabular} \\
\hline 411 & \begin{tabular}{|l|} 
Forklift Requalification \\
Generai Emergency Preparedness \\
\end{tabular} \\
\hline 817 & \begin{tabular}{|l|} 
General Emergency Prepareaness \\
General Employee Radiation Training (GERT) \\
\end{tabular} \\
\hline 818 & \begin{tabular}{|l|} 
General Employee Radiation iraning (GERT) - Refresher \\
General Employee Radiation Training (GE
\end{tabular} \\
\hline 813 & $\begin{array}{l}\text { General Employee Radiation I rainug (GeK } \\
\text { Glovebox Operations (Radiological) } \\
\end{array}$ \\
\hline 814 & \begin{tabular}{|l|} 
Glovebox Operations (Radiological) \\
Glovebox Operations (Radiological) On-the-Job Training \\
\end{tabular} \\
\hline $66 \overline{4}$ & $\begin{array}{l}\text { Glovebox Operations (Radiological) Un-tue-jou } \\
\text { Hazard Communication: Asbestos }\end{array}$ \\
\hline 673 & \begin{tabular}{|l} 
Hazard Communication: Asbestos \\
Hazard Communication: Bloodborne Pathogens Refresher \\
\end{tabular} \\
\hline 662 & 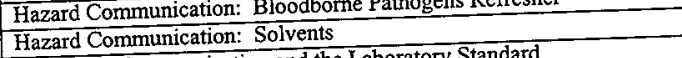 \\
\hline 671 & $\begin{array}{l}\text { Hazard Communication: Solvents } \\
\text { Hazardous Communication and the Laboratory Standard } \\
\end{array}$ \\
\hline 674 & \begin{tabular}{|l|} 
Hazardous Communication and the Laooratorive Training \\
Hazardous Material Shipping Representative \\
\end{tabular} \\
\hline 833 & \begin{tabular}{|l|} 
Hazardous Material Shipping Kepresentauve 1amios \\
Hazardous Waste Management \\
\end{tabular} \\
\hline 676 & \begin{tabular}{|l|} 
Hazardous Waste Management \\
HazMat Shipping Awareness Training \\
\end{tabular} \\
\hline 675 & \begin{tabular}{|l|} 
HazMat Shipping Awareness \\
HazMat Training for Warehouse and Transportation Personnel \\
\end{tabular} \\
\hline 839 & HazMat Training tor Wer 8-Hour Refresher \\
\hline 681 & \begin{tabular}{|l} 
HazWOper 8-Hour Rerresner \\
Hearing Conservation (Noise Control)
\end{tabular} \\
\hline 679 & \begin{tabular}{|l|} 
Hearing Conservation (Nouse Controi) \\
Hot Work Firewatch Training \\
\end{tabular} \\
\hline 988 & \begin{tabular}{|l|} 
Hot Work Firewatch Irainug \\
Hot Work Permit Training \\
\end{tabular} \\
\hline 959 & \begin{tabular}{|l|} 
Hot Work Permit Traning \\
Independent Verification Techniques and Requirements \\
\end{tabular} \\
\hline 685 & \begin{tabular}{|l|} 
Independent Veritication \\
Laboratory Hood Safety \\
\end{tabular} \\
\hline 686 & \begin{tabular}{|l|} 
Laboratory Hood Safety \\
Laboratory Hood Safety On-the-Job Training \\
\end{tabular} \\
\hline 683 & \begin{tabular}{|l|} 
Laboratory Hood Safety Un-ue-joo \\
Laser Safety \\
\end{tabular} \\
\hline 578 & $\begin{array}{l}\text { Laser Safety } \\
\text { Licensed Radioactive Material Custodian Training }\end{array}$ \\
\hline 700 & Licensed Radioactive Mat and Tag - General Employee Orientation \\
\hline 692 & Lock and Tag - General Empioyee \\
\hline 844 & $\begin{array}{l}\text { Lock and Tag for Authorized Stant } \\
\text { Low-Level Waste Generator Training }\end{array}$ \\
\hline 845 & $\begin{array}{l}\text { Low-Level Waste Generator } 1 \text { ramug } \\
\text { Low-Level Waste Generator Training for Bargaining Unit }\end{array}$ \\
\hline 652 & \begin{tabular}{|l|} 
Low-Level Waste Generator L raining or \\
PNNL NEPA Training Course \\
\end{tabular} \\
\hline 715 & $\begin{array}{l}\text { PNNL NEPA Training Course } \\
\text { Radiation Generating Device Operator/Custodian }\end{array}$ \\
\hline 687 & $\begin{array}{l}\text { Radiation Generating Device Uperator } \\
\text { Radiological Work in Fume Hoods Initial Training }\end{array}$ \\
\hline 688 & \begin{tabular}{|l} 
Radiological Work in Fume Hoods Initual Lraning \\
Radiological Work in Fume Hoods On-the-Job Training \\
\end{tabular} \\
\hline 819 & $\begin{array}{l}\text { Radiological Work in Fume Hoods Un-ine-jou Laling } \\
\text { Radiological Worker I }\end{array}$ \\
\hline 820 & $\begin{array}{l}\text { Radiological Worker I } \\
\text { Radiological Worker I-Refresher }\end{array}$ \\
\hline
\end{tabular}




\begin{tabular}{|c|l|}
\hline $\begin{array}{l}\text { Course } \\
\text { Code }\end{array}$ & \multicolumn{1}{|c|}{ Course Title } \\
\hline 821 & Radiological Worker II - \\
\hline 822 & Radiological Worker II - Refresher \\
\hline 716 & $\begin{array}{l}\text { Respiratory Protection Training - Issuers and Wearers (Air Purifying } \\
\text { respirators) }\end{array}$ \\
\hline 720 & Respiratory Protection Training - Single-Use Dust/Mist Respirators \\
\hline 823 & Temporary Radiological Containments \\
\hline 834 & Transuranic (TRU) Waste Packager \\
\hline
\end{tabular}

\subsubsection{Material Control (30\%)}

Description: This performance indicator is a composite of two performance sub-indicators that provide an evaluation of Battelle's ability to manage hazardous materials in a manner that fully protects the worker and the environment and insures compliance with all applicable Federal, State and local regulations.

\subsubsection{Chemical Management System}

Measure: This sub-indicator provides a measure of the overall accuracy and completeness of the chemical inventory data contained in the Laboratory's Chemical Management System. The overall accuracy and completeness of the data in CMS will be assessed based on a sample (as defined in the FY98 Self-Assessment Plan for CMS) of the chemical holdings for ETD, EHSD, ED, NSD, and F\&O.

Description: A score of overall accuracy and completeness of the chemical inventory data as determined by the FY98 Self-Assessment Plan for CMS. Each division (ETD, $\mathrm{ED}$, EHSD, and NSD) and the F\&O directorate will complete at least one self-assessment on the accuracy and completeness of the data in the CMS by the end of FY 1999. If multiple assessments are performed, the FY99 performance will be the result of the last assessment.

Assumption:

- The FY98 Self-Assessment Plan criteria for determining accuracy and completeness of the chemical inventory data should be reviewed and revised as needed to more appropriately assess the data. The revised plan should be submitted to RL by November 1998 for review and approval.

- Approval will be given within 30 days of submittal

Baseline information: The assessment performed in March of 1998 resulted in a score of 80 .

\section{Performance:}

$\begin{array}{ll}\text { Target: } & \text { Score of } 95 \text { in CMS accuracy } \\ \text { Neutral: } & \text { Score of } 85 \text { in CMS accuracy } \\ \text { Minimum: } & \text { Score of } 75 \cdot \text { in CMS accuracy }\end{array}$

Benefit: The Chemical Management Data System is used in emergency response waste management and various other systems. It is critical that it be accurate. 


\subsubsection{Generator management of SAA (Slop Jars)}

Measure: This performance indicator (PI) measures the percentage of hazardous waste "slop jars", a specific type of satellite accumulation area (SAA) waste, that pass verification. This $\mathrm{PI}$ is a direct measure of generator accountability, as the generator is compiling the data used to perform waste designation and weight percent calculations of the "slop jars"

Description: Upon receipt, Waste Operations will verify the content of all "siop jars" as compared to the Chemical Disposal/Recycle Record (CDRR). As a minimum, a pH test and visual inspection will be performed. Other tests, as deemed necessary by Waste Operations may also be performed, but are not required. The failure of any test or inspection will not allow the "slop jar" to pass verification. Additionally notice of failed verification from any other on-site or off-site facility, that is directly traceable to a unique "slop jar", will count as a failed verification. On a quarterly basis, the percentage of "slop jars" that pass verification will be reported. This data will be the total number of "slop jars" that passed verification divided by the total number of "slop jars" received by Waste Operations times 100 during the fiscal year quarter. Battelle's performance will be the percentage that passes verification during the $4^{\text {th }}$ quarter of FY99. For purposes of this subindicator, only notices from other on-site or off-site facility received prior to 9/30/99 will be included.

Assumption: "Slop jar" is defined as: Up to 5 gallon containers holding compatible laboratory wastes which are typically stored in satellite accumulation areas or up to 55 gallon containers holding compatible operations/maintenance wastes which are typically stored in 90 day accumulation areas.

Baseline Information: "Slop jars" represents approximately $25-30 \%$ of all waste within the Laboratory and are related to approximately $90 \%$ of the waste discrepancies and/or verification failures. The current failure rate for "slop jar" verification is approximately $10 \%$. The actions necessary to meet target performance for this PI will directly and indirectly support several of the planned actions in response to the EPA multi-media assessment.

Performance:

$\begin{array}{lr}\text { Target } & 98 \% \\ \text { Neutral } & 95 \% \\ \text { Minimum } & 90 \%\end{array}$

Benefit: As identified in the background information, "slop jars" represent approximately $25-30 \%$ of all waste within the Laboratory and are related to approximately $90 \%$ of the waste discrepancies. By focusing attention and improving the management of "slop jars", Battelle will reduce it's risk of having deficiencies to regulations and policy, reduce it's risk of fines due to those deficiencies, reduce rework cost associated with "slop jars" that do not pass verification, and reduce the verification activities once a high rate of passing has been demonstrated.

\subsubsection{ES\&H Lagging Performance Indicators (10\%)}

Description: This Performance Indicator is a composite of nine Performance Sub-indicators, designed to provide an overall evaluation of the Laboratory's Environment, Safety and Health Program relative to the expectations of DOE and Battelle. These sub-indicators and their specific levels (metrics) are developed jointly by DOE and the Contractor. 


\subsubsection{OSHA Lost Workday Case Incidence Rate (Lost Workday Case Rate)}

Measure: This sub-indicator provides a measure of the Laboratory's processes for identifying, and eliminating or controlling hazards which can result in occupational illnesses and injuries that are serious enough to result in "Lost Workdays" as defined by the requirements of 29 CFR 1904.

Description: (Number of Lost Workday Cases x 200,000) / hours worked. This measure approximates the number of Lost Workday Cases per 100 employees per year.

Assumptions:

- Hours worked includes labor hours for Contractor staff members, temporary personnel for which labor hours are recorded, and AWU-NW appointees. The accidents for all of these groups are recorded in the OSHA Log, and reported to the DOE under the Laboratory Research Contractor Number.

- Contractor incidence rates are reported on a Fiscal Year basis to support the designated performance appraisal period. DOE baseline data is reported on Calendar Year basis to conform to OSHA recordkeeping and reporting requirements. Calendar Year 1996 is the most recent complete year for which DOE accident data is available.

- The OSHA definition of a Lost Workday Case is any occupational injury or illness case involving days away from work and/or days of restricted work activity.

Baseline information: The Contractor Lost Workday Case Incidence Rate for the period of Fiscal Years 1995 through 1997 was 1.4. The DOE Research Contractor OSHA Lost Workday Case Incidence Rate for the period of Calendar Year 1992 through 1996 was 1.6.

Performance:

Target: $\quad 1.2$

Neutral: $\quad 1.4$

Minimum: $\quad 1.7$

\subsubsection{OSHA Recordable Case Incidence Rate (Recordable Case Rate)}

Measure: This sub-indicator provides a measure of the Laboratory's processes for identifying, and eliminating or controlling hazards which can result in occupational illnesses and injuries that are serious enough to meet the OSHA criteria for entry into the $\log$ and Summary of Occupational Injuries and Illness (OSHA form 200, or OSHA Log).

Description: (Number of OSHA Recordable Cases X 200,000)/ Hours Worked. This measure approximates the number of OSHA Recordable Cases per 100 employees per year. 
Assumptions:

- Hours worked includes labor hours for Laboratory staff members, temporary personnel for which labor hours are recorded, and AWU-NW appointees. The accidents for all of these groups are recorded in the OSHA Log, and reported to the DOE under the Laboratory Research Contractor Number.

- Laboratory incidence rates are reported on a Fiscal Year basis to support the designated performance appraisal period. DOE baseline data is reported on Calendar Year basis to conform to OSHA recordkeeping and reporting requirements. Calendar Year 1996 is the most recent complete year for which DOE accident data is available.

Baseline Information: The Contractor OSHA Recordable Case Incidence Rate for the period of Fiscal Years 1995 through 1997 was 2.5. The DOE Research Contractor OSHA Recordable Case Incidence Rate for the period of Calendar Years 1992 through 1996 was 3.6.

Performance:

$\begin{array}{ll}\text { Target: } & 2.3 \\ \text { Neutral: } & 2.5 \\ \text { Minimum: } & 2.8\end{array}$

\subsubsection{OSHA Lost Workday Incidence Rate (Lost Workday Rate)}

Measure : This sub-indicator provides a measure of the Laboratory's processes for identifying, and eliminating or controlling hazards which can result in occupational illnesses and injuries that are serious enough to result in "Lost Workdays" as defined by the requirements of 29 CFR 1904 and effectively manage the lost workdays for those cases that do occur.

Description: [(Number of Days Away from Work + Number of Restricted Workdays) X $(200,000)]$ / Hours Worked. This measure approximates the number of Lost Workdays per 100 employees per year.

Assumptions:

- Hours worked includes labor hours for Laboratory staff members, temporary personnel for which labor hours are recorded, and AWU-NW appointees. The accidents for all of these groups are recorded in the OSHA Log, and reported to the DOE under the Laboratory Research Contractor Number.

- Contractor incidence rates are reported on a Fiscal Year basis to support the designated performance appraisal period. DOE baseline data is reported on Calendar Year basis to conform to OSHA recordkeeping and reporting requirements. Calendar Year 1996 is the most recent complete year for which DOE accident data is available.

- The OSHA definition of lost workdays is the sum of the Days Away from Work and Restricted Workdays recorded for the cases entered into the OSHA log.

- It is not possible to determine actual performance at the end of any given fiscal year, as data continues to be collected until all cases are closed (i.e., cases that close after 
FY end will cause an increase in the total). However, as of September 7, 1998, FY98 performance is 13.87 and FY97 performance is 28.82 . Since this is only measured until the end of FY99 the following performance values are more challenging than taking a three-year average as the baseline.

Baseline Information: The Contractor Lost Workday Incidence Rate for the period of Fiscal Years 1995 through 1997 was 53.1. The DOE Research Contractor OSHA Lost Workday Incidence Rate for the period of Calendar Years 1992 through 1996 was 48.0.

Performance:

Target: $\quad 20$

Neutral: $\quad 30$

Minimum: $\quad 40$

\subsubsection{Unplanned Doses:}

Measurement: This subindicator provides a measure of the Laboratory's processes for controlling dose.

Description: Number of unplanned doses as defined.

- Any single occupational dose that exceeds an expected dose by $100 \mathrm{mrem}$.

- a single unplanned dose onsite to a minor, student, or member of the public that exceeds 50 mrem

- unplanned doses above ACLs as defined in the Hanford Site Radiological Control Manual.

A.ssumptions:

- There will be no significant change in scope of radiological work within the Laboratory

Baseline: There have been 2 unpianned doses reported during the past three years ( 2 in FY98, 0 in FY97, and 0 in FY96):

Performance:

Target: $\quad 0$

Neutral: $\quad 2$

Minimum: 4

\subsubsection{Spread of Radioactive Contamination}

Measurement: This subindicator provides a measure of the Laboratory's processes for controlling the spread of radioactive contamination.

Description: Number of instances of uncontrolled unwanted (i.e., non-legacy) spread of radioactive contamination meeting the following criteria:

- Any unplanned spill of liquids in excess of one gallon contaminated with radioactive material in concentrations greater than five times the Derived Concentration Guide values listed in DOE 5400.5, Figure III-1 
- Identification of radioactive contamination outside a radiological area (as defined in 10 CFR 835, Occupational Radiation Protection) or radiological buffer area established for contamination control, but within a Controlled Area, in excess of 10 times the total contamination levels in 10 CFR 835, Appendix D. For tritium, until a total contamination value is specified by 10 CFR 835 Appendix D, report contaminations in excess of 10 times $10,000 \mathrm{dpm} / 100 \mathrm{~cm} 2$.

- Identification of radioactive contamination onsite that is not located within a Controlled Area, Fixed Contamination Area, or Soil Contamination Area, and is in excess of two times the total contamination levels in 10 CFR 835, Occupational Radiation Protection, Appendix D. For tritium, until a total contamination value is specified by 10 CFR 835 Appendix D, report contaminations in excess of 2 times $10,000 \mathrm{dpm} / 100 \mathrm{~cm} 2$.

- Identification of radioactive contamination offsite in excess of any of the surface contamination levels specified in DOE 5400.5, Figure IV-1, that has not been previously identified and formally documented. For the first group listed in Figure IV-1 (i.e., transuranics...) use the values specified in Table 1 (provided as Appendix B to this Manual) of the EH-412 memorandum "Application of DOE 5400.5 Requirements for Release and Control of Property Containing Residual Radioactive Material", dated November 17, 1995.

Assumptions:

- There will be no significant change in scope of radiological work within the Laboratory

Baseline: There have been 10 instances of spread of radioactive contamination reported during the past three years ( 5 in FY98, 2 in FY97, and 3 in FY96)

Performance:

Target: $\quad 2$

Neutral: $\quad 5$

Minimum: 7

\subsubsection{Loss of Radioactive Sources}

Measurement: This subindicator provides a measure of the Laboratory's processes for controlling radioactive sources.

Description: Number of losses of accountability of a sealed or unsealed radioactive source that meet the following criteria:

- Loss of accountability of a sealed source or identification of lost radioactive material that exceeds ten times and is less than 100 times the quantities specified in DOE N 441.1, RADIOLOGICAL PROTECTION FOR DOE ACTIVITIES.

- Loss of accountability of a sealed source or identification of lost radioactive material that is one to ten times the quantities specified in DOE N 441.1, RADIOLOGICAL PROTECTION FOR DOE ACTIVITIES.

- The loss of a source that is exempted from inventory and source integrity tests as listed in Exhibit 1, RCP-4.3.03 of PNL-MA-26 will not count against this indicator. 
Assumptions:

- There will be no significant change in scope of radiological work within the Laboratory

Baseline: There have been 5 losses of radioactive sources reported during the past three years ( 1 in FY98, 1 in FY97, and 3 in FY96)

Performance:

Target: $\quad 0$

Neutral: $\quad 2$

Minimum: 3

\subsubsection{Skin and Personal Clothing Contamination Events}

Measurement: This subindicator provides a measure of the Laboratory's processes for controlling personnel contaminations.

Description: Number of personnel or clothing radiological contaminations meeting the following criteria:

- Any measurement of personnel or clothing contamination (excluding protective clothing) at a level equal to or exceeding five times the total contamination limits identified in 10 CFR 835, Occupational Radiation Protection, Appencix D, measured (prior to washing or decontamination) in accordance with the DOE Radiological Control Manual Article 338, or equivalent. The contamination jevel shall be based on direct measurement and not averaged over any area. For tritium, until a total contamination vaiue is specified by 10 CFR 835 Appendix D, report contaminations at a level equal to or exceeding 5 times $10,000 \mathrm{dpm} / 100 \mathrm{~cm} 2$.

- Any measurement of personnel or clothing contamination (excluding protective clothing) at a level exceeding but less than five times the total contamination limits identified in 10 CFR 835, Occupational Radiation Protection, Appendix D, measured (prior to washing or decontamination) in accordance with the DOE Radiological Control Manual Article 338, or equivalent. The contamination level shall be based on direct measurement and not averaged over any area. For tritium, until a total contamination value is specified by 10 CFR 835 Appendix $D$, report contaminations greater than $10,000 \mathrm{dpm}$ but less than 5 times $10,000 \mathrm{dpm} / 100 \mathrm{~cm} 2$.

Assumptions:

- There will be no significant change in scope of radiological work within the Laboratory

Baseline: There have been 28 personnel or clothing contaminations reported during the past three years ( 5 in FY98, 13 in FY97, and 10 in FY96)

Performance:

Target: $\quad 5$

Neutral: $\quad 10$

Minimum: 15 


\subsubsection{Environmental Protection}

Measurement: This subindicator provides a measure of the Laboratory's processes for protecting the environment by controlling and managing;

- release of radionuclides

- release of hazardous substances/regulated pollutants/oil

- hazardous material contamination

- impact to ecological resources

- compliance with Environmental Agreements

\section{Radionuclide Release}

Measurement: This sub-indicator provides a measure of the Laboratory's processes for controlling the release of radionuclides.

Description: This indicator will track the following:

- Number of radionuclide releases meeting the following criteria:

$>$ Any monitored facility or site boundary where ambient exposure or concentration exceed what permitted emissions would predict as a result of normal operations.

$>$ Any controlled, uncontrolled, or accidental release that will be reported formally in writing to State/local agencies in a format other than routine periodic reports.

- Number of hazardous substances/regulated pollutants/oil releases meeting the following criteria:

$>$ Any spill of greater than 42 gallons of oil of any kind or in any form, including, but not limited to, petroleum, fuel oil; sludge, oil refuse, and oil mixed with wastes other than dredged spoil outside of a permitted containment area. For operations involving oil field crude oil or condensate, any discharge less than the Unusual Occurrence level but in excess of 10 barrels.

- Number of hazardous material contaminations meeting the following criteria:

$>$ Discovery of onsite contamination due to Laboratory operations that exceeds $50 \%$ of a reportable quantity for such material per 40 CFR 302 .

$>$ Discovery of offsite contamination due to Laboratory operations that does not represent an immediate threat to the public but exceeds a reportable quantity for such material per 40 CFR 302.

- Number of occurrences causing significant impact to any ecological resource for which the DOE is a trustee (i.e., destruction of a critical habitat, damage to a historic/archeological site, damage to wetlands, etc.).

- Number of issues related to compliance of environmental agreements meeting the following criteria:

Any agreement, compliance, remediation or permit-mandated activity for which formal notification of enforcement has been received from the relevant outside 
regulatory agency that a site/facility is considered to be in noncompliance with a schedule or requirement. These include the following: Notice of Violation, Notice of Deficiency, Notice of Noncompliance, and Notice of Correction.

Assumptions:

- There will be no significant change in the scope of Research and Development work, which changes the assumptions used to develop the performance ranges.

- Environmental Management Services must concur with the classification of all occurrences measured in this performance indicator.

- Events that are deemed to count against the Environmental Protection Performance Indicator (2.1.4.8) will not count against the Transportation Performance Indicator (2.1.4.9). Likewise, events that are deemed to count against the Transportation Performance Indicator (2.1.4.9) will not count against the Environmental Protection Performance Indicator (2.1.4.8).

Baseline: There have been 7 events of this nature during the past three years ( 2 in FY98, 3 in FY97, and 2 in FY96).

\section{Performance:}

$\begin{array}{ll}\text { Target: } & 1 \\ \text { Neutral: } & 3 \\ \text { Minimum: } & 4\end{array}$

\subsubsection{Transportation of DOE Hazardous Materials}

Measurement: This subindicator provides a measure of the Laboratory's processes for controlling the transportation of DOE Hazardous Materials.

Description: Number of issues meeting the following criteria:

- Any packaging or transportation activity involving:

the offsite release of a reportable quantity of non-radioactive hazardous material (including hazardous waste); or

the onsite release of a reportable quantity of radioactive materials, or hazardous materials (including hazardous waste).

- Noncompliance's of the DOT Hazardous Materials Regulations or the transportation and packaging requirements of the Nuclear Regulatory Commission involving:

$>$ an unqualified person signing shipping papers;

$>$ the highway routing selection requirements for highway route controlled shipments or the notification requirements for spent-fuel shipments not being observed; or

$>$ the applicable packaging requirements for the assembly, handling, or selection of a package not being in accordance with the applicable regulations. 
- Any violation of the Hazardous Material Regulations or Federal Motor Carrier Safety Regulations if that violation is determined by DOT inspection and does not result in a penalty.

Assumptions:

- There will be no significant change in the scope of Research and Development work, which changes the assumptions used to develop the performance ranges.

- Environmental Management Services must concur with the classification of all occurrences measured in this performance indicator.

- Events that are deemed to count against the Environmental Protection Performance Indicator (2.1.4.8) will not count against the Transportation Performance Indicator (2.1.4.9). Likewise, events that are deemed to count against the Transportation Performance Indicator (2.1.4.9) will not count against the Environmental Performance Indicator (2.1.4.8).

Baseline: There have been 14 issues related to the transportation of DOE hazardous materials reported during the past three years ( 3 in FY98, 7 in FY97, 4 in FY96).

Performance:

$\begin{array}{ll}\text { Target: } & 2 \\ \text { Neutral: } & 4 \\ \text { Minimum: } & 6\end{array}$

2.2 Objective: Increase mission capabilities through enhancement and effective use of Laboratory facilities and assets. (33\%)

\section{Performance Indicators}

2.2.1 Facilities (Buildings): Utilization of space is commensurate with science and technology mission needs $(60 \%)$

Description: This Performance Indicator is a composite of three Performance Sub-indicators, designed to provide an overall evaluation of the Laboratory's processes for space utilization relative to the needs of its science and technology mission and expectations of DOE and Battelle.

Secondary considerations are DOE needs for space utilization information on a site-wide or complex-wide basis.

\subsubsection{Total office space assigned per number of staff members in an organization}

Description:

- The total staff count (denominator) is defined as individuals working on site (Richland) in DOE and Battelle owned and leased office space that are included in the HR PeopleSoft database. Battelle bargaining unit employees have been removed from this staff count, as the majority of them do not require an office and are not assigned specific office space.

- The total usable office square foot (numerator) is defined as DOE and Battelle owned and leased office space that is part of the Space Chargeback System. 
Since this sub-indicator is focused on office space, the following is excluded from the numerator and the denominator:

- Laboratory \& shop space, warehouse space, bathrooms, halls, copier rooms, lunchrooms, auditorium, LAN and telephone closets, conference rooms, lobby areas, and vestibules are all considered common space and will not be contained in this sub-indicator.

- Staff and office space in buildings that are isolated and/or not within the Laboratory's direct regional control have been removed (e.g., WDC, 622, Tacoma, Portland, and Seattle).

- Office space that is tied to construction, unavailable for use, or contained in buildings slated for standby.

Measure: A broadly variant office occupancy ratio throughout the Laboratory can portray a misconception of office space utilization. Optimization of the office space use is also dependent on understanding the average office square foot per person. This indicator seeks to:

- Establish office square foot per person guidelines

- Ensure that Laboratory staff are housed in the most economical and efficient manner possible given their mission needs and the configuration of the space they occupy.

- Understand if there are actions that could be taken to influence the Laboratory's office space assignments in FY 1999.

This measure will be reported quarterly on an overall Laboratory basis.

Baseline \& Assumiptions: None

Performance: The total usable office square foot (numerator) divided by the total staff count (denominator)

The expected performance is the current PNNL average office occupancy ration which is $131 \mathrm{ft}^{2} /$ personnel. Current building designs, however, physically configure office space across PNNL to an average size of $144 \mathrm{ft}^{2} /$ office, which contributes to the difficulty in improving on the average office $\mathrm{ft}^{2} /$ person. This measurement will be used in conjunction with satisfaction survey and benchmarking information to optimal occupancy ratios for PNNL. The FY 1999 target is $121 \mathrm{ft}^{2} /$ person.

Target: $\quad 0 \mathrm{fr}^{2} /$ person deviation from the target Neutral: $\quad \pm 10 \mathrm{ft}^{2} /$ person deviation from the target Minimum: $\quad \pm 20 \mathrm{ft}^{2} /$ person deviation from the target

\subsubsection{Staff Churn Rate}

Description: Chum is a measure of the frequency of internal movement of employees, and is a major benchmark for space managers. A high degree of staff churn diverts financial resources away from the development and delivery of $R \& D$ product.

The total staff count (denominator) is defined as individuals working on site (Richland) . in DOE and Battelle owned and leased office spaces that are included in the HR PeopleSoft database. Staff moves information (numerator) will be extracted from the Laboratory's Move Tracking System (MTS). 
To focus the measurement of churn, the following is excluded from both the numerator and the denominator:

- Deleted bullet

- Moves within buildings that are isolated and/or not within Battelle's immediate regional control (WDC, 622, Tacoma, Portland, and Seattle)

- New ???? set ups or leaving staff closures.

Measure: In this first year this indicator will help:

- Understand if there are actions that could be taken to influence the amount of discretionary churn that occurs

- Establish baseline data by which future decisions can be made.

This measure will be reported quarterly on an overall Laboratory basis.

Baseline \& Assumptions: None

Performance: The total number of staff moves (numerator) divided by total number of staff (denominator).

$\begin{array}{ll}\text { Target: } & 50 \% \\ \text { Neutral: } & 55 \% \\ \text { Minimum: } & 65 \%\end{array}$

2.2.1.3 Continuous improvement in $\mathrm{F} \& \mathrm{O}$ services and operations realized from benchmarking

Description: The Facility and Operations Directorate has committed to benchmarking as a fundamental strategy to identify high impact areas for emphasis on continuous improvement. The Directorate has established the vision of being the benchmark for the services it delivers by improving on the quality, satisfaction, and cost effectiveness of those services with most significance and impact to the Laboratory.

Basis and Assumptions: FY 1999 will be the third year that the Contractor has participated in benchmarking activities and intends to continue involvement in the exercise conducted by Facility Issues. As additional pertinent national benchmarking opportunities are identified, participation will be expanded to aid in meeting the stated objective. The measures identified have been developed from a two-year performance base (FY97 \& FY98) resulting from the Facility Issues benchmarking exercise, and establish as satisfactory the level of performance obtained in FY 1998.

Performance:

Target: $\quad 8$ points

Neutral: $\quad 4$ points

Minimum: 0 points

Measures:

Part 1: Improvement in cost per unit measure position in the FY 1999 Facility Issues National Benchmarking comparative survey for total cost. 
Performance Scoring:

4 Points will be awarded for a $5 \%$ improvement in cost per unit measure from FY98 to FY99 and ranking in second quartile

2 Points will be awarded for a $5 \%$ improvement in cost per unit measure from FY98 to FY99

0 Points will be awarded for a $0 \%$ to $5 \%$ improvement in cost per unit measure from FY98 to FY99

Part 2. Facility Issues Customer Satisfaction survey results show overall improvements from previous year.

Performance Scoring:

4 Points will be awarded for a $4 \%$ overall improvement from FY98 to FY99 and improvement in $50 \%$ or more of areas measured

2 Points will be awarded for a $4 \%$ overall improvement from FY98 to FY99 and improvement in $25 \%$ to $50 \%$ of areas measured

0 Points will be awarded for a $0 \%$ to $4 \%$ overall improvement from FY98 to FY99

\subsubsection{R\&D Equipment Utilization (10\%)}

Description: This performance indicator reflects the desire for effective utilization of existing $\mathrm{R} \& \mathrm{D}$ equipment/systems and as such measures both the availability for use (i. $e$. was the equipment available when needed) and utilization of the R\&D equipment'systems (i. e. was the equipment actuaily used). The focus will be on R\&D capital equipment/systems representing a range in value from $\$ 50 \mathrm{~K}$ to $>\$ 5 \mathrm{M}$, with a representative suite of $R \& D$ equipment/systems selected from each of the four R\&D Divisions (Energy, EHSD, ETD, NSD).

Measure: The availability and the use of R\&D equipment/systems in support of the R\&D mission of the Laboratory will be measured in FY99 to establish a basis for decisions that would effectively increase equipment effectiveness across programmatic and organizational boundaries.

Baseline \& Assumptions: The equipment/systems to be measured in this indicator will be DOE owned, and be of $\$ 50 \mathrm{~K}$ value or greater. In order to establish a defined value base, three strata will be identified from which equipment/systems will be selected: $\$ 50 \mathrm{~K}$ to $\angle \$ 1 \mathrm{M}, \$ 1 \mathrm{M}$ to $\$ 5 \mathrm{M}$ and $>\$ 5 \mathrm{M}$. It is also desirable to obtain a representative suite of equipment/systems from across each of the R\&D Divisions, however, each Division will not necessarily contribute equipment systems in each of the value categories. For example, performance measures obtained for R\&D equipment valued at $>\$ 1 \mathrm{M}$ will come only from the William $\mathrm{R}$. Wiley Environmental Molecular Sciences Laboratory (EHSD) since this is the only place such equipment currently exists. The systems in this category include the IBM SP, the ion accelerator and the 11.5 T FTICR-MS.

Performance: Performance will be based on obtaining usage and availability data on all instruments/systems identified by DOE-RL in FY99. A preliminary list of equipment for which data will be obtained is given below. This list will be critically examined and revised by DOE-RL during FY99. The data model will be developed and implemented in the $1^{\text {st }}$ quarter of FY99. Performance measures will be developed from the data collection set collected in the $1^{\text {st }}$ quarter of FY 1999 and will be incorporated via approved change control. 
Equipment/System List:

- IBM SP $(>\$ 5 \mathrm{M})$

- Ion Accelerator (>\$5M)

- WD29329 11.5 T FT-ICR/MS (\$1.9M)

- WB68822 Perkin Elmer Auger (\$634k)

- WB62779 VG Mass Spectrometer $(\$ 148 \mathrm{k})$

- WB58199 Philips X-ray Diffraction (\$50k)

- WD14617 Viking Mass Spectrometer $(\$ 150 \mathrm{k})$

- FA09330 Fame Wind Tunnel (\$113k)

- WD24709 Fisons ICP Mass Spectrometer $(\$ 460 \mathrm{k})$

- WD06789 Nicolet FT-IR (\$116k)

- WB37395 Jomar Neutron Coincidence Counter (\$83k)

- WB69345 Bruker Time-of-Flight Mass Spectrometer $(\$ 160 \mathrm{k})$

- WD00800 Coherent YAG Laser System (\$150k)

- WD13096 Rework Machine (\$137k)

- WD28358 Optical Correlator (\$96k)

- WD22262 Eddy Current Tester (\$54k)

Benefits: Facilitate more effective use of R\&D equipment by providing data on the potential availability of existing equipment.

2.2.3 Facilities and Services Integtation: An increased level of interaction with other Hanford Site contractors supporting facility infrastructure and services. (30\%)

This Performance Indicator is a composite of four Petformance Sub-indicators, designed to provide an overall evaluation of the Laboratory's processes for increasing the laboratories mission capabilities through its facility assets. These Sub-indicators and their specific levels (metrics) are developed by DOE.

2.2.3.1 Increased level of interaction with other Hanford Site contractors on key issues supporting facility infrastructure and services.

Description: The Hanford Site Integration Group (SIG) is the principal forum for communication and discussion of cross cutting site technical issues and information. The SIG goal is to produce a Hanford Site Technical Baseline that provides a consistent traceable linkage connecting strategic level documents to the project baseline documents. This connection will establish a vital link between the individual contractors who have responsibilities within the 300 Area. It will also ensure that the S\&T infrastructure requirements for the current and future mission will be established and maintained to continue the S\&T Mission beyond the site clean-up mission.

\section{Measure:}

1) A Battelle representative is an active SIG participant;

2) Battelie will work with the SIG to make decisions that support the Hanford Site and will provide timely responses to all action items involving Battelle.

3) Bafteile will provide timely updates to the Battelle Waste Management Project Specification.

Baseline \& Assumptions: The SIG is an existing committee that establishes the links between contractors throughout the Hanford Site. Prior to establishing this PI, Battelle had a limited focus as an SIG member. With this connection, Battelle can actively influence the actions and decisions established by the Sitewide Systems Engineering. 
Performance: (Outstanding and Neutral Performances require completion of measures 2 and 3.)

Target: A Battelle representative participates in at least 90 percent of the scheduled SIG meeting.

Neutral: A Battelle representative participates in at least 75 percent of the scheduled SIG meetings.

Minimum: Not completing measures 2 or 3 or a Battelle representative attending less than 75 percent of the scheduled SIG meetings.

Benefits: The benefit for the PI is to establish the link between the Laboratory and site decisions made by the SIG, which has not existed previously. The connection will be a long-term benefit to the Laboratory and the Hanford Site by establishing appropriate Infrastructure priorities required to meet the Laboratory's S\&T Mission.

2.2.3.2 Minimization of impact to the Laboratory due to site infrastructure failures and future usage by development/deployment of effective System Engineering process.

Description: A System Engineering process will require Battelle to have appropriate data elements, definitions and mission for each facility. This process will establish the performance requirements needed such as Sitewide services, design, construction, startup/test, operation, decommissioning/stabilization, and decontamination. This process will also assist in risk management/issues resolution and formalize the implementation of baseline change control, evaluations, and budget/funds management. The implementation and updates of Facility Life Cycle Plans, 15-Year Facility Plan, Strategic Facility Plan, and Institutional Plan for DOE facilities will be required to achieve a functional System Engineering process. This will ensure that the Battelle infrastructure requirements will not be impacted. These documents will inciude the strategic outyear analysis for Network Infrastructure Upgrades.

Measure: The successful development and completion of the Facility Life Cycle Plans, 15-Year Faciitty Plan, FY 2000 Strategic Plan, and FY 2000-2004 Institutional Plan for all active Battelle managed DOE EM and ER facilities.

Baseline \& Assumptions: The Institutional Plan is a high level document that Battelle develops throughout the year. Facilities have responsibility for the Site and Facilities section of this document. This section analyses the laboratory as a whole, space allocation, and current/future plans for facilities requirements. Each year Facilities and Operations $(F \& O)$ develop this section and resolves comment generated during the review cycle.

The 15-Year Facility Plan is a document that establishes the out year mortgages required to maintain a world class facility. This document will be used as a baseline for capital funding for facility and infrastructure improvements. The document provides a detailed look at the improvements required for one to two years and a strategic outlook beyond the two years.

The Strategic Facility Plan is a tactical plan focusing on facility investments between one to three years. This plan establishes the strategic mission and relates facility infrastructure requirements. It is updated annually and is also a budgeting tool. 
The original fifteen Life Cycle Plans (LCP) were developed in FY 1997 and were modified and updated in FY 1998. The LCP's are vital documents that provide the detailed history, current mission, and future infrastructure requirements. These documents are used to develop annual work plans, which establish the budget for the next fiscal year. These documents are updated as changes occur in the building and as new requirements associated with the building are imposed.

Performance: (Outstanding and Neutral Performances require development, update and input to the Institutional Plan, 15-Year Facility Plan, and Strategic Facility Plan.)

Target: Develop at least 75 percent of the Life Cycle Plans for EM and ER buildings by the end of FY 1999.

Neutral: Develop at least 60 percent of the Life Cycle Plans for EM and ER buildings by the end of FY 1999.

Minimum: Not completing the development of any of the following:

- Institutional Plan,

- 15-Year Facility Plan,

- Strategic Facility Plan, and

- less than 60 percent of the Life Cycle Plans for EM and ER buildings by the end of FY 1999.

Benefits: The benefit of this PI. will establish an internal/extemal emphasis on these documents as planning tools. This PI will formalize the process for completion of these documents and will assure $\mathrm{F} \& \mathrm{O}$ establishes a formal baseline-planning document.

2.2.3.3 Improve the scope definition and cost of site services by using activity-based and customer-focused methods.

Description: These measures highlight Battelle's effort to improve the scope and cost effectiveness of site services by strengthening the link between RL, service providers, and service user-customers. The effort may address a wide range of services including, but not limited to, fire protection, medical, and steam heating. The measures focus on actions under Battelle's direct control, such as developing proposals with input from other Hanford Site players.

\section{Measures:}

1) Submit at least one proposal to the Site Integration Group to involve Hanford customers in the development and evaluation of Hanford Site support services.

2) Make at least one proposed site service cost reduction which will benefit the Hanford Site. DOE-RL and other Hanford Site Contractors will be involved in the development to ensure a solid proposal with clearly identified cost savings to the government. The proposal will be presented to DOE-RL in FY 1999.

3) Assist DOE-RL in the development and initial test preparation of an approach that accomplishes the above measure.

Baseline \& Assumptions: Hanford Site services costs are a major share of the Hanford contractors' operational costs. In a typical year, approximately 20 percent of Battelle's facility costs are for energy and utilities. Currently, Battelle spends approximately \$7M on energy and utilities in the 300 Area.

Over the past years, Battelle has participated, as a minor role, with $\mathrm{RL}$ and service providers on a number of initiatives. Some of those initiatives led to significant 
improvements in service or costs such as the DOE Energy Savings Performance Contract (ESPC): A number of new initiatives can continue the cost-effectiveness trend over the next 3 years. These initiative include several new ESPC contracts and preparing for the deregulation of the electrical industry.

Many site service customers have the motivation and the qualified staff to help $\mathrm{RL}$ and service providers optimize the scope and cost of services. Although informal or temporary teams of RL, provider, and customer staff have successfully operated in the past, a long-term and routine approach has not been established for many services.

Making site services more activity-based and customer-focused may encounter significant barriers such as the following:

- Site service programs are combining their costs into super-pools that weaken the link to customer needs and to activity-based costing.

- Site service programs may want to consider RL as the customer and discount the service-users as secondary customers.

- Some providers and customers may believe their contracted scope, limited budgets, or federal/DOE requirements prevent them from studying their options or making improvements.

\section{Performance:}

Outstanding: Completion of measures 1,2, and 3 .

Excellent: Completion of measures 1 and 2.

Good: $\quad$ Completion of only measure 1.

Marginal: $\quad$ Completion of only measure 2.

Unsatisfactory: Not completing measures 1 or 2 .

Benefits: The minimal benefit of completing these measures is keeping the costeffectiveness of site services on the table with $R L$ and service providers. The full benefits include the following:

- RI and service providers routinely seek and incorporate customers' input for their program planning and evaluations.

- $R L$ and service providers implement improvements to better meet customer needs

- $R L$ and service providers reduce costs through program improvements, new technology, better user-accountability, and more equitable cost allocations.

2.2.3.4 Complete Scheduled Network Infrastructure Upgrade Projection Plans and Projects.

Description: Facilities and Operations (F\&O) and Information Technology (IT) together prioritized and coordinated the completion of the annual network upgrade projects. These projects require a cross mix of staff to work together to successfully complete the project.

Measure:

1) Concurrence on the FY 1999 Network Infrastructure Project Plans by October 31, 1998, from IT Core Program Manager and F\&O Program Manager.

2) The close out of the approved FY 1999 Network Infrastructure Projects; within 30 days of their approved schedule date. 
3) Concurrence on the FY 2000 Network Infrastructure Project Plans by June 30, 1999, from IT Core Program Manager and F\&O Program Manager.

Baseline \& Assumptions:

1) "Closed out" projects are defined by the date when all of the work packages associated with that project are closed in the financial system.

2) The Network Infrastructure upgrades authorized prior to FY 1999 are listed below:

Project Title

325 Network Upgrade

MSL Network Upgrade

320 Network Upgrade

\section{Performance:}

Outstanding: Completion on measures 1, 3, and 100 percent of 2 .

Excellent: Completion on measures 1, 3 and 66 percent of 2 .

Good: $\quad$ Completion on measures 1,3, and 33 percent of 2 .

Marginal: Completion on measures 1 and 3.

Unsatisfactory: Completing of measure 1 or 2 or 3 .

Benefits: This measurement is the desired (commercial practice) project life cycle approach required for Network Infrastructure Projects. This measure will demonstrate that these projects are managed to an appropriate level. This measure will allow Battelle and DOE-RL to review and monitor the status of these projects. Project management reporting such as projected schedule and cost vs. actual schedule and cost will be analyzed to determine how well the projects are managed.

\section{Critical Outcome Performance Rating and Additional Performance-Based Fee}

Figures $2 \mathrm{~A}, 2 \mathrm{~B}, 2 \mathrm{C}, 2 \mathrm{D}, 2 \mathrm{E}, 2 \mathrm{~F}$, and $2 \mathrm{G}$ document the associated agreements on performance expectations in the form of contingency functions. The overall performance tating for this outcome will be determined by summing the effectiveness scores for all Objectives as depicted in Tables 2.1 through 2.8 , below, normalizing the scores using Table 2.9 and comparing the normalized sum to the rating scale in Table 2.10 . Additional performance-based fee earned (if any) for this outcome is determined by comparing the overall outcome score $(5.0-3.5)$ to the amount available within Table 2.11 . 
Figure 2A, Operational Excellence Objective 2.1, Indicator 2.1.1 Contingency Diagram

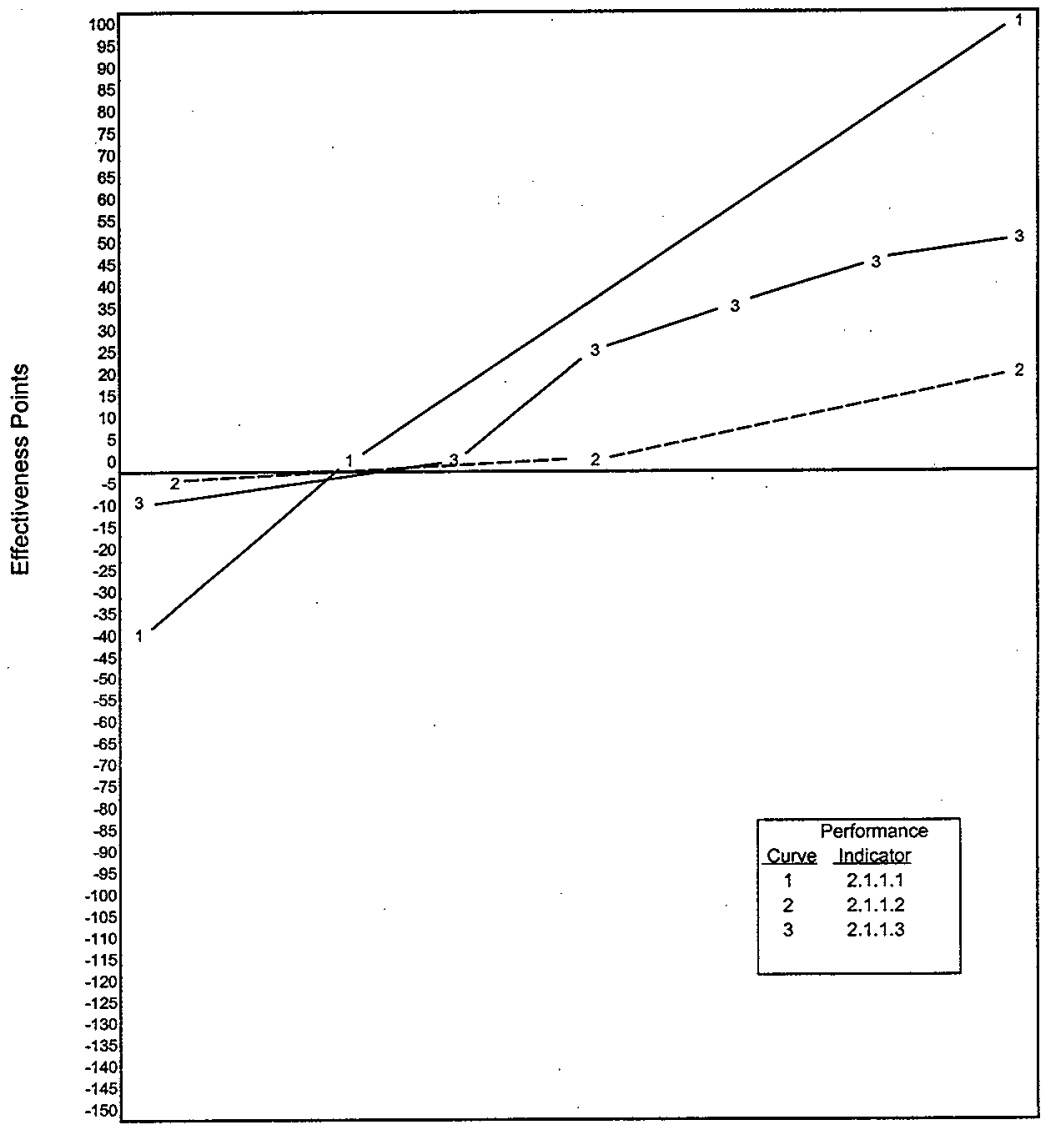

Performance.Indicator

1 Worker Involvement

2 Dose Index (delta)

3 SBMS User involvement

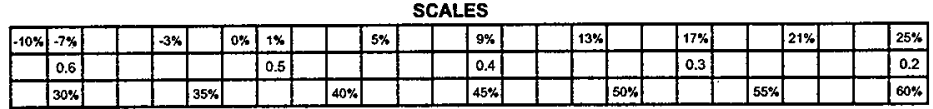


Figure 2B, Operational Excellence Objective 2.1, Indicator 2.1.2 Contingency Diagram

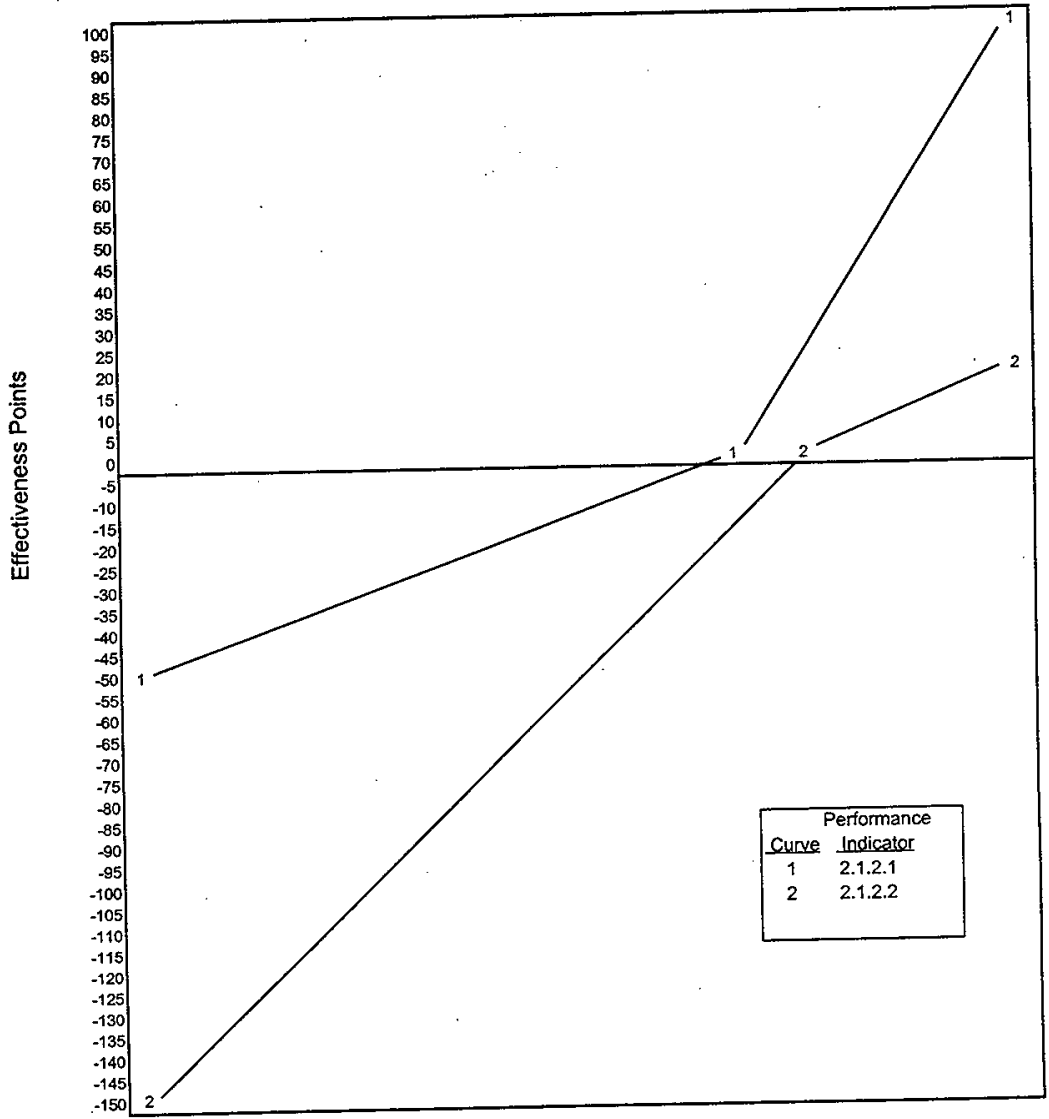

Performance Indicator

1 SDTP and Required

2 ES\&H Training Courses

SCALES

\begin{tabular}{|l|l|l|l|l|l|l|l|l|l|l|l|l|l|l|l|l|l|l|l|l|l|l|l|l|}
\hline $70 \%$ & & & & & & & & $75 \%$ & & & & & & & & $80 \%$ & & & & & & & & $85 \%$ \\
\hline $70 \%$ & & & & & & $75 \%$ & & & & & & $80 \%$ & & & & & & $95 \%$ & & & & & & $90 \%$ \\
\hline
\end{tabular}


Figure 2C, Operational Excellence Objective 2.1, Indicator 2.1.3 Contingency Diagram

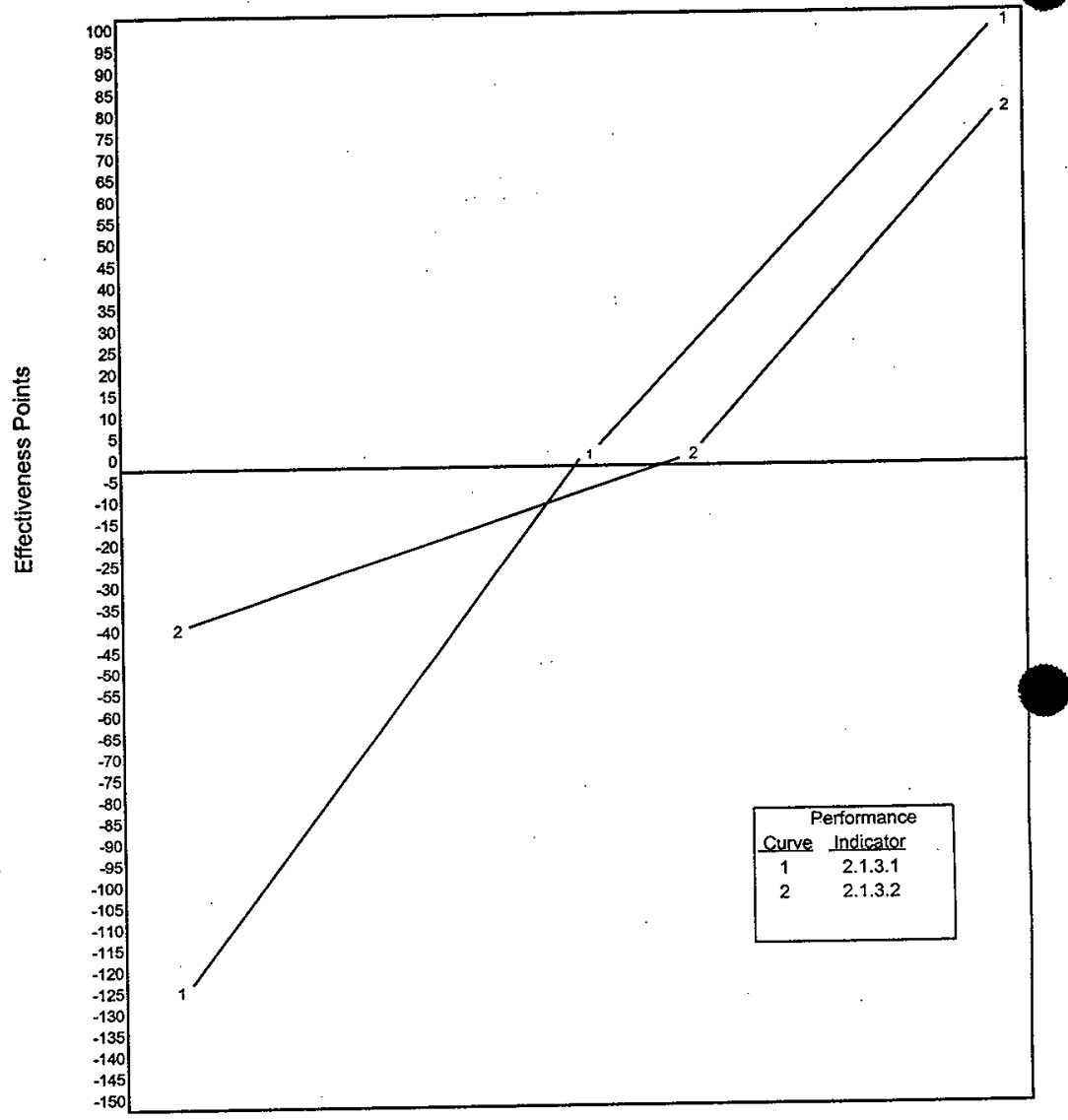

Performance indicator

1 Chemical Mgmt System

2 Generator Mgmt of Jars

\begin{tabular}{|c|c|c|c|c|c|c|c|c|}
\hline \multicolumn{9}{|c|}{ SCALES } \\
\hline $75 \%$ & & $80 \%$ & & $85 \%$ & & $90 \%$ & & $95 \%$ \\
\hline $\mid 00 \%$ & 91\% & $92 \%$ & \begin{tabular}{|l|l|}
$83 \%$ \\
\end{tabular} & $84 \%$ & $95 \%$ & $68 \%$ & $97 \%$ & $988 \%$ \\
\hline
\end{tabular}


Figure 2D, Operational Excellence Objective 2.1, Indicator 2.1.4 Contingency Diagram

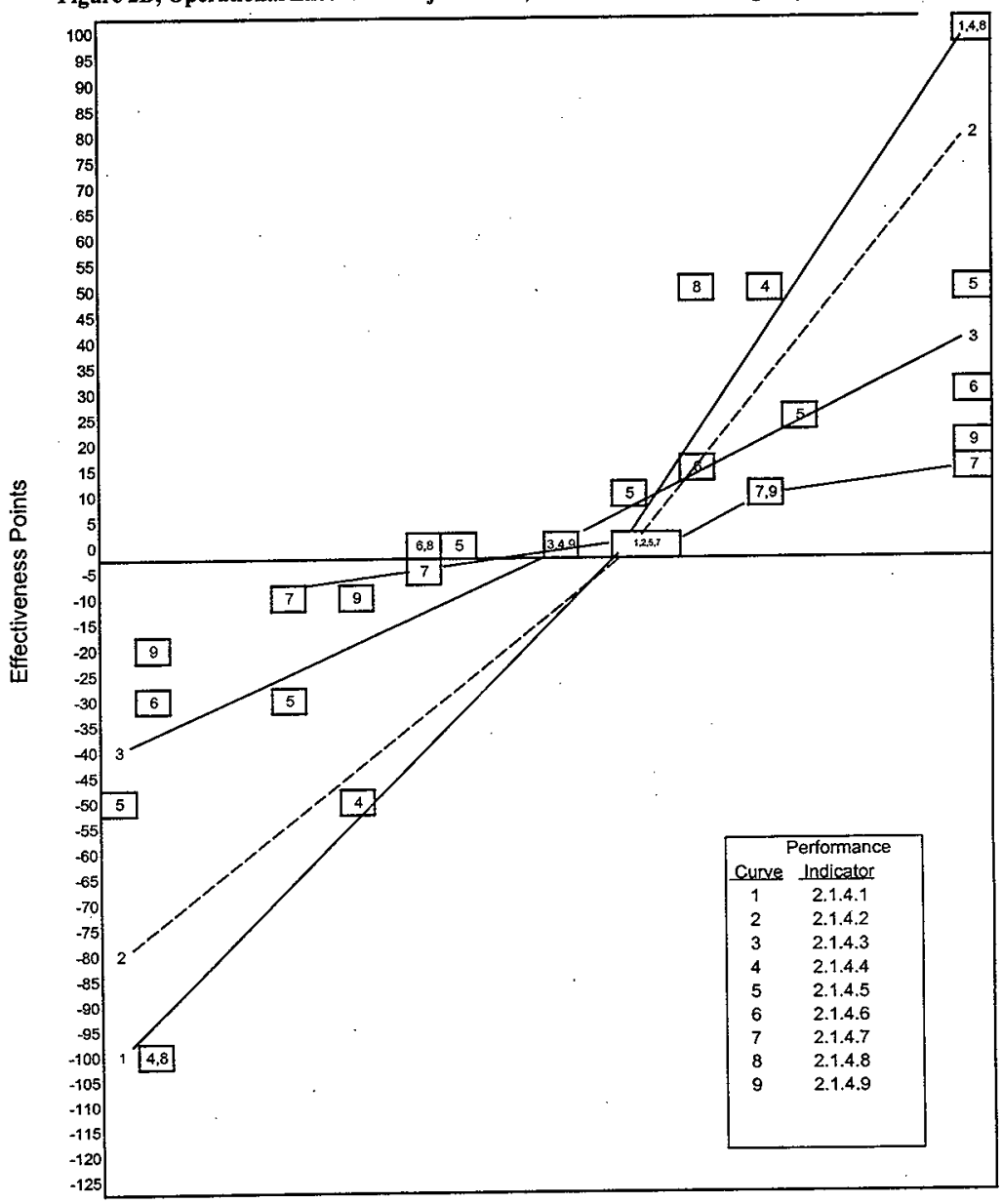

Performance Indicator

1 Lost WorkDay Case Rate

2 Recordable Case Rate

3 Lost WorkDay Incident Rate

4 Unplanned Doses

5 Spread of Rad Contam.

6 Loss of Rad Sources

7 Skin \& Clothing Con Events

8 Environmental Protection

9 Transport of DOE Haz Matl

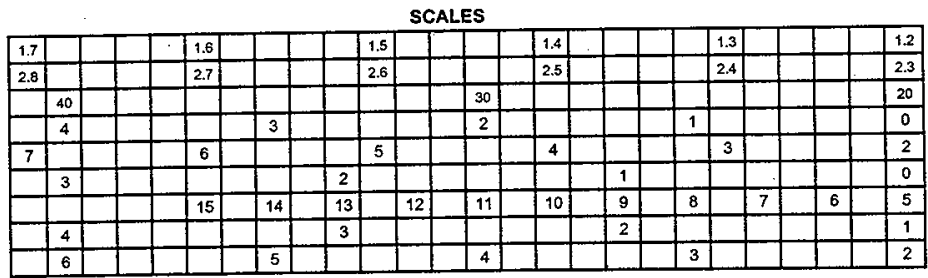


Figure 2E, Operational Excellence Objective 2.2, Indicator 2.2.1 Contingency Diagram

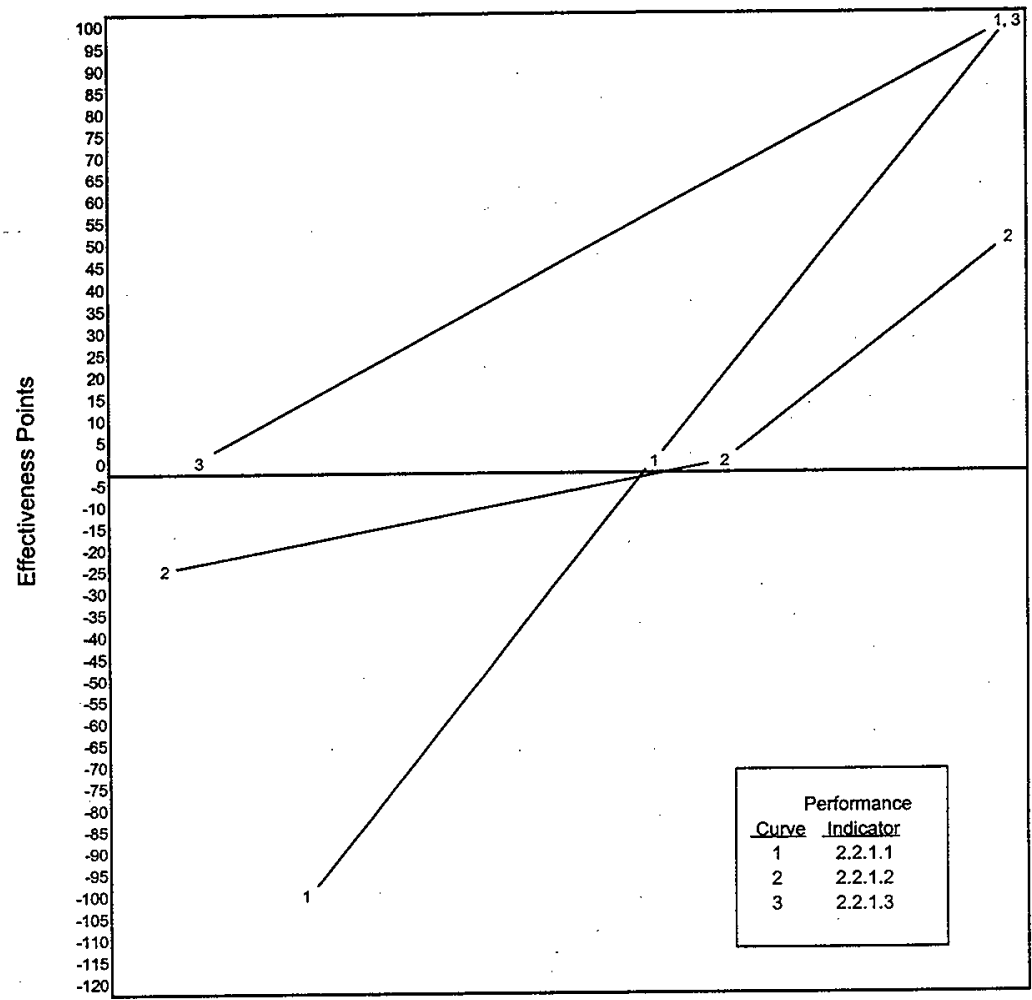

Perfomance Indicator

SCALES

1 Office space per staff

2 Staff "Chum" Rate

3 Benchmarking

\begin{tabular}{|c|c|c|c|c|c|c|c|c|c|c|c|c|c|c|c|c|c|c|c|c|c|c|c|c|}
\hline & & & & 20 & & & & & 15 & & & & & 10 & & & & & 5 & & & & & 0 \\
\hline 65 & & & & & & & & $60 \%$ & & & & & & & & $55 \%$ & & & & & & & & $50 \%$ \\
\hline 0 & & & & & & 2 & & & & & & 4 & & & & & & 6 & & & & & & 8 \\
\hline
\end{tabular}


Figure 2F, Operational Excellence Objective 2.2, Indicator 2.2.2 Contingency Diagram

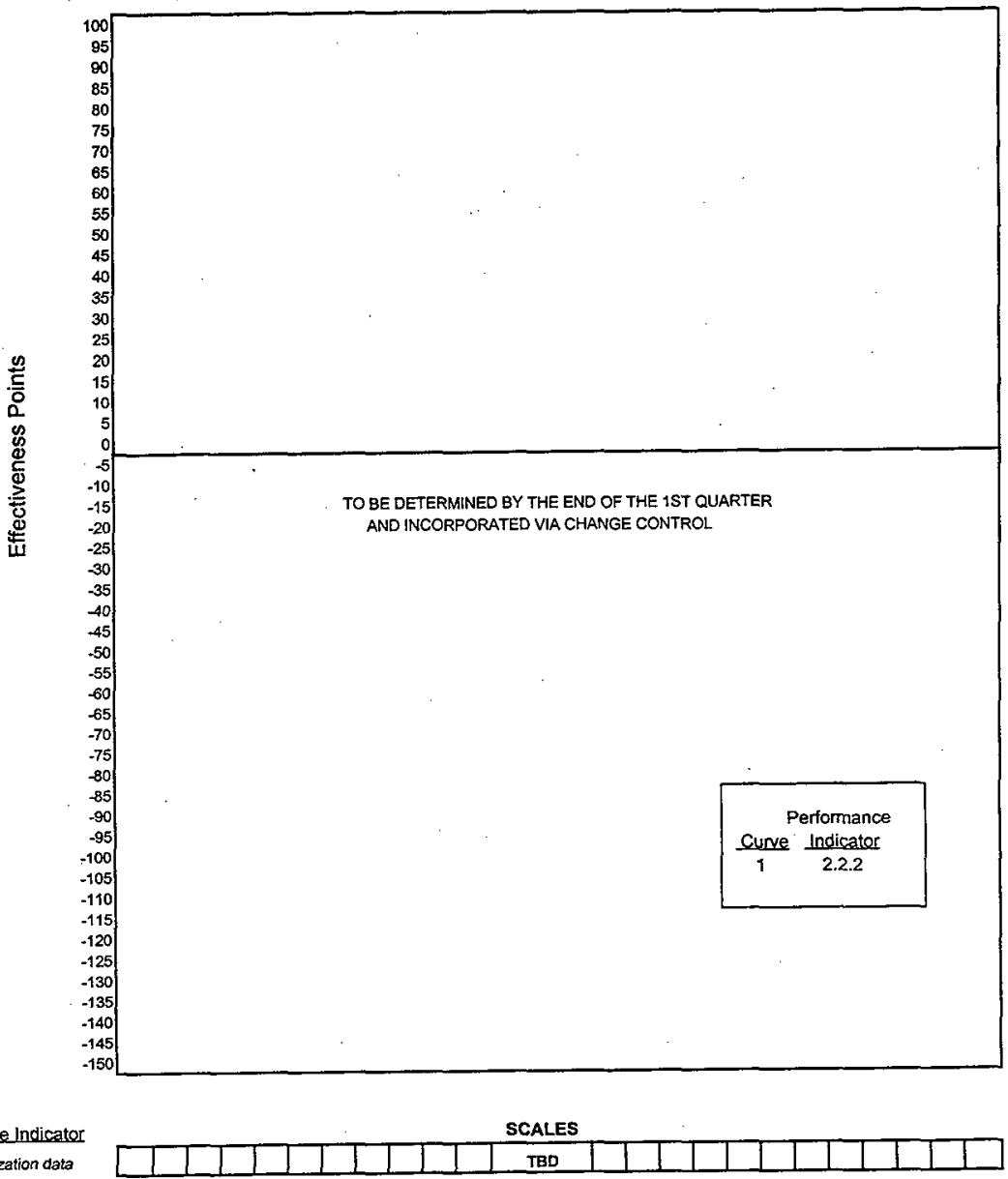

1 Capacity Utilization data Obtained 
Figure 2G, Operational Excellence Objective 2.2, Indicator 2.2.3 Contingency Diagram

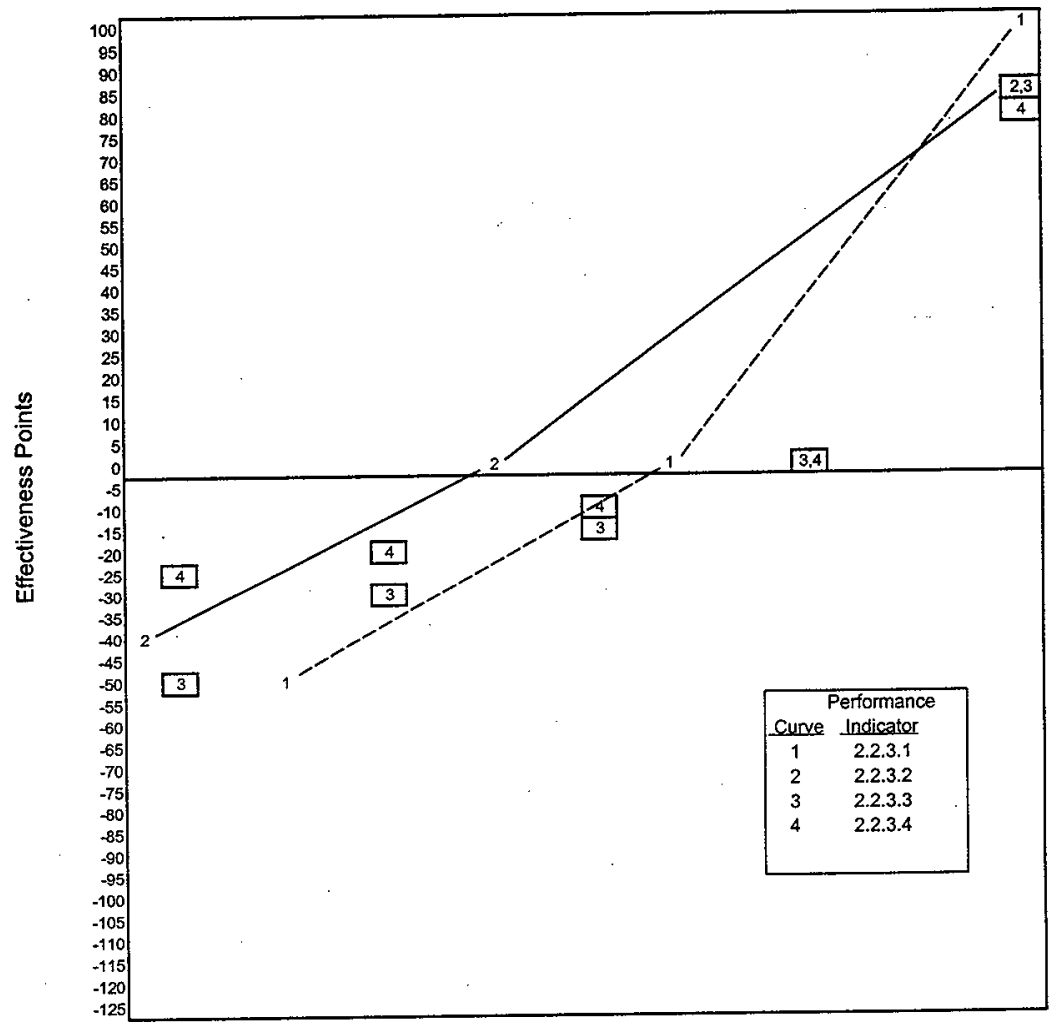

Performance Indicater

SCALES

1 Level of Interaction

2 Minimization of impact

3 Improve the scope

4 Network infrastructure

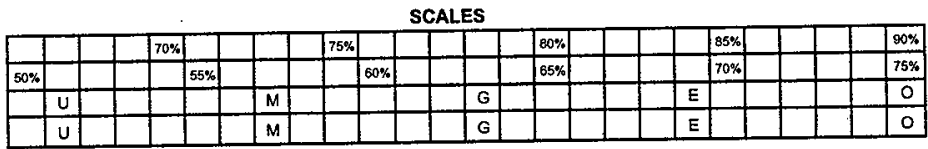




\begin{tabular}{|c|c|c|c|}
\hline 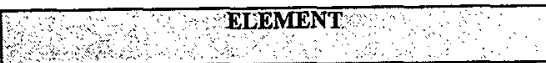 & $\begin{array}{l}\text { Performance } \\
\text { Level }\end{array}$ & $\begin{array}{c}\text { Effectiveness } \\
\text { Score }\end{array}$ & $\begin{array}{l}\text { Value } \\
\text { Points }\end{array}$ \\
\hline $\begin{array}{l}\text { 2.1.1 Worker involvement, knowledge, and culture } \\
\text { relative to ES\&H }\end{array}$ & 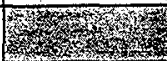 & W. & \\
\hline $\begin{array}{l}\text { 2.1.1.1 Management interactions with workers to ensure } \\
\text { staff involvement in work planring, knowledge of } \\
\text { requirements and attitude/culture relative to ES\&H }\end{array}$ & & & \\
\hline 2.1.1.2 Dose Index & & & \\
\hline $\begin{array}{l}\text { 2.1.1.3 User involvement in SBMS Subject Area } \\
\text { development }\end{array}$ & & & \\
\hline se & $\begin{array}{r}\text { Composite } \\
\text { Total }\end{array}$ & & \\
\hline
\end{tabular}

Table 2.1 - Objective 2.1, Indicator 2.1.1 Performance Rating Development

\begin{tabular}{|c|c|c|c|}
\hline ELEMENT & $\begin{array}{c}\text { Performance } \\
\text { Level }\end{array}$ & $\begin{array}{l}\text { Effectiveness } \\
\text { Score }\end{array}$ & $\begin{array}{l}\text { Value } \\
\text { Points }\end{array}$ \\
\hline $\begin{array}{l}2.1 .2 \mathrm{ES} \& H \text { training commensurate with assigned } \\
\text { responsibilities }\end{array}$ & How & 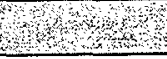 & \\
\hline 2.1.2.1 Completion of SDTP and required ES\&H training & & & \\
\hline 2.1.2.2 Completion of ES\&H Training Courses & & & \\
\hline 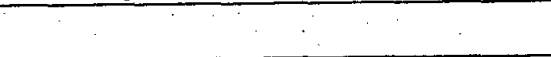 & $\begin{array}{r}\text { Composite } \\
\text { Total }\end{array}$ & & \\
\hline
\end{tabular}

Table 2.2 - Objective 2.1, Indicator 2.1.2 Performance Rating Development

\begin{tabular}{|l|c|c|c|}
\hline \multicolumn{1}{|c|}{ ELEMENT } & $\begin{array}{c}\text { Performance } \\
\text { Level }\end{array}$ & $\begin{array}{c}\text { Effectiveness } \\
\text { Score }\end{array}$ & $\begin{array}{c}\text { Value } \\
\text { Points }\end{array}$ \\
\hline 2.1.3 Material Control & & & \\
\hline 2.1 .3 .1 Chemical Management System & & & \\
\hline 2.1 .3 .2 Generator management of SAA (Slop Jars) & Composite & & \\
\hline & Total & & \\
\hline
\end{tabular}

Table 2.3 - Objective 2.1, Indicator 2.1.3 Performance Rating Development 


\begin{tabular}{|c|c|c|c|}
\hline Wha ELEMENT & $\begin{array}{c}\text { Performance } \\
\text { Level }\end{array}$ & $\begin{array}{l}\text { Effectiveness } \\
\text { Score }\end{array}$ & $\begin{array}{l}\text { Value } \\
\text { Points }\end{array}$ \\
\hline 2.1.4 ES\&H Lagging Performance Indicators & 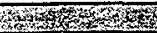 & Q & $\therefore$ \\
\hline $\begin{array}{l}\text { 2.1.4.1 OSHA Lost Workday Case Incidence Rate (Lost } \\
\text { Workday Case Rate) }\end{array}$ & & & \\
\hline $\begin{array}{l}\text { 2.1.4.2 OSHA Recordable Case Incidence Rate } \\
\text { (Recordable Case Rate) }\end{array}$ & & & \\
\hline $\begin{array}{l}\text { 2.1.4.3 OSHA Lost Workday Incidence Rate (Lost } \\
\text { Workday Rate) }\end{array}$ & & & \\
\hline 2.1.4.4 Unplanned Doses & & & \\
\hline 2.1.4.5 Spread of Radioactive Contamination & & & \\
\hline 2.1.4.6 Loss of Radioactive Sources & & & \\
\hline 2.1.4.7 Skin and Personal Clothing Contamination Events & & & \\
\hline 2.1.4.8 Environmental Protection & & & \\
\hline 2.1.4.9 Transportation of DOE Hazardous Materials & & & \\
\hline$\therefore \quad \cdots$ & $\begin{array}{r}\text { Composite } \\
\text { Total }\end{array}$ & & \\
\hline
\end{tabular}

Table 2.4 - Objective 2.1, Indicator 2.1.4 Performance Rating Development

\begin{tabular}{|c|c|c|c|}
\hline ELEMENT & $\begin{array}{l}\text { Performance } \\
\quad \text { Level }\end{array}$ & $\begin{array}{c}\text { Effectiveness } \\
\text { Score } \\
\end{array}$ & $\begin{array}{l}\text { Value } \\
\text { Points }\end{array}$ \\
\hline $\begin{array}{l}\text { 2.2.1 Facilities (Buildings): Utilization of space is } \\
\text { commensurate with science and technology mission } \\
\text { needs }\end{array}$ & 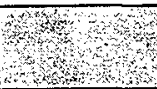 & $\sqrt{2}$ & \\
\hline $\begin{array}{l}\text { 2.2.1.1 Total office space assigned per number of staff } \\
\text { members in an organization }\end{array}$ & & & \\
\hline 2.2.1.2 Staff Chum Rate & & & \\
\hline $\begin{array}{l}\text { 2.2.1.3 Continuous improvement in F\&O services and } \\
\text { operations realized from benchmarking }\end{array}$ & & & \\
\hline & $\begin{array}{r}\text { Composite } \\
\text { Total }\end{array}$ & & \\
\hline
\end{tabular}

Table 2.5 - Objective 2.2, Indicator 2.2.1 Performance Rating Development

\begin{tabular}{|c|c|c|c|}
\hline ELEMENT & $\begin{array}{c}\text { Performance } \\
\text { Level }\end{array}$ & $\begin{array}{l}\text { Effectiveness } \\
\text { Score }\end{array}$ & $\begin{array}{l}\text { Value } \\
\text { Points }\end{array}$ \\
\hline \multicolumn{4}{|l|}{ 2.2.2 R\&D Equipment Utilization } \\
\hline . & $\begin{array}{r}\text { Composite } \\
\text { Total }\end{array}$ & 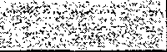 & \\
\hline
\end{tabular}

Table 2.6 - Objective 2.2, Indicator 2.2.2 Performance Rating Development 


\begin{tabular}{|c|c|c|c|}
\hline ELEMENT & $\begin{array}{c}\text { Performance } \\
\text { Level }\end{array}$ & $\begin{array}{l}\text { Effectiveness } \\
\text { Score }\end{array}$ & $\begin{array}{l}\text { Value } \\
\text { Points }\end{array}$ \\
\hline $\begin{array}{l}\text { 2.2.3 Infrastructure: Physical asset acquisitions and } \\
\text { modifications follow an integrated and systematic } \\
\text { process }\end{array}$ & 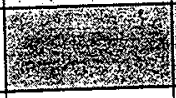 & Xy & \\
\hline $\begin{array}{l}\text { 2.2.3.1 Increased level of interaction with other Hanford } \\
\text { Site contractors on key issues supporting facility } \\
\text { infrastructure and services }\end{array}$ & & & \\
\hline $\begin{array}{l}\text { 2.2.3.2 Minimization of impact to the Laboratory due to } \\
\text { site infrastructure failures and future usage by } \\
\text { development/deployment of effective System } \\
\text { Engineering process }\end{array}$ & & & \\
\hline $\begin{array}{l}\text { Engineering process } \\
2.2 .3 .3 \text { Improve the scope definition and cost of site } \\
\text { services by using activity-based and customer-focused } \\
\text { methods }\end{array}$ & & & \\
\hline $\begin{array}{l}\text { methods } \\
\text { 2.2.3.4 Complete Scheduled Network infrastructure } \\
\text { Upgrade Projection Plans and Projects }\end{array}$ & & & \\
\hline$\frac{\text { Upgrade riojecilon }}{\ddots}$ & $\begin{array}{r}\text { Composite } \\
\text { Total } \\
\end{array}$ & & \\
\hline
\end{tabular}

Table 2.7 - Objective 2.2, Indicator 2.2.3 Performance Rating Development 


\begin{tabular}{|c|c|c|c|c|c|c|c|}
\hline 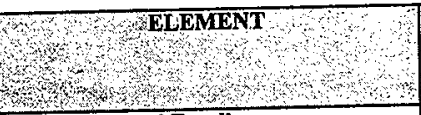 & $\begin{array}{l}\text { Volue } \\
\text { Points } \\
\text { Tables } \\
4.147\end{array}$ & Weight & 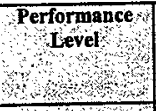 & $\begin{array}{r}\text { Effectiveness } \\
\text { Score } \\
\end{array}$ & \begin{tabular}{r|} 
Value \\
Points \\
\\
\end{tabular} & Weight & $\begin{array}{l}\text { Wejghted } \\
\text { points } \\
\text { pos }\end{array}$ \\
\hline 2.0 Operational Excellence & and & 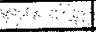 & $\therefore$ row & $x^{2}$ & $x+2$ & (1) & 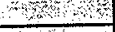 \\
\hline $\begin{array}{l}\text { 2.1 Sustain and enhance operational } \\
\text { excellence in safety and health, and } \\
\text { environmental protection }\end{array}$ & 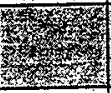 & mon & 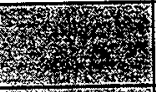 & & & & a \\
\hline 2.1.1 Composite from Table 2.1 & & $30 \%$ & 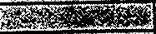 & 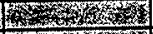 & & & . \\
\hline 2.1.2 Composite from Table 2.2 & & $30 \%$ & 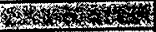 & 6. & & $\therefore$ & 4 \\
\hline 2.1.3 Composite from Table 2.3 & & $30 \%$ & 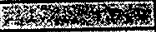 & 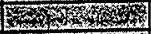 & & $\therefore$ & \\
\hline 2.1.4 Composite from Table 2.4 & & $10 \%$ & 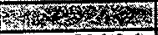 & 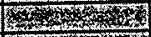 & & & 8 \\
\hline 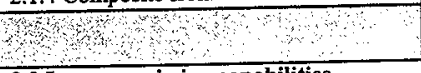 & & $\because \cdots$ & $\begin{array}{r}\text { Objzal } \\
\text { Total }\end{array}$ & 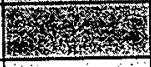 & & $67 \%$ & \\
\hline $\begin{array}{l}2.2 \text { Increase mission capabilities } \\
\text { through enhancement and effective use } \\
\text { of Laboratory facilities and equipment }\end{array}$ & & & & & & & \\
\hline 2.2.1 Composite from Table 2.5 & & $60 \%$ & & & & & $\therefore$ \\
\hline 2.2.2 Value from Table 2.6 & & $10 \%$ & 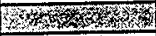 & 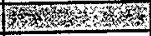 & & & \\
\hline 2.2.3 Composite from Table 2.7 & & $30 \%$ & & & & & \\
\hline $\begin{array}{lll}\ddots & 1 \\
\ddots & \ddots\end{array}$ & & & $\begin{array}{r}\text { Obj } 2.2 \\
\text { Total }\end{array}$ & & & $33 \%$ & \\
\hline & & & & & & Total & \\
\hline
\end{tabular}

Table 2.8 Operational Excellence Critical Outcome Performance Rating Development 


\begin{tabular}{|c|c|c|c|c|c|c|c|}
\hline 2.1 .1 & 2.1 .2 & 2.1 .3 & 2.1 .4 & 2.2 .1 & 2.2 .2 & 2.2 .3 & \\
\hline \begin{tabular}{|c|} 
Worker \\
Involvemen \\
t relevant to \\
ES\&H
\end{tabular} & $\begin{array}{c}\text { ES\&H } \\
\text { Training }\end{array}$ & $\begin{array}{c}\text { Material } \\
\text { Control }\end{array}$ & $\begin{array}{c}\mathrm{ES \& H} \\
\text { Lagging } \\
\text { Indicators }\end{array}$ & $\begin{array}{l}\text { Utilization of } \\
\text { Space }\end{array}$ & $\begin{array}{c}\text { R\&D } \\
\text { Equipment } \\
\text { Utilization }\end{array}$ & \begin{tabular}{|} 
Physical \\
asset \\
acquisitions
\end{tabular} & Rating \\
\hline 170 & 120 & 180 & 535 & 150 & 100 & 350 & 5.0 \\
\hline 162 & 114 & 171 & 508 & 143 & 95 & 333 & 4.9 \\
\hline 153 & 108 & 162 & $\overline{482}$ & 135 & 90 & 315 & 4.8 \\
\hline 145 & 102 & 153 & 455 & 128 & 85 & 298 & $\overline{4.7}$ \\
\hline 136 & 96 & 144 & 428 & 120 & 80 & 280 & 4.6 \\
\hline $8+128$ & 90 & 135 & 401 & 113 & 75 & 263 & .4 .5 \\
\hline 119 & 84 & 126 & $\overline{375}$ & 105 & 70 & 245 & $\overline{4.4}$ \\
\hline 111 & 78 & 117 & 348 & 98 & 65 & $2 \overline{28}$ & 4.3 \\
\hline 102 & 72 & 108 & 321 & 90 & 60 & 210 & $\overline{4.2}$ \\
\hline 94 & 66 & 99 & 294 & 83 & 55 & 193 & 4.1 \\
\hline 85 & 60 & 90 & 268 & 75 & 50 & 175 & 4.0 \\
\hline 77 & 54 & 81 & 241 & 68 & 45 & 158 & 3.9 \\
\hline 68 & 48 & 72 & 214 & 60 & 40 & 140 & 3.8 \\
\hline 60 & 42 & 63 & 187 & 53 & 35 & 123 & 3.7 \\
\hline 51 & 36 & 54 & 161 & 45 & 30 & 105 & 3.6 \\
\hline 43 & 30 & 45 & 134 & 38 & 25 & 88 & 3.5 \\
\hline 34 & 24 & 36 & 107 & 30 & 20 & 70 & 3.4 \\
\hline 26 & 18 & 27 & 80 & 23 & 15 & 53 & 3.3 \\
\hline 17 & 12 & 18 & 54 & 15 & 10 & 35 & 3.2 \\
\hline 9 & 6 & 9 & 27 & 8 & 5 & 18 & 3.1 \\
\hline 0 & 0 & 0 & 0 & 0 & 0 & $\overline{0}$ & 3.0 \\
\hline-3 & -10 & -8 & 27 & -6 & -5 & -8 & 2.9 \\
\hline-6 & -20 & -17 & -53 & -13 & -10 & -17 & 2.8 \\
\hline-8 & -30 & -25 & -80 & -19 & -15 & -25 & 2.7 \\
\hline-11 & -40 & -33 & -106 & -25 & -20 & -33 & 2.6 \\
\hline-14 & -50 & -41 & -133 & -31 & -25 & -41 & 2.5 \\
\hline-17 & -60 & -50 & -159 & -38 & -30 & -50 & 2.4 \\
\hline-19 & -70 & -58 & -186 & -44 & -35 & -58 & 2.3 \\
\hline-22 & -80 & -66 & -212 & -50 & -40 & -66 & 2.2 \\
\hline-25 & -90 & -74 & -239 & -56 & -45 & -74 & 2.1 \\
\hline-28 & -100 & -83 & -265 & -63 & -50 & -83 & 2.0 \\
\hline-30 & -110 & -91 & -292 & -69 & -55 & -91 & 1.9 \\
\hline-33 & -120 & -99 & -318 & -75 & -60 & -99 & 1.8 \\
\hline-36 & -130 & -107 & -345 & -81 & -65 & -107 & 1.7 \\
\hline-39 & -140 & -116 & -371 & -88 & -70 & $-1 \overline{16}$ & 1.6 \\
\hline-41 & -150 & -124 & -398 & -94 & -75 & -124 & 1.5 \\
\hline-44 & -160 & -132 & -424 & -100 & -80 & -132 & 1.4 \\
\hline-47 & -170 & -140 & -451 & -106 & -85 & $-1 \overline{40}$ & 1.3 \\
\hline-50 & -180 & -149 & -477 & -113 & -90 & -149 & 1.2 \\
\hline-52 & -190 & -157 & -504 & -119 & -95 & -157 & 1.1 \\
\hline-55 & -200 & -165 & -530 & -125 & -100 & -165 & 1.0 \\
\hline
\end{tabular}

Table 2.9 - Operational Excellence Critical Outcome Score Normalization Table 


\begin{tabular}{|c|c|c|c|c|c|}
\hline Total Score & $5.0-4.5$ & $4.4-3.5$ & $3.4-2.5$ & $2.4-1.5$ & $1.4-1.0$ \\
\hline Final Rating & Outstanding & Excellent & Good & Marginal & Unsatisfactory \\
\hline
\end{tabular}

Table 2.10 - Operational Excellence Critical Outcome Final Rating

\begin{tabular}{|c|c|c|}
\hline Outcome Rating & Score & $\begin{array}{l}\text { Fetormancesiased } \\
\text { Fee }\end{array}$ \\
\hline \multirow{6}{*}{ Outstanding } & 5.0 & $\$ 280,000$ \\
\hline & 4.9 & $\$ 262,500$ \\
\hline & 4.8 & $\$ 245,000$ \\
\hline & 4.7 & $\$ 227,500$ \\
\hline & 4.6 & $\$ 270,000$ \\
\hline & 4.5 & $\$ 192,500$ \\
\hline \multirow{10}{*}{ Excellent } & $\overline{4.4}$ & $\$ 175,000$ \\
\hline & 4.3 & $\$ 157,500$ \\
\hline & 4.2 & $\$ 740,000$ \\
\hline & 4.1 & $\$ 122,500$ \\
\hline & 4.0 & $\$ 105,000$ \\
\hline & 3.9 & $\$ 87,500$ \\
\hline & 3.8 & $\$ 70,000$ \\
\hline & 3.7 & $\$ 52,500$ \\
\hline & 3.6 & $\$ 35,000$ \\
\hline & 3.5 & $\$ 17,500$ \\
\hline Good or Less & $\overline{3.4}$ & $\$ 0$ \\
\hline
\end{tabular}

Table 2.11 - Operational Excellence Critical Outcome Additional Performance-Based Fee Matrix 


\subsection{LEADERSHIP AND MANAGEMENT (20\%)}

\section{Critical Outcome}

Battelle will provide leaders/managers and produce efficient management systems that effectively support employees in the performance of their mission responsibility.

Modification: The objectives, indicators and expected levels of performance identified below have been developed based on the best information available at the time. Should circumstances arise which require modifications to any of the objectives, indicators and/or expected levels of performance within this outcome it shall be accomplished through the approved change control process described within this document. If the Parties cannot reach agreement on the changes the Contracting Officer shall have the right to make reasonable changes as specified within the contract DE-AC06-76RLRL01830.

3.1 Objective - Battelle will provide leadership and management to foster a work environment that optimizes staff satisfaction and individual contribution. (30\%)

\section{Performance Indicators}

\subsubsection{Staff separations rate}

Description: Using Saratoga Institute data, Battelle will measure retention performance against similar organizations. Specifically, the percentage of voiuntary separations of both full-time and part-time head count will be compared to the mean separation rate for $R \& D$ as reported in the 1999 Edition of the Saratoga Institute, "Human Resources Financial Report," Voluntary Separation Rate (Total) Section.

Performance:

Ratings will be based on the mid-point of the $10^{\text {th }}, 25^{\text {th }}, 50^{\text {th }}, 75^{\text {th }}$, and $90^{\text {th }}$ percentiles.

Rating $\quad$ Score

Outstanding At or below 17.5 percentile of SI data

Excellent At or below 27.5 percentile of SI data

Good At or below 62.5 percentile of SI data

Marginal At of below 87.5 percentile of SI data

Unsatisfactory At or below 97.5 percentile of SI data

Performance-Related Assumptions: None Identified

\subsubsection{Personal/Professional Development}

Description: The percentage of staff reporting positive perceptions in the spring 1999 QWL survey for Personal/Professional Development as compared to R\&D normative trends provided by ISR: 
Performance:

Rating

Outstanding

Excellent

Good

Marginal

Unsatisfactory $\underline{\text { Score }}$

Composite percentage positive response is at or above one (1) standard deviation above the mean

Composite percentage positive response is at or above the mean

Composite percentage positive response is at or above one (1) standard deviation below the mean

Composite percentage positive response is at or above two (2) standard deviations below the mean

Composite percentage positive response is at or above three (3)

standard deviations below the mean

Baseline Information: The August 1997 and 1998 surveys were used to determine Lab-wide focus areas. Using ISR normative data for 1997, Personnel/Professional Development was identified as the most critical staff satisfaction issue the Contractor needed to address. 1997

"Personal/Professional Development" composite comparisons produced the following results:

\begin{tabular}{lrrr} 
Group & \# of Responses & \% Positive Sco \\
\cline { 2 - 3 } Battelle & 1,753 & & $39 \%$ \\
US National Norm & 162,190 & & $47 \%$ \\
US R\&D Norm & 32,037 & & $50 \%$
\end{tabular}

This data demonstrates that Battelle performance in this area is $8 \%$ below comparisons to national data and $11 \%$ below comparisons to R\&D data. ISR defined the difference between Battelle's responses and the comparison group's responses as "statistically significant." The statistical test that produces this result indicates that there are only five chances in a hundred that a difference that great could occur by chance.

Interim surveys conducted through FY 1998 suggest that little to no progress has been made in this area (little or no percentage increase in positive responses). Results from the formal 1998 survey conducted in August will be available October 1998, at which time DOE and Battelle will more fully evaluate progress in 1998. Performance targets for FY99 may be adjusted if significant improvement was achieved in FY98 and will be incorporated via approved change control.

Performance-Related Assumptions: in FY99, DOE and Battelle will work with ISR to develop and administer an enhanced QWL survey. The Personal/Professional Development indicators (questions), identified by DOE and the Contractor will measure progress to date in this dimension. The enhanced survey, to be administered in the spring of 1998 will also assess overall progress toward fostering a work environment that optimizes staff satisfaction and individual contribution as well as identify potential new focus areas for future improvement. ISR will conduct independent sample interviews with top management and stratified sample staff focus groups to provide enhancements to the survey. Modifications to individual composite questions will be developed upon completion of the focus group meetings; composite questions will provide for meaningful measurements with national normative trends.

3.2 Objective - Battelle Leadership provides effective management systems to dive improvements enabling DOE to optimize oversight activities. (40\%) 


\section{Performance Indicators}

3.2.1 Contractor's independent annual averaged rating of the Divisions/Directorates self-assessment program performance

Description: The Integrated Assessment management system owner and DOE-AMT will collaboratively evaluate each of the Laboratory organizations on their self-assessment program Performance. The evaluation will be conducted against requirements established within the Laboratory's Standards Based Management System (SBMS). Each of the evaluations will be qualified on a 1,000-point scale. The results of the evaluations will be averaged to provide a measure of the effectiveness of the Laboratory's implementation of the Integrated Assessment management system.

Baseline Information: Baseline data was collected in FY 1997 by the Laboratory's Independent Oversight annual assessment of 13 organizations in their implementation of self-assessment program. The mean score for this evaluation was 279 for FY97. This represents the approach/deployment elements of evaluating organizational performance and is worth 550 of the 1,000-point total.

Performance Expectation Related Assumptions: The best score anticipated for FY 1999 is a mean score of 580 points. This represents $55 \%$ of the mean FY98 score (equaling 390 points) and achieving a $40 \%$ score for the "Results" scoring band (equaling 180 points). This would be considered outstanding performance. The performance range is the scoring band that the 580 points fall into with the lowest anticipated score of 400 points.

Performance:

Target: $\quad 580$

Neutral: $\quad 500$

Minimum: $\quad 400$

3.2.2 DOE's satisfaction with the implementation of the Contractor's self-assessment process.

Description: DOE-RL counterparts of the Laboratory research divisions and management systems will provide a rating to determine their level of satisfaction with the Contractors' self-assessment process in the following areas:

- The DOE-RL level of participation with the Contractor in the development and execution of the self-assessment plans.

- The DOE-RL level of participation with the Contractor in the communication and reporting of results of the self-assessment pians.

- The DOE-RL level of satisfaction with the Contractors' effort in using the results of the selfassessment to effect improvement.

Baseline Information: This is the third year for this indicator and should reflect the maturity of the self-assessment process. The prior two years (FY 1998, FY 1997) performance was assessed via survey. FY 1997 resulted in a $58 \%$ DOE-RL rating with their involvement, resulting from a satisfaction level of 3 or higher on a 5-point scale. Although the ratings for FY 1998 are not yet available RL does not expect a marked improvement in this area. However, should the FY 1998 levels come in higher or lower than expected the targets for this indicator will be revisited and appropriate changes will be made via approved change control. The best level of performance that can be expected during FY 1999 is a $90 \%$ average DOE-RL satisfaction rating of 3 or higher on a 5 point scale. 
Performance Expectation Related Assumptions: The targeted level of performance for this indicator is a DOE-RL satisfaction rating of 3 or higher on a 5-point scale.

Performance:

Target: $\quad 90 \%$ rating 3 or higher on a 5-point scale

Neutral: $\quad 58 \%$ rating 3 or higher on a 5 -point scale

Minimum: $\quad 30 \%$ rating 3 or higher on a 5-point scale

3.2.3 Staff satisfaction with internal products and services from the management systems.

Description: Feedback from Laboratory internal customers of the products and services delivered by internal Laboratory management systems will be obtained through the use of a composite set of questions taken from the annual staff Quality of Work Life (QWL) survey. The survey will use a 5 point Likert scale and will be administered during the $2^{\text {nd }}$ quarter of the fiscal year. The survey questions shall be developed and approved by DOE-RL/MET, in partnership with the Laboratory Director of Quality.

Baseline Information: Baseline data for this indicator was collected via the FY97 and FY98 QWL survey. The data collected during the FY97 survey was evaluated on a 7 point Likert scale. Staff rated their satisfaction as a 4.5. This correlates to a mean score of 3.33 on a 5-point scale. Results of the FY98 survey are not yet available.

Performance Expectation Related Assumptions: Results of the FY98 survey will become available during October 1998 and based on this information adjustments to the FY99 performance expectations may be made via approved change control.

Performance:

Target: $\quad 3.7$

Neutral: $\quad 3.3$

Minimum: $\quad 3.2$

3.3 Objective - Battelle leadership and management promote open and effective business operations. $(30 \%)$

\section{Performance Indicators}

\subsubsection{Research/support staff labor ratio}

Description: The ratio of staff dollars expended on research activities relative to staff dollars expended on support activities.

This indicator will be based on the total labor cost of all staff plus Associated Western University (AWU) students that charge to research activities. Research activities are defined as all client funded projects including capital, Laboratory directed research and development (LDRD) projects, internal research and development (IR\&D), the program management portion of program development and management, and that portion of service center labor (including B\&U) which is charged direct to client funded projects. All other staff labor cost will be considered support. Labor cost will be the actual labor doliars charged to the activities as described above.

Formula: Research labor cost divided by support labor cost. 
Baseline Information: Historical performance data is provided below.

FY94 2.2; FY95 2.2; FY96 2.6; FY97 - 2.7; FY98 2.61; FY99 2.61

Performance Expectation Related Assumptions: Two assumptions have been used in the development of this indicator, however, adjustments to year-end actuals will be made:

1. Base salary escalation will be about $3.1 \%$ in FY 99 .

2. The benefit rate will remain at $28 \%$ in FY99.

Performance:

Target: $\quad 2.70$

Neutral: $\quad 2.61$

Minimum: 2.50

\subsubsection{Average cost per research FTE}

Description: The total average cost charged per full time equivalent charging to research activities:

This indicator will be based on total Laboratory costs under the 1830 contract less direct funded capital and construction costs, subcontracts and other Hanford contractor costs, single procurements greater than $\$ 1 \mathrm{M}$, and specific one time only costs directed by the Department of Energy (ex. ROF costs). Full time equivalents will be based on labor hours charged by Laboratory staff and AWU students to research activities excluding those hours charged to capital or construction projects and 1831 research activities.

Formula: Total 1830 costs less direct funded capital and construction costs, less direct funded subcontracts and other Hanford contractor costs, less direct funded single procurements greater than $\$ 1 \mathrm{M}$, and less one time only DOE directed costs divided by 1830 research activities labor hours divided by 1832 . Research activities are defined as all client funded projects including capital, Laboratory directed research and development (LDRD) projects, internal research and development (IR\&D), the program management portion of program development and management, and that portion of service center labor (including $B \& U$ ) which is charged direct to client funded projects.

Baseline Information: Historical performance data is provided below. All results will be in FY94 dollars for comparison and trending purposes. FY94 is the base year of this metric across the DOE complex as it represents the initial tracking year.

FY94 122; FY95 119; FY96 117; FY97-120; FY98 - 116; FY99 116.

Performance Expectation Related Assumptions: A single assumption was used in the development of this indicator.

1. A full time equivalent $=1832$ hours

\section{Performance:}

Target: $\quad 111$

Neutral: $\quad 116$

Minimum: $\quad 122$

3.3.3 DOE's evaluation of overall Contractor performance in the business management functional areas. 
Description: This indicator will measure the overall effectiveness/performance of the business management (BMOP) functions in delivering products and services and complying with applicable requirements as viewed by the cognizant DOE RL business management organizations. The BMOP functions include:

\begin{tabular}{|c|c|c|c|}
\hline WDOERL & & BuS & ESSMANAGEMENT (BMOP) ACTIVMTES, \\
\hline SID/OEA & $\begin{array}{l}\text { Facilities \& } \\
\text { Operations }\end{array}$ & 1. & $\begin{array}{l}\text { Administrative Services (including mail, printing, record } \\
\text { access and library) }\end{array}$ \\
\hline OEA & $\begin{array}{l}\text { Education \& } \\
\text { External Rel. }\end{array}$ & 2. & $\begin{array}{l}\text { Congressional, Public, and Intergovernmental Affairs } \\
\text { (including openness, whistle blower protection, and public } \\
\text { participation) }\end{array}$ \\
\hline HRM & HR & 3. & Diversity \\
\hline BUD/CFR/FMD & $\begin{array}{l}\text { Finance and } \\
\text { Internal Audit }\end{array}$ & 4. & Finance, Budget, and Internal Audit \\
\hline SID & Energy/IT & 5. & Information Management/Y2K \\
\hline MET/PID & Strat. Planning & 6. & Laboratory and Institutional Business Planning \\
\hline $\mathrm{PMD} / \mathrm{SID}$ & Facilities & 7. & Life Cycle Assets Management \\
\hline HRM/OTR & $\mathrm{HR}$ & 8. & Manpower and Personnel (including training) \\
\hline SAS/STP & $\begin{array}{l}\text { National } \\
\text { Security }\end{array}$ & 9. & $\begin{array}{l}\text { Nonproliferation and National Security which includes the } \\
\text { following: } \\
\text { - Intelligence } \\
\text { - Nuclear Safeguards and Security } \\
\text { - Classification/Declassification } \\
\text { - Emergency Management }\end{array}$ \\
\hline SID & Finance & 10. & Personal Property \\
\hline PRO/CFR & Finance & 11. & Procurement \\
\hline OEA & Comm. & 12. & Scientific and Technical Information Administration \\
\hline STP & Econ. Dev. & 13. & Technology Partnerships Administration \\
\hline CWP/MET & HR/Econ. Dev. & 14. & Worker and Community Transition \\
\hline FMD/STP & Legal & 15. & Work-for-Others Administration \\
\hline OCC & Legal & 16. & Legal and Patent Services \\
\hline
\end{tabular}

Performance Rating Measurement: Performance against this Performance Indicator will be measured by the averaged adjectival rating assigned to each of the business management functions listed above. Each of the sixteen BMOP functional activities reviewed will be asked to provide an adjectival rating as follows:

$\begin{array}{lll}\text { Outstanding } & - & 5 \\ \text { Excellent } & - & 4\end{array}$




$\begin{array}{lll}\text { Good } & - & 3 \\ \text { Marginal } & - & 2 \\ \text { Unsatisfactory } & - & 1\end{array}$

RL business management organizations will utilize the contractor self-assessment as the primary means for performance evaluation. RL business management organizations may utilize one or more of the following, in addition to the self-assessment, in evaluating the Contractors performance:

1. Operational awareness (daily oversight).activities performed throughout the year;

2. For Cause reviews; and

3. Other outside agency reviews (OIG, GAO, DCAA, etc.) conducted throughout the year.

The overall business management functions rating will be determined by the average of all reviewed areas per the following rating scale. Ail business functions shall be weighted equally.

$$
\begin{array}{ll}
5.0-4.5= & \text { Outstanding } \\
4.4-3.5= & \text { Excellent } \\
3.4-2.5= & \text { Good } \\
2.4-1.5= & \text { Marginal } \\
1.4-1.0= & \text { Unsatisfactory }
\end{array}
$$

Performance:

$\begin{array}{ll}\text { Target: } & 4.6 \\ \text { Neutral: } & 3.8 \\ \text { Minimum: } & 3.0\end{array}$

\section{Critical Outcome Performance Rating and Additional Performance-Based Fee}

Figures $3 \mathrm{~A}, 3 \mathrm{~B}$ and $3 \mathrm{C}$ document the associated agreements on performance expectations in the form of contingency functions. The overall performance rating for this outcome will be determined by summing the effectiveness scores for all Objectives as depicted in Table 3.1, below, normalizing the scores using Table 3.2 and comparing the normalized sum to the rating scale in Table 3.3. Additional performancebased fee earned (if any) for this outcome is determined by comparing the overall outcome score $(5.0-3.5)$ to the amount available within Table 3.4 . 
Figure 3A, Leadership and Management Objective 3.1, Contingency Diagram

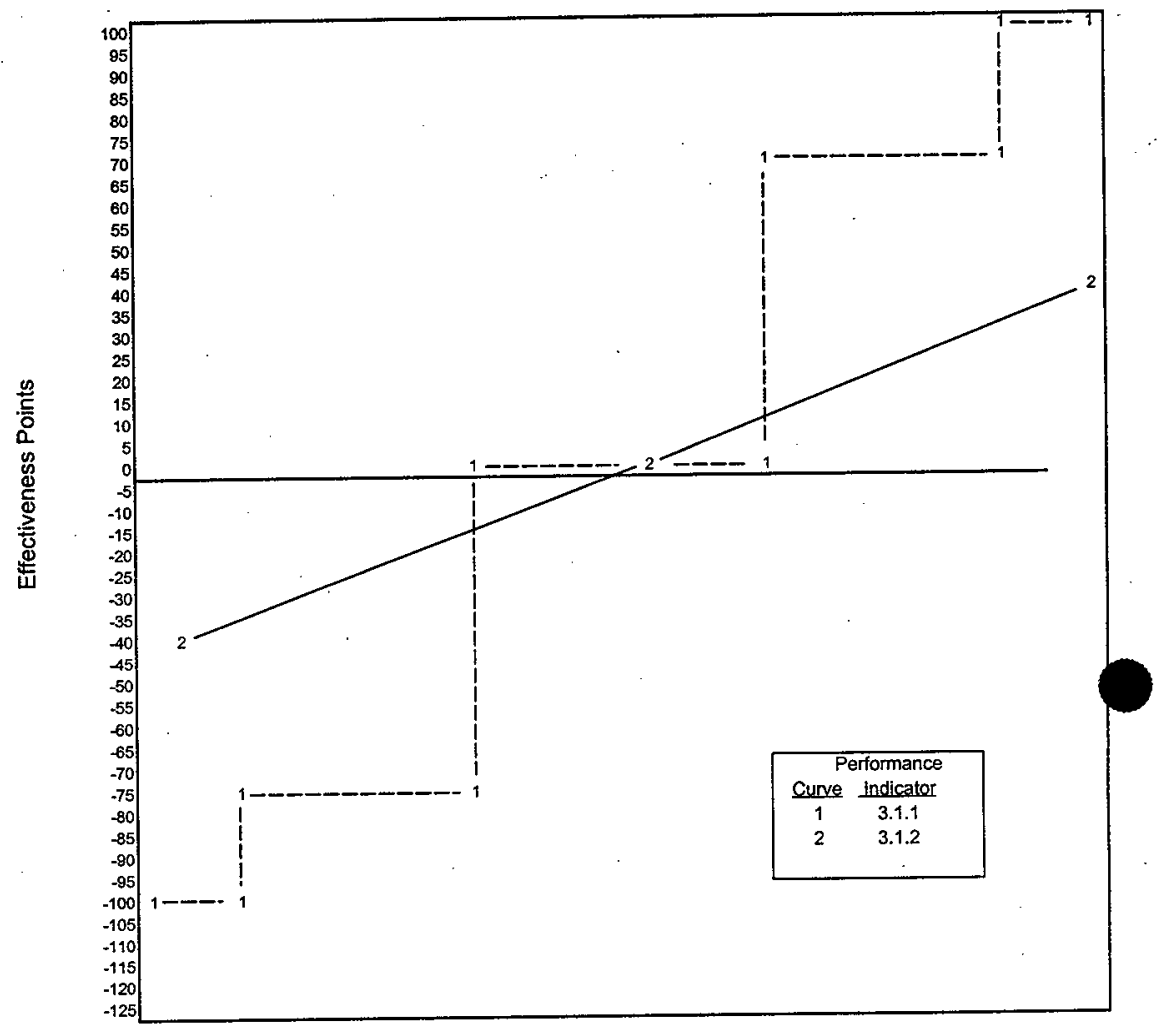

Performance Indicator

1 Staff Separation Rate (\%)

2 Perform. Feedback (S.D.)
SCALES

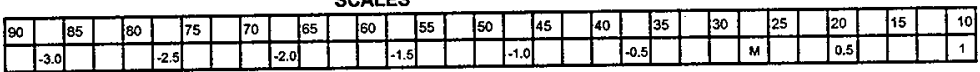


Figure 3B, Leadership and Management Objective 3.2, Contingency Diagram

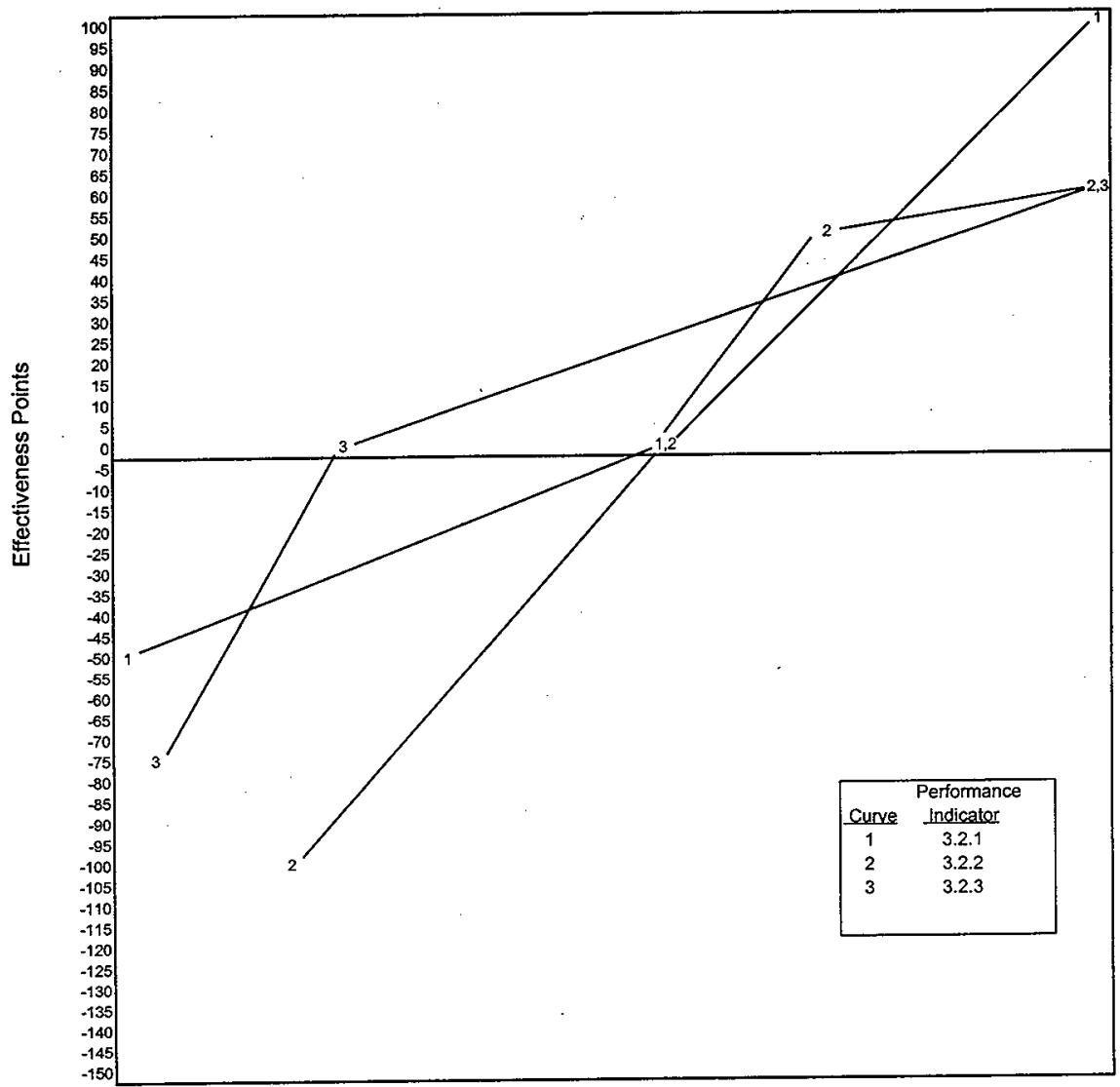

Perfomance indicator

SCALES

Eval of IA Effect

DOE Sat with IA

Staff Sat of MS

\begin{tabular}{|c|c|c|c|c|c|c|c|c|c|c|c|c|c|c|c|c|c|c|c|c|}
\hline 400 & 410 & 420 & 430 & 440 & 450 & 460 & 470 & & 480 & 490 & 500 & 510 & 520 & 530 & 540 & & 550 & 560 & 570 & 580 \\
\hline & & & 30 & 34 & 38 & 42 & 46 & & 50 & 54 & 58 & 62 & 66 & 70 & 74 & & 78 & 82 & 86 & 90 \\
\hline & 3.2 & & & 3.3 & & & & 3.4 & & & & 3.5 & & & & 3.6 & & & & 3.7 \\
\hline
\end{tabular}


Figure 3C, Leadership and Management Objective 3.3, Contingency Diagram

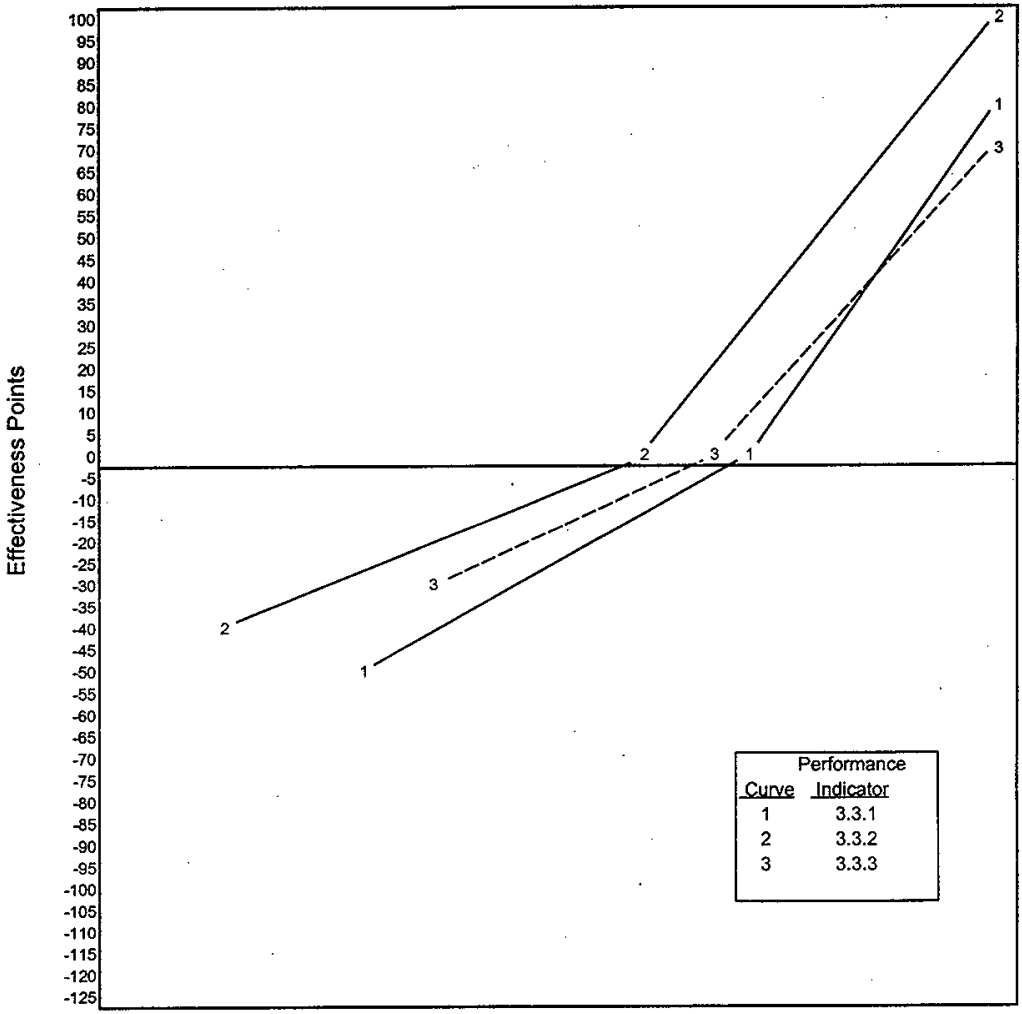

Performance indicator

1 Research/Support Ratio

2 Ave. Cost per FTE

3 Feedback from BMO

\begin{tabular}{|c|c|c|c|c|c|c|c|c|c|c|c|c|c|}
\hline \multicolumn{14}{|c|}{ SCALES } \\
\hline & & & & 2.50 & 2.52 & 2.54 & 2.56 & 2.58 & 2.60 & 2.62 & 2.64 & 2.66 & 2.70 \\
\hline & & 122 & 121 & 120 & 119 & 118 & 117 & 116 & \begin{tabular}{|l|}
115 \\
\end{tabular} & \begin{tabular}{|c|}
194 \\
\end{tabular} & \begin{tabular}{|l|}
113 \\
\end{tabular} & 112 & 111 \\
\hline & & & 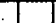 & & 3.0 & 3.2 & 3.4 & 3.6 & \begin{tabular}{|c|}
3.8 \\
\end{tabular} & 4.0 & 4.2 & 4.4 & 4.6 \\
\hline
\end{tabular}




\begin{tabular}{|c|c|c|c|c|c|}
\hline ELEMENT & $\begin{array}{c}\text { Performance } \\
\text { Level }\end{array}$ & $\begin{array}{l}\text { Effectiveness } \\
\text { Score }\end{array}$ & $\begin{array}{l}\text { Value } \\
\text { Points }\end{array}$ & Weight & $\begin{array}{l}\text { Weighted } \\
\text { Points }\end{array}$ \\
\hline 3.0 Leadership and Management & I & $8 \ldots$ & & & \\
\hline $\begin{array}{l}\text { 3.1 Battelle will provide leadership \& } \\
\text { management to foster a work } \\
\text { environment that optimizes staff } \\
\text { satisfaction and individual } \\
\text { contribution. }\end{array}$ & & & 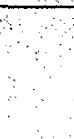 & & \\
\hline 3.1.1 Staff separation rate & & & $\therefore$ & & \\
\hline $\begin{array}{l}\text { 3.1.2 Personal/Professional } \\
\text { Development }\end{array}$ & & & & & \\
\hline and & $\begin{array}{r}\text { Obj 3.1 } \\
\text { Total }\end{array}$ & & & $30 \%$ & \\
\hline $\begin{array}{l}\text { 3.2 Battelle Leadership provides } \\
\text { effective management systems to drive } \\
\text { improvements enabling DOE to } \\
\text { optimize oversight activities }\end{array}$ & & & & & \\
\hline $\begin{array}{l}\text { 3.2.1 Contractor's independent annual } \\
\text { average rating of the } \\
\text { Divisions/Directorates self-assessment } \\
\text { program performance }\end{array}$ & & & & & \\
\hline $\begin{array}{l}3.2 .2 \text { DOE's satisfaction with the } \\
\text { implementation of the Contractor's self- } \\
\text { assessment process }\end{array}$ & & & & & \\
\hline $\begin{array}{l}3.2 .3 \text { Staff satisfaction with internal } \\
\text { products and services from the } \\
\text { management systems }\end{array}$ & & & & & \\
\hline & $\begin{array}{r}\text { Obj } 3.2 \\
\text { Total }\end{array}$ & & & $40 \%$ & \\
\hline $\begin{array}{l}\text { 3.3 Battelle leadership and } \\
\text { management promote effective } \\
\text { business operations }\end{array}$ & & & & & \\
\hline 3.3.1 Research/Support staff labor ratio & & & & & \\
\hline 3.3.2 Average cost per research FTE & & & & & \\
\hline $\begin{array}{l}\text { 3.3.3 DOE's evaluation of overall } \\
\text { Contractor performance in the business } \\
\text { management functional areas }\end{array}$ & & & & & \\
\hline & $\begin{array}{r}\text { Obj } 3.3 \\
\text { Total } \\
\end{array}$ & & & $30 \%$ & \\
\hline & & & & Total & \\
\hline
\end{tabular}

Table 3.1 - Leadership and Management Critical Outcome Performance Rating Development 


\begin{tabular}{|c|c|c|c|}
\hline Objective 3.1 & Objective 3.2 & Objective 3.3 & Value Points \\
\hline $47 x^{2}$ & 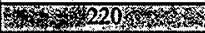 & 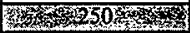 & W \\
\hline 133 & 209 & 238 & 4.9 \\
\hline 126 & 198 & 225 & 4.8 \\
\hline 119 & 187 & 213 & 4.7 \\
\hline 112 & 176 & 200 & 4.6 \\
\hline 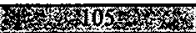 & 56 & X & 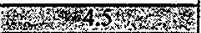 \\
\hline 98 & 154 & 175 & 4.4 \\
\hline 91 & 143 & 163 & 4.3 \\
\hline 84 & 132 & 150 & 4.2 \\
\hline 77 & 121 & 138 & 4.1 \\
\hline 70 & 110 & 125 & 4 \\
\hline 63 & 99 & 113 & 3.9 \\
\hline 56 & 88 & 100 & 3.8 \\
\hline 49 & 77 & 88 & 3.7 \\
\hline 42 & 66 & 75 & 3.6 \\
\hline 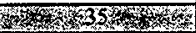 & Syly & 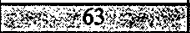 & 2478 ; \\
\hline 28 & 44 & 50 & 3.4 \\
\hline 21 & 33 & 38 & 3.3 \\
\hline 14 & 22 & 25 & 3.2 \\
\hline 7 & 11 & 13 & 3.1 \\
\hline 0 & 0 & 0 & 3 \\
\hline-7 & -11 & -6 & 2.9 \\
\hline-14 & -23 & -12 & 2.8 \\
\hline-21 & -34 & -18 & 2.7 \\
\hline-28 & -45 & -24 & 2.6 \\
\hline Mes $435 \%$ & 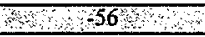 & s. $30 \%$ & Wha 2.5 \\
\hline-42 & -68 & -36 & 2.4 \\
\hline-49 & .79 & -42 & 2.3 \\
\hline-56 & -90 & -48 & 2.2 \\
\hline-63 & -101 & -54 & 2.1 \\
\hline-70 & -113 & -60 & 2 \\
\hline-77 & -124 & -66 & 1.9 \\
\hline-84 & -135 & .72 & 1.8 \\
\hline-91 & -146 & .78 & 1.7 \\
\hline-98 & -158 & -84 & 1.6 \\
\hline hos 105 , & 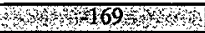 & $4+490$, & mo $1.5 \mathrm{~s}$ \\
\hline-112 & -180 & -96 & 1.4 \\
\hline-119 & -191 & -102 & 1.3 \\
\hline-126 & -203 & -108 & 1.2 \\
\hline-133 & -214 & -114 & 1.1 \\
\hline (7) & 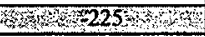 & 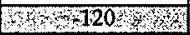 & $60+2$, 1 ; \\
\hline
\end{tabular}

Table 3.2 - Leadership and Management Critical Outcome Score Normalization Table 


\begin{tabular}{|c|c|c|c|c|c|}
\hline Total Score & $5.0-4.5$ & $4.4-3.5$ & $3.4-2.5$ & $2.4-1.5$ & $1.4-1.0$ \\
\hline Final Rating & Outstanding & Excellent & Good & Marginal & Unsatisfactory \\
\hline
\end{tabular}

Table 3.3 - Leadership and Management Critical Outcome Final Rating

\begin{tabular}{|c|c|c|}
\hline Outcome Rating & Score & $\begin{array}{l}\text { Pertomance-Based } \\
\text { Fee }\end{array}$ \\
\hline \multirow{6}{*}{ Outstanding } & 5.0 & $\$ 280,000$ \\
\hline & 4.9 & $\$ 262,500$ \\
\hline & 4.8 & $\$ 245,000$ \\
\hline & 4.7 & $\$ 227,500$ \\
\hline & 4.6 & $\$ 210,000$ \\
\hline & 4.5 & $\$ 192,500$ \\
\hline \multirow{10}{*}{ Excellent } & $\overline{4.4}$ & $\$ 175,000$ \\
\hline & 4.3 & $\$ 157,500$ \\
\hline & 4.2 & $\$ 140,000$ \\
\hline & 4.1 & $\$ 122,500$ \\
\hline & 4.0 & $\$ 105,000$ \\
\hline & 3.9 & $\$ 87,500$ \\
\hline & 3.8 & $\$ 70,000$ \\
\hline & 3.7 & $\$ 52,500$ \\
\hline & 3.6 & $\$ 35,000$ \\
\hline & 3.5 & $\$ 17,500$ \\
\hline Good or Less & $\overline{3.4}$ & $\$ 0$ \\
\hline
\end{tabular}

Table 3.4 - Leadership and Management Critical Outcome Additional Performance-Based Fee Matrix 


\subsection{COMMUNITY RELATIONS (5\%)}

\section{Battelle will involve and benefit the communities to assure that PNNL and Battelle remain valued assets to the Tri-Cities and the Northwest Region.}

Modification: The objectives, indicators and expected levels of performance identified below have been developed based on the best information available at the time. Should circumstances arise which require modifications to any of the objectives, indicators and/or expected levels of performance within this outcome it shall be accomplished through the approved change control process described within this document. If the Parties cannot reach agreement on the changes the Contracting Officer shall have the right to make reasonable changes as specified within the contract DE-AC06-76RLRL01830.

4.1 Objective - Battelle will continue/establish partnerships with local and regional organizations to enhance science, mathematics, and technology education reform efforts in schools. (15\%)

Description: Through focused partnerships, the Laboratory's human and technical resources, as well as Battelle's corporate distributions are linked with school districts and other academic support organizations to promote science, mathematics, and technology education reform. These partnerships link institutional goals, interests, and capabilities so that substantive collaborations between the Laboratory and schoois and other academic support organizations may occur.

\section{Performance Indicator}

4.1.1 The impact of Laboratory-sponsored programs for teachers of science, mathematics, and technology education in partner school districts.

Description: A critical aspect of partnerships that focus on science, mathematics and technology education is the professional development of teachers. This performance indicator measures the impacts of Laboratory-sponsored programs on teachers by measuring three critical areas that affect the quality of learning experiences in classrooms. Impacts of Laboratory programs on 1) teacher content knowledge, 2) field/lab and other skills that can be used in the classroom, and 3) the application/transferability of the experience to the classroom, as reported by teacher participants, are measured.

Baseline Information: Baseline information was developed from two summer programs that were conducted at the Laboratory in FY98. Evaluation information from 30 teachers was used to establish the baseline. One program, Scientists-Student-Teacher High School Research Program, involved teachers in an 8-week research experience. The other program, Partnership for Arid Lands Stewardship Teacher Leader Institute, involved teachers in an intensive 2-week teacher development workshop. Teachers rated the impacts of these programs using a four-point Likert Scale ( 1 being low impact and 4 being high impact). Content, skills, and application to the classroom rating scores were combined to give one score reflecting impacts. As they are funded from indirect budgets these programs are severely constrained financially. The chalienge of this indicator is to sustain the portfolio of investments in teachers, retaining the quality and intensity of the opportunities while finding creative ways to offset reduced financial support. The maximum combined rating a participant could give was a score of 12 out of 12 .

\section{Results:}

11 of 30 participants rated the impacts at $12 / 12$

5 of 30 participants rated the impacts at $11 / 12$

9 of 30 participants rated the impacts at $10 / 12$

5 of 30 participants rated the impacts at $9 / 12$ 
Eighty-three percent (83\%) of FY98 participants rated the professional development experience at $10 / 12$ or better.

Performance Expectation Related Assumptions:

Science, mathematics, and/or technology education teachers, from partner school districts, participate in Laboratory-sponsored professional development experiences (either teacher development or teacher research experience). Using a 4-point Likert Scale, participants are asked to evaluate the impact of these experiences on the following:

their content knowledge,

their science process and generic thinking skills,

their ability to apply the experience to the classroom.

For each participant's evaluation, the sum for these three criteria is calculated (total of 12 points possible).

Performance:

Target: $\quad 83 \%$ of participants' evaluations have a sum of 10 or higher.

Neutral: $\quad 75 \%$ of participants' evaluations have a sum of 9 or higher.

Minimum: $\quad 70 \%$ of participants' evaluations have a sum of 8 or higher.

4.2 Obiective - Battelle will put technology to work in the Tri-Cities and Pacific Northwest to create and sustain a diversified and strong economy. (50\%)

\section{Performance Indicators}

4.2.1 Number of primary sector jobs created within the local area over the five fiscal years beginning with FY 1998 and ending with FY 2002.

Definitions:

1. "Number of...jobs" - Specific, detailed information regarding the criteria for the crediting of jobs will be summarized in a separate document. DOE will prepare this document, with input from, and in negotiation with Battelle. DOE will be responsible for final decisions regarding criteria. In addition to these criteria, DOE may chose to use "third-party, neutral entities in the assessment of job-creation claims by Battelle. If used, the process for selection of individuals/entities used will be discussed with Battelle and documented, along with the names of the individuals/entities selected. Finally, DOE will perform verification of claims

2. "primary sector" jobs - jobs resulting from: a) the sale of goods and/or services to entities outside the local area, such that money flows into the local economy from outside the local area, and/or b) the sale of goods and/or services to entities within the local area such that funds stay within the local area which previously would have gone to vendors outside the area.

3. "local area" - The 10 county region made up of the two counties that contain the Hanford Site, plus the counties adjacent to them. The counties are: Benton, Franklin, Yakima, Walla Walla, Grant, Klickitat, Adams, and Whitman in Washington and Morrow and Umatilla in Oregon.

Description: This indicator has been developed to track the number of jobs resulting from the efforts of the Contractor's Economic Development Office (EDO). The focus of this effort in the past has been the creation of high technology jobs. The importance of this criterion for 1999 will be incorporated into the job-counting criteria discussed in definition \#1 above. 
The contractor has committed to create or help form new businesses and provide technical assistance to existing businesses, collectively adding an average of 100 new jobs to the local area's work force each year. Over the five-year term of the contract, this will result in adding 500 new jobs to the local area's work force. It is recognized that the 500 new jobs will not be created in a linear fashion, and those efforts in the first year(s) of the contract will likely result in fewer jobs being added to the workforce than the last year(s) of the contract. Job creation goals will be established annually in this plan that will total 500 new jobs by the end of the five-year term of the contract (FY 2002).

For the purposes of this indicator, prior year efforts (FY 1997 and earlier) of the EDO will not be counted toward the five-year goal of 500 new jobs. However, if EDO provides assistance or support to businesses created in prior years that they can demonstrate helped any of these existing businesses expand, the incremental jobs created will be counted toward the goal.

Baseline information: In FY 1996, EDO's efforts resulted in the addition of 37 new jobs to the area's workforce. These 37 jobs were the end results of EDO's efforts, which inciuded the creation of ten new technology based businesses, and providing technical assistance to 49 firms in the immediate Tri-Cities Area.

Performance Expectation Related Assumptions: None identified.

Performance targets:

Target: $\quad 150$ cumulative jobs thru FY 1999, beginning in FY 1998

Neutral: $\quad 100$ cumulative new jobs thru FY 1999, beginning in FY 1998

Minimum: $\quad 50$ cumulative new jobs thru FY 1999, beginning in FY 1998.

4.3 Objective - Battelle will serve the communities to further enhance the Laboratory's status as a valued corporate citizen of the Northwest region. (35\%)

Just as the Pacific Northwest National Laboratory's business mission underlies its role of advancing science and technology, its commitment to the community drives its efforts to serve the neighborhoods in which staff live and work. Building on an already solid reputation as a valued corporate citizen, Battelle will establish two programs to ensure its efforts directly address societal issues in the community and those identified in the FY98 Community Survey. Specifically, the Community Survey indicated that most respondents did not associate the Battelle/PNNL name with volunteer efforts in the community. Also, respondents indicated that Battelle needed to more actively recruit within local minority populations.

Further, Battelie will enhance the Laboratory's reputation in the Northwest by implementing a targeted campaign linking a regional industry with relevant cross-cutting capabilities, products, and specialized user facilities at the Laboratory.

\section{Performance Indicators}

\subsubsection{Successfully deploy a community volunteerism program}

Description: This indicator will measure the implementation of a new program to inform staff of community needs, encourage participation in volunteer programs, and recognize and reward staff for their volunteer efforts. This new program, which will be introduced at the Laboratory in FY 1999 (pending funding), decentralized volunteer program. The mission of program is to positively impact the quality of life in communities in which Battelle staff work and live by supporting volunteer programs that meet the community's needs, capitalize on staff's interests, and are 
consistent with corporate citizenship priorities. The program will focus on volunteer activities in four categories: arts and culture; civic and community; education and health; and human services.

Baseline information: While this program has been implemented in Columbus, it will be new to the Laboratory this year. No Laboratory baseline information exists. The first year we will measure the success of implementation of the program. Subsequent years will measure the success (results) of the program through number of volunteer hours-spent working in the community.

Performance steps: The steps listed below signify. elements of the program that are important to its ultimate success. Nothing here shall be construed as an exception to the contract clause entitled "Allowable Costs and Fee." One point is assigned to each step, with a combined value of 8 points. Target: 8 points; Neutral Level: 5 points; Minimum Level: 0 points.

- Put in place an Advisory Council. The council will serve as a sounding board for the program's future directions, and council members will be expected to act as ambassadors for the program.

- Communicate to the staff about the new program. This could include a web site, a newsletter, and informational forums.

- Establish 10 "volunteer projects" within the new program.

- Establish a baseline of volunteer hours.

- Hold a Volunteer Fair featuring the volunteer projects within the new program and highlight additional volunteer opportunities for staff.

- Use feedback from participants to make improvements to the program.

- Begin making contacts with key community agencies to increase program visibility and identify volunteer opportunities.

- Provide training sessions for volunteer project "directors."

Performance targets:

$\begin{array}{ll}\text { Target: } & 8 \text { points } \\ \text { Neutral: } & 5 \text { points } \\ \text { Minimum: } & 0 \text { points }\end{array}$

4.3.2 The percentage increase in the hiring rate of minorities in mid-level professional feeder job groups.

Description: As found in the Laboratory's Mock Audit of our Affirmative Action Program in 1997, Battelle hiring rate of minorities was found to be low. This finding was reiterated in the Community Survey in 1998. This particular indicator will use hiring reports to measure Battelle progress in Battelle's hiring rate of minorities within the following job categories (Engineer [Level 3], Scientist [Level 3], Specialist [Levels 33-35]). Some programs/tools that have been developed to increase this hiring rate are: Sponsorship of a Minority/Woman Career Fair (planned for Spring, 1999), implementation of a Recruiting Referral Program (where current staff are paid up to $\$ 3,000$ for the referral of a qualified woman os minority who is hired into a professional/managerial job category), implementation of an on-line application process (Job Seeker), and quarterly meetings with the Leadership Team to assess progress.

Baseline Information: This is a new measure this year. The baseline is comprised of both availability percentages (determined by a weighted factor analysis) and the 1998 hiring rates in the mid-level job professional job categories. The calendar year 1998 baselines are as follows: 
Engineer (Level-3)

Scientist (Level 3)

Specialist (Levels 33-35)
$10.2 \%$

$12.7 \%$

$8.8 \%$
$12.5 \%$

$4.1 \%$

$0.0 \%$

\section{Performance Expectation Related Assumptions:}

1) Battelle will have the opportunity to place at least 40 individuals into mid-level professional positions (job openings);

2) Battelle will have at least 5 qualified minorities in their applicant flow for those positions.

\section{Performance:}

Target: $\quad$ Hiring at a $75 \%$ average rate increase over the FY98 average rate of all three-job categories.

Neutral: Hiring at a $50 \%$ average rate increase over the FY98 average rate of all three-job categories.

Minimum: Hiring at no increase (0\%) over the FY98 average of all three-job categories.

4.3.3 Successful deployment of campaigns to increase awareness of Laboratory capabilities applicable to issues and industries of regional significance.

Description: Battelle will deploy a pilot campaign aimed at state opinion leaders to increase name recognition for and positive awareness of the Laboratory's capacity to help resolve regional issues. A separate effort will increase name recognition for and positive awareness of PNNL in a regional industry through a pilot campaign aimed at the Washington biotechnology industry.

Baseline information: The 1998 Community Survey showed that PNNL/Battelle are well known and respected in the local community. Older Battelle surveys show limited national name recognition for the Pacific Northwest Laboratory, but no data currently exists to show regional recognition of the Pacific Northwest National Laboratory.

Building name recognition and awareness is a multi-year, multi-faceted process; therefore, we must identify and measure interim steps toward success. Once mechanisms are put in place, we can measure the effect of our efforts, but it's likely to take more than a year to achieve progress we can actually measure. The performance targets listed are steps toward ultimately measuring success.

Performance Assumptions: None.

Performance Steps: The steps listed below are sequential within each category. The steps need to be completed in the order listed; we cannot progress to step 3 in issues, for example, without completing step 2. One point is assigned to each step, with a combined value for issues and industry of 10 points.

\section{Issues}

Step 1. baseline evaluation of state issues completed

Step 2. internal audit of PNNL existing activities within issue areas completed

Step 3. Integrated campaign defined

Step 4. informational activities under way

\section{Industry}

Step 1. internal audit of biotechnology capabilities, projects, and facilities completed

Step 2. baseline survey of biotechnology industry completed

Step 3. integrated campaign defined

Step 4. informational activities under way 
Step 5. selected companies/individuals identified for intensive follow-up activities

Step 6. measurement of increased awareness and name-recognition begun

Performance targets:

Target:

Neutral:

Minimum:
10 Points (Steps completed)

5 Points (Steps completed)

0 Points (Steps completed)

\section{Critical Outcome Performance Rating and Additional Performance-Based Fee}

Figures $4 \mathrm{~A}, 4 \mathrm{~B}$ and $4 \mathrm{C}$ document the associated agreements on performance expectations in the form of contingency functions. The overall performance rating for this outcome will be determined by summing the effectiveness scores for all Objectives as depicted in Table 4.1, below, normalizing the scores using Table 4.2 and comparing the normalized sum to the rating scale in Table 4.3. Additional performancebased fee earned (if any) for.this outcome is determined by comparing the overall outcome score $(5.0-3.5)$ to the amount available within Table 4.4 . 
Figure 4A, Community Relations Objective 4.1, Contingency Diagram

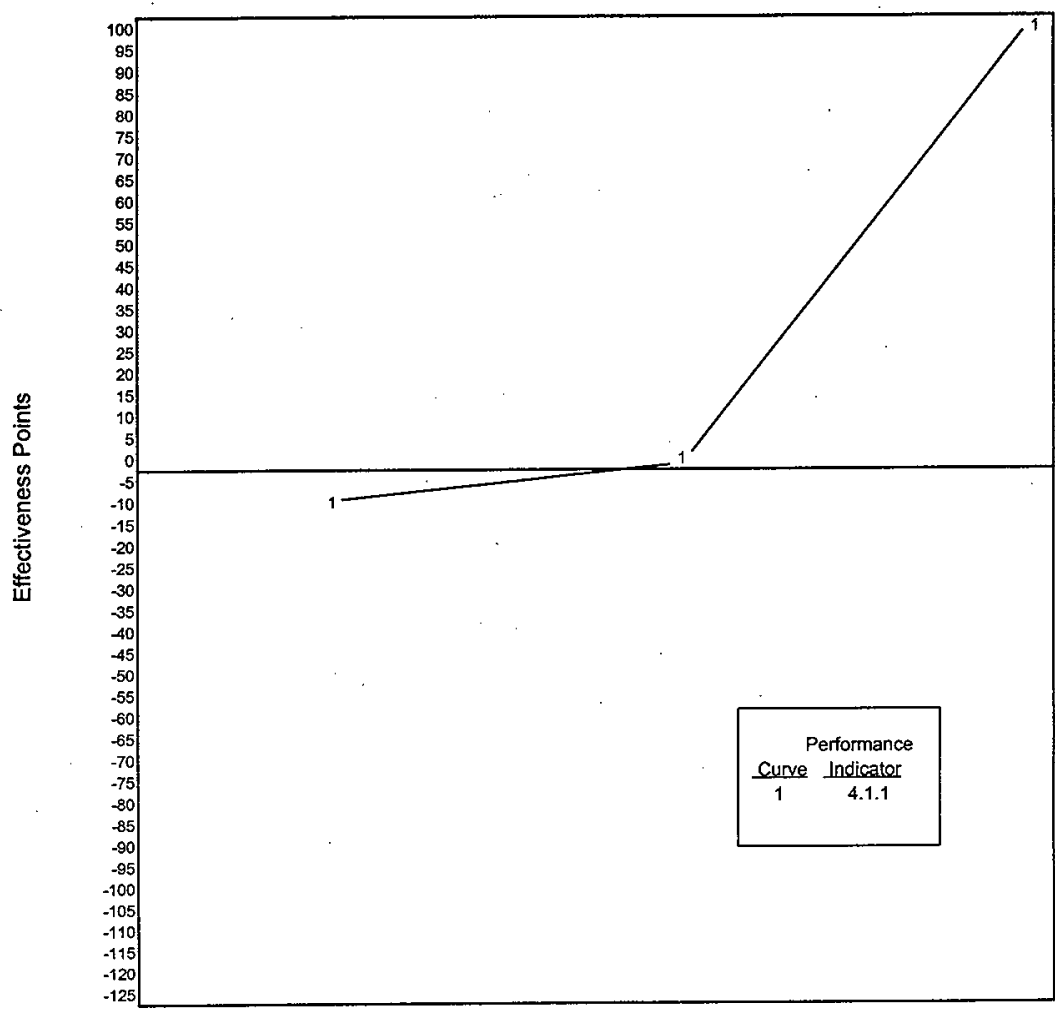

Pefformance Indicator

1 Impact of Lab-sponsored programs for toachers
SCALES

\begin{tabular}{|l|l|l|l|l|l|l|l|l|l|l|l|l|l|l|l|l|l|l|l|l|l|l|l|l|}
\hline \hline & & & & 70 & & 71 & & 72 & & 73 & & 74 & & 75 & & 76 & & 77 & & 78 & & 79 & & 83 \\
\hline
\end{tabular}


Figure 4B, Community Relations Objective 4.2, Contingency Diagram

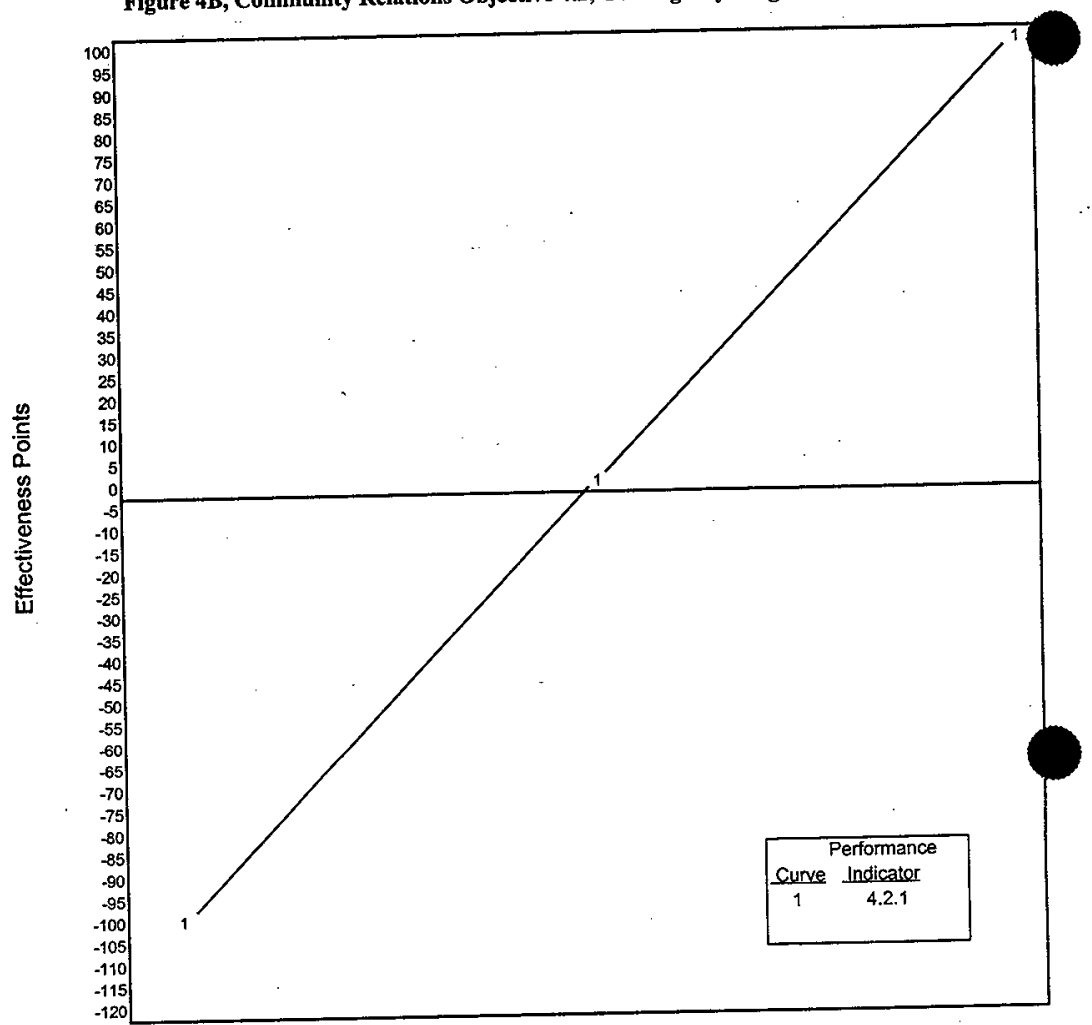

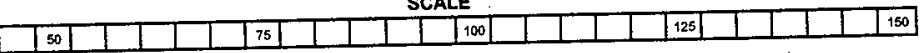


Figure 4C, Community Relations Objective 4.3, Contingency Diagram

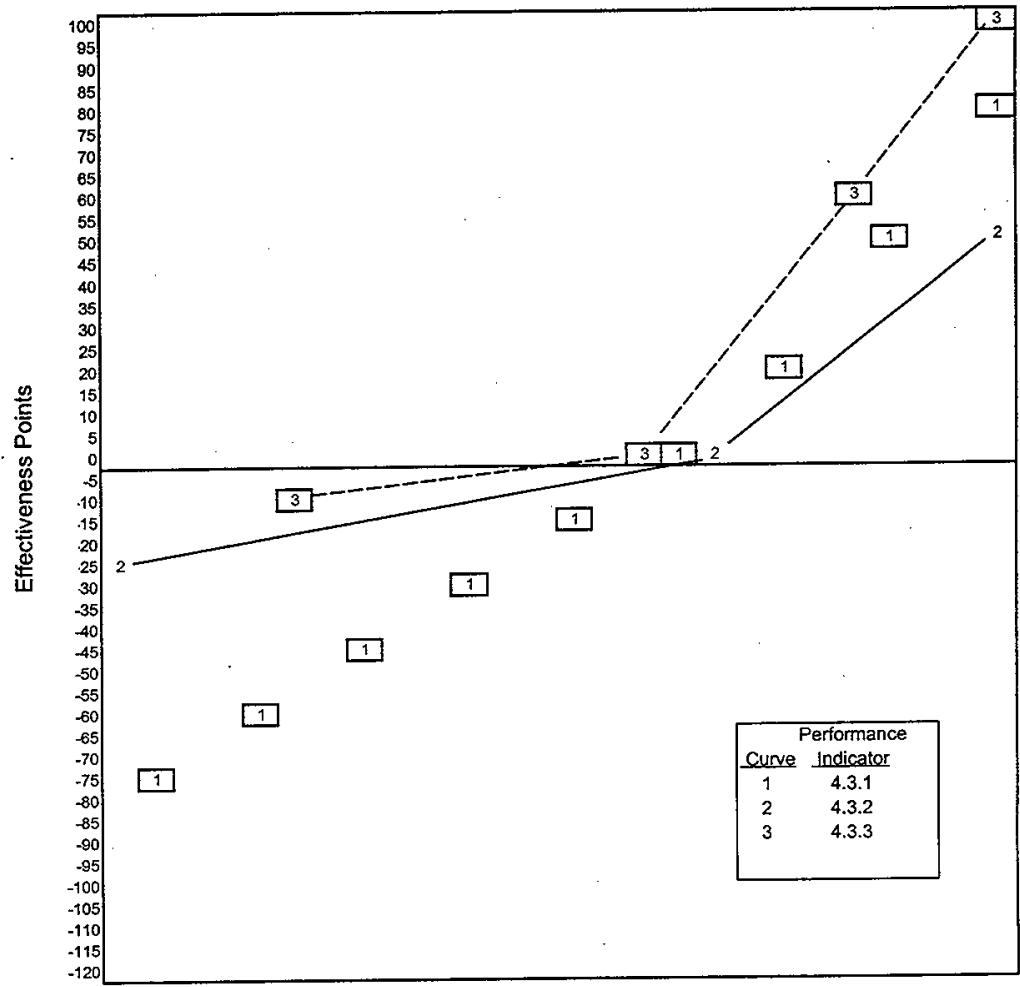

Performance Indicator

1 Community Volunteerism

2 Minority Hiring (\%)

3 Lab capabilities awamess

SCALES

\begin{tabular}{|c|c|c|c|c|c|c|c|c|c|c|c|c|c|c|c|c|c|c|c|c|c|c|c|c|c|}
\hline & 0 & & & 1 & & & 2 & & & 3 & & & 4 & & & 5 & & & 6 & & & 7 & & & 6 \\
\hline 0 & 3 & 6 & 9 & 12 & 15 & 18 & 21 & 24 & 27 & 30 & 33 & 36 & 39 & 42 & 45 & 48 & 51 & 54 & 57 & 60 & 63 & 66 & 69 & 72 & 75 \\
\hline & & & & & 0 & & 1 & & 2 & & 3 & & 4 & & 5 & & 6 & & 7 & & 8 & & 9 & & 10 \\
\hline
\end{tabular}




\begin{tabular}{|c|c|c|c|c|c|}
\hline WELEMENT & $\begin{array}{l}\text { Performance } \\
\text { Level }\end{array}$ & $\begin{array}{l}\text { Effectiveness } \\
\text { Score }\end{array}$ & $\begin{array}{l}\text { Value } \\
\text { Points }\end{array}$ & Wéight & $\begin{array}{l}\text { Weighted } \\
\text { Points }\end{array}$ \\
\hline 4.0 Community Relations & 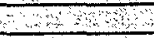 & 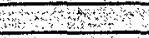 & 13 & 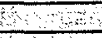 & in \\
\hline $\begin{array}{l}\text { 4.1 Battelle will continue/establish } \\
\text { partnerships with local and regional } \\
\text { organizations to enhance science, } \\
\text { mathematics and technology education } \\
\text { reform efforts in schools }\end{array}$ & & & & & \\
\hline $\begin{array}{l}\text { 4.1.1 The impact of Laboratory- } \\
\text { sponsored programs for teachers of } \\
\text { science, mathematics, and technology } \\
\text { education in partner school districts }\end{array}$ & & & & & \\
\hline 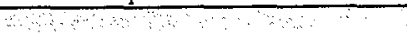 & Obj 4.1 Total & & & $15 \%$ & \\
\hline $\begin{array}{l}\text { 4.2 Battelle will put technology to work } \\
\text { in the Tri-Cities and Pacific Northwest } \\
\text { to create and sustain a diversified and } \\
\text { strong economy }\end{array}$ & & & $\cdots$ & & \\
\hline \multirow[t]{2}{*}{$\begin{array}{l}\text { 4.2.1 Number of primary sector jobs } \\
\text { created within the local area over the five } \\
\text { fiscal years beginning with FY } 1998 \text { and } \\
\text { ending with FY } 2002\end{array}$} & & & & & \\
\hline & Obj 4.2 Total & & & $50 \%$ & \\
\hline $\begin{array}{l}\text { 4.3 Battelle will serve the communities } \\
\text { to further enhance the Laboratory's } \\
\text { status as a valued corporate citizen of } \\
\text { the Northwest region }\end{array}$ & & & & • & \\
\hline $\begin{array}{l}\text { 4.3.1 Successfully deploy a community } \\
\text { volunteerism progratm }\end{array}$ & & & & & \\
\hline $\begin{array}{l}\text { 4.3.2 The percentage increase in the } \\
\text { hiring rate of minorities in mid-level } \\
\text { professional feeder job groups }\end{array}$ & & & & & \\
\hline \multirow[t]{3}{*}{$\begin{array}{l}\text { 4.3.3 Successful deployment of } \\
\text { campaigns to increase awareness of } \\
\text { Laboratory capabilities applicable to } \\
\text { issues and industries of regional } \\
\text { significance }\end{array}$} & & & & & \\
\hline & Obj 4.3 Total & & & $35 \%$ & \\
\hline & & & & Total & \\
\hline
\end{tabular}

Table 4.1 - Community Relations Critical Outcome Performance Rating Development 


\begin{tabular}{|c|c|c|c|}
\hline Objective 4.1 & Objective 4.2 & Objective 4.3 & Value Points \\
\hline 17\% & W & 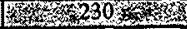 & 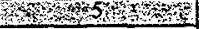 \\
\hline 95 & 95 & 219 & 4.9 \\
\hline 90 & 90 & 207 & 4.8 \\
\hline 85 & 85 & 196 & 4.7 \\
\hline 80 & 80 & 184 & 4.6 \\
\hline 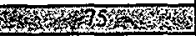 & 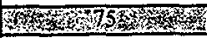 & 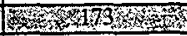 & 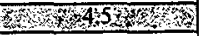 \\
\hline 70 & 70 & 161 & 4.4 \\
\hline 65 & 65 & 150 & 4.3 \\
\hline 60 & 60 & 138 & 4.2 \\
\hline 55 & 55 & 127 & 4.1 \\
\hline 50 & 50 & $115^{\circ}$ & 4 \\
\hline 45 & 45 & 104 & 3.9 \\
\hline 40 & 40 & 92 & 3.8 \\
\hline 35 & 35 & 81 & 3.7 \\
\hline 30 & 30 & 69 & 3.6 \\
\hline $\mathrm{N}, \mathrm{H}, \mathrm{25}, \mathrm{x}$ & 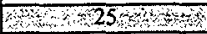 & 60258 , & 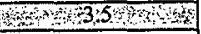 \\
\hline 20 & 20 & 46 & 3.4 \\
\hline 15 & 15 & 35 & 3.3 \\
\hline 10 & 10 & 23 & 3.2 \\
\hline 5 & 5 & 12 & 3.1 \\
\hline 0 & 0 & 0 & 3 \\
\hline-1 & -3 & -5 & 2.9 \\
\hline-1 & -5 & -10 & 2.8 \\
\hline-2 & -8 & -14 & 2.7 \\
\hline-2 & -10 & -19 & 2.6 \\
\hline $4 x+3 \mathrm{~W}$ & $-13, \ldots$ & $x^{2}+1424$ & $2: 5$ \\
\hline-3 & -15 & -29 & 2.4 \\
\hline-4 & -18 & -33 & 2.3 \\
\hline-4 & -20 & -38 & 2.2 \\
\hline$-\overline{5}$ & -23 & -43 & 2.1 \\
\hline-5 & -25 & -48 & 2 \\
\hline-6 & -28 & -52 & 1.9 \\
\hline-6 & -30 & -57 & 1.8 \\
\hline-7 & -33 & -62 & 1.7 \\
\hline-7 & -35 & -67 & 1.6 \\
\hline 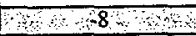 & $3 \times 6-38 \mathrm{~s}, 4$ & Whe 71 s & $1.5: \div:$ \\
\hline-8 & -40 & -76 & 1.4 \\
\hline-9 & -43 & -81 & 1.3 \\
\hline-9 & $-\overline{45}$ & -86 & 1.2 \\
\hline-10 & $-\overline{48}$ & -90 & 1.1 \\
\hline tक 10 & Sop & Dor 495 \% & 51 \\
\hline
\end{tabular}

Table 4.2 - Community Relations Critical Outcome Score Normalization Table 


\begin{tabular}{|c|c|c|c|c|c|}
\hline Total Score & $5.0-4.5$ & $4.4-3.5$ & $3.4-2.5$ & $2.4-1.5$ & $1.4-1.0$ \\
\hline Final Rating & Outstanding & Excellent & Good & Marginal & Unsatisfactory \\
\hline
\end{tabular}

Table 4.3 - Community Relations Critical Outcome Final Rating

\begin{tabular}{|c|c|r|}
\hline Outcome Rating & Score & $\begin{array}{c}\text { Pertormance-Based } \\
\text { Fee }\end{array}$ \\
\hline \multirow{4}{*}{ Outstanding } & 5.0 & $\$ 70,000$ \\
\cline { 2 - 3 } & 4.9 & $\$ 65,625$ \\
\cline { 2 - 3 } & 4.8 & $\$ 61,250$ \\
\cline { 2 - 3 } & 4.7 & $\$ 56,875$ \\
\cline { 2 - 3 } & 4.6 & $\$ 52,500$ \\
\cline { 2 - 3 } & 4.5 & $\$ 48,125$ \\
\hline \hline \multirow{5}{*}{ Excellent } & 4.4 & $\$ 43,750$ \\
\cline { 2 - 3 } & 4.3 & $\$ 39,375$ \\
\cline { 2 - 3 } & 4.2 & $\$ 35,000$ \\
\cline { 2 - 3 } & 4.1 & $\$ 30,625$ \\
\cline { 2 - 3 } & 4.0 & $\$ 26,250$ \\
\cline { 2 - 3 } & 3.9 & $\$ 27,875$ \\
\cline { 2 - 3 } & 3.8 & $\$ 17,500$ \\
\cline { 2 - 3 } & 3.7 & $\$ 13,125$ \\
\cline { 2 - 3 } & 3.6 & $\$ 8,750$ \\
\cline { 2 - 3 } & 3.5 & $\$ 4,375$ \\
\hline \multirow{5}{*}{ Good or Less } & 3.4 & $\$ 10$ \\
\hline
\end{tabular}

Table 4.4 - Community Relations Outcome Additional Performance-Based Fee Matrix 


\section{SELF-ASSESSMENT}

RL views the Contractor's self-assessment as the primary tool to determine if they are accomplishing agreed-to outcomes, objectives and performance measures and doing so in a manner that is acceptable. In addition, the Contractor utilizes self-assessment as a primary mechanism for evaluating the overall effectiveness of their organizations and to promote continues improvement. The key to the performancebased evaluation process, which we have employed within the Laboratory, is the utilization of selfassessment as the primary tool for evaluation of the Contractor. In order for this concept to succeed we must diligently work with our contractor counterparts throughout each year to track the progress of the outcomes and objectives set forth within the contract or the individual Division and Directorate-level selfassessment plans. This regular interaction should be carried out under the principles of partnership and trust that form the basis of our relationship with the Contractor.

I. Contractor Laboratory Level Self-Assessments

The Contractor is required to deliver a Laboratory Level Self-Assessment Plan to the RI Office of Assistant Manager for Science and Technology (AMT) within the first quarter of each fiscal year. This plan is to include the Critical Outcomes and their corresponding objectives and performance indicators as well as a compilation of the independent Division and Directorate self-assessment plans.

The Contractor is required to provide monthly and/or quarterly updates (as appropriate) on the performance of the Critical Outcomes and their corresponding performance indicators. The Contractor shall provide a formal status briefing at mid-year, with a fornal self-evaluation report issued to RL at year-end. Specific due dates for the above mentioned briefings and reports shall to be agreed upon by the Laboratory Director and the RL Assistant Manager for Science \& Technology.

In addition, the year-end report must provide:

- an overall summary of performance for FY99

- performance ratings for each critical outcome and the Laboratory overall, and

- a summary of key strengths and weaknesses identified as part of the Division/Directorate level self-assessment activities.

II. Contractor Division and Directorate Level Self-Assessments

The Contractor shall develop Division and Directorate-level self-assessment plans for each fiscal year. Using the critical outcomes as the basis, Division and Directorate-level self-assessment plans are to be developed in cooperation with both their internal and external (RL, HQ, or other counterparts). Final plans are to be provided to the Contractor's Director of Quality with a copy issued to the AMT Management and Economic Transition Division. Copies of the individual plans should also be provided to the corresponding external RL customer (as appropriate).

The year-end Division and Directorate-level self-evaluation reports are to be submitted to the Contractor's Director of Quality as part of the Integrated Self-Assessment Program. The mid-year reports are not required deliverables to RL however; it is recommended that they be made available to the appropriate RL counterparts for purposes of assisting RL with their management and oversight responsibilities. Copies of the year-end Division and Directorate-level self-evaluation reports are to be provided to the AMT Management and Economic Transition Division and the corresponding external RL customer. 


\section{RL Annual Performance Evaluation}

RL, will conduct an annual performance review during the first quarter following the end of each fiscal year culminating in a final evaluation report issued to the Contractor. This review will provide RL with a formal opportunity to follow-up on any specific issues associated with the critical outcomes or Division/Directorate level self-assessment activities. Use of the Contractor's year-end self-assessment reports, knowledge gained through daily interactions, DOE "For Cause" reviews (if any), and any reviews conducted by outside organizations (i.e., OIG, GAO, DCAA) should be the primary means for determining the Contractors performance for the year. This information, along with the results of any individual issue reviews (as necessary) during the two-week review period, shall be utilized to provide the Contractor with the overall written performance appraisal. 


\section{Identification:}

Date:

Critical Outcome:

Objective Number(s):

Performance Indicator Number(s):

\section{Discussion:}

1. Description of Proposed Modification: Attach to this form.

2. Rationale/Justification for Modification: Attach to this form.

\section{Concurrence;}

Battelle Point-of-Contact (preparer):

$$
\text { (Typed or Printed Name) } / \text { (Initials)/ (Date) }
$$

RL Point-of-Contact:

$$
\begin{array}{lll}
\text { (Typed or Printed Name) } / & \text { (Initials) } / \quad \text { (Date) }
\end{array}
$$

Battelle Critical Outcome Owner:

$$
\text { (Typed or Printed Name) } / \text { (Initiais) / (Date) }
$$

RL Critical Outcome Owner:

$$
\text { (Typed or Printed Name) } / \text { (Initials) } / \text { (Date) }
$$

Administrative Processing :

Battelle Review:

RL Review:

Revision of Performance Evaluation document into which the Change was incorporated:

Contract Modification Required? Yes No

\section{Approvals:}

Battelle Contracting Officer

RL Contracting Officer

$$
\text { (Name Typed) }-\overline{(\overline{D a t e})} \quad-\quad \text { (Name Typed) }-\frac{}{\text { (Date) }}
$$

Revision 0, 10/1/98 


\begin{tabular}{|c|c|c|}
\hline ELEMENT & PNNL & $\mathbf{R L}$ \\
\hline 1.0 SCIENTIFIC \& TECHNOLOGICAL EXCELLENCE & $\begin{array}{l}\text { Gerry Stokes/ } \\
\text { Bill Shipp/ } \\
\text { Mike Kluse/ } \\
\text { Don McConnell }\end{array}$ & Debbie Trader \\
\hline 1.1 Conduct high quality science and technology programs & Gerry Stokes & Roger Pressentin \\
\hline $\begin{array}{l}\text { 1.1.1 Results of external peer review of relevance and excellence, : } \\
\text { including Divisional reviews }\end{array}$ & Ron Walters & Billie Mauss \\
\hline $\begin{array}{l}\text { 1.1.2 Recognition by the scientific community, inciuding awards, } \\
\text { invited talks at major scientific meetings, and service on major } \\
\text { committees and scientific bodies }\end{array}$ & Ray Stults & Billie Mauss \\
\hline 1.1.3 Number of R\&D 100 and FLC Awards & Julie Gephart & Billie Mauss \\
\hline 1.1.4 Number of publications in peer reviewed journals & Erik Anderson & Billie Mauss \\
\hline 1.1.5 Number of quality academic/scientific partnerships & Eric Leber & Billie Mauss \\
\hline 1.1.6 Results of DOE-OER Evaluation of the Quality of Science & Gerry Stokes & Billie Mauss \\
\hline $\begin{array}{l}1.2 \text { Deliver science and technology products relevant to } \mathrm{DOE} \\
\text { missions and national needs }\end{array}$ & $\begin{array}{l}\text { Gerry Stokes/ } \\
\text { Bill Shipp/ } \\
\text { Mike Kluse/ } \\
\text { Don McConnell } \\
\end{array}$ & Roger Pressentin \\
\hline $\begin{array}{l}\text { 1.2.1 Results of DOE-OER's evaluation of the relevance of Battelle } \\
\text { work to DOE Missions and Needs }\end{array}$ & Gerry Stokes & Roger Pressentin \\
\hline $\begin{array}{l}\text { 1.2.2 The results of DOE-OER's evaluation of the Laboratory's } \\
\text { programmatic performance }\end{array}$ & Gerry Stokes & Roger Pressentin \\
\hline $\begin{array}{l}1.2 .3 \text { Effectively lead the technical aspects of the national Tanks Focus } \\
\text { Area }\end{array}$ & Tom Brouns & Lance Mamiya \\
\hline 1.2.4 Effectively support the Hanford Tanks Privatization Effort & Terri Stewart & Roger Pressentin \\
\hline $\begin{array}{l}1.2 .5 \text { Number of innovative technologies and approaches successfully } \\
\text { deployed in commercial practice }\end{array}$ & $\begin{array}{l}\text { John Sealock/ } \\
\text { Karis Alderson }\end{array}$ & Dave Biancosino \\
\hline 1.2.6 Provide significant solutions to Hanford problems/needs & Bill Bonner & Shannon Saget \\
\hline $\begin{array}{l}\text { 1.2.7 Customer Feedback on relevance and excellence in } \\
\text { Environmental Quality }\end{array}$ & Mardell Sours & Roger Pressentin \\
\hline $\begin{array}{l}1.2 .8 \text { Number of solutions and deployments to significant national } \\
\text { security problems/issues }\end{array}$ & Gretchen Gerke & Debbie Trader \\
\hline $\begin{array}{l}\text { 1.2.9 Customer Feedback on relevance and excellence in National } \\
\text { Security }\end{array}$ & Gretchen Gerke & Debbie Trader \\
\hline $\begin{array}{l}1.2 .10 \text { Number of energy technologies, systems and technical } \\
\text { solutions deployed }\end{array}$ & Bryan Mohler & Harry Bell \\
\hline 1.2.11 Customer Feedback on relevance and excellence in Energy & Bryan Mohler & Harry Bell \\
\hline 1.3 Successfully operate the Wiley Lab and ARM Facilities & Gerry Stokes & Jeff Day \\
\hline 1.3.1 Successful operation of the Wiley Laboratory & Doug Ray & Jeff Day \\
\hline 1.3.2 Operation of ARM Extended Research Facilities & Bill Pennell & Jeff Day \\
\hline $\begin{array}{l}\text { 1.3.3 Results of DOE-OER's evaluation of the quality of the } \\
\text { Laboratory's User Facilities }\end{array}$ & Gerry Stokes & Jeff Day \\
\hline
\end{tabular}




\begin{tabular}{|c|c|c|}
\hline $\begin{array}{l}\text { 1.4 Demonstrate leadership and excellence in program planning } \\
\text { and management of critical outcomes }\end{array}$ & $\begin{array}{l}\text { Gerry Stokes/ } \\
\text { Bill Shipp/ } \\
\text { Mike Kluse/ } \\
\text { Don McConnell }\end{array}$ & Roger Pressentin \\
\hline $\begin{array}{l}\text { 1.4.1 Demonstrate programmatic leadership within Fundamental } \\
\text { Science }\end{array}$ & Gerry Stokes & Jeff Day \\
\hline 1.4.2 Demonstrate programmatic leadership in Environmental Quality & & Roger Pressentin \\
\hline $\begin{array}{l}\text { 1.4.3 Effectively lead the technical aspects of the Groundwater and } \\
\text { Vadose Zone efforts }\end{array}$ & Tom Page & Jim Hanson \\
\hline $\begin{array}{l}\text { 1.4.4 Customer Feedback on Leadership for key National Security } \\
\text { Programs }\end{array}$ & Gretchen Gerke & Debbie Trader \\
\hline $\begin{array}{l}\text { 1.4.5 DOE customer feedback on technical and managerial leadership } \\
\text { in the Energy thrust areas }\end{array}$ & Brian Mohler & Harry Bell \\
\hline 1.4.6 Number of formal agreements ... with private sector entities & Brian Mohler & Harry Bell \\
\hline 2.0 OPERATIONAL EXCEXLENCE & $\begin{array}{l}\text { Peggy Williams/ } \\
\text { Dick Watkins }\end{array}$ & Roger Christensen \\
\hline $\begin{array}{l}\text { 2.1 Sustain and enhance operational excellence in safety and } \\
\text { health, and environmental protection }\end{array}$ & $\begin{array}{l}\text { Sharon Dossett/ } \\
\text { Dave Carroll } \\
\end{array}$ & Julie Turner \\
\hline $\begin{array}{l}\text { 2.1.1 Management interactions with workers to ensure staff } \\
\text { involvement in work planning, knowledge of requirements and } \\
\text { attitude/culture relative to ES\&H }\end{array}$ & Hañs Vogel & Julie Turner \\
\hline 2.1.2 ES\&H training commensurate with assigned responsibilities & Paul Weeks & Craig Richins \\
\hline 2.1.3 Material control & Alice Ikenberry & Annette Barnard \\
\hline 2.1.4 ES\&H lagging performance indicators & Sharon Dossett & Mary Beth Burandt \\
\hline $\begin{array}{l}2.2 \text { Increase mission capabilities through enhancement of effective } \\
\text { use of Laboratory facilities and assets }\end{array}$ & John Wald & Cesar Collantes \\
\hline 2.2.1 Facilities (buildings) composite & Byron Robertson & Cesar Collantes \\
\hline 2.2.2 R\&D Equipment Utilization & Doug Ray & Theresa Aldridge \\
\hline 2.2.3 Infrastructure composite & Greg Herman & Kyle Sato \\
\hline 3. LEADERSHIP \& MANAGEMENT & $\begin{array}{l}\text { Paula Linnen/ } \\
\text { Jeff Smith/ } \\
\text { Tom Baranouskas } \\
\end{array}$ & Joe Wiley \\
\hline $\begin{array}{l}\text { 3.1 Battelle will provide leadership and management to foster a } \\
\text { work environment that optimizes staff satisfaction and individual } \\
\text { contribution }\end{array}$ & Paula Linnen & Steve Einan \\
\hline 3.1.1 Staff separations rate & Marilyn Merryman & Steve Einan \\
\hline 3.1.2 Personal/Professional Development & Marilyn Merryman & Steve Einan \\
\hline $\begin{array}{l}\text { 3.2 Battelle leadership provides effective management systems to } \\
\text { drive improvements enabling DOE to optimize oversight activities }\end{array}$ & Jeff Smith & Steve Einan \\
\hline $\begin{array}{l}\text { 3.2.1 Contractor's independent annual average rating of the } \\
\text { Divisions/Directorates self-assessment program performance }\end{array}$ & Larry McClellan & Mark Coronado \\
\hline $\begin{array}{l}3.2 .2 \text { DOE's satisfaction with the implementation of the Contractor's } \\
\text { self-assessment process }\end{array}$ & Larry McClellan & Mark Coronado \\
\hline $\begin{array}{l}\text { 3.2.3 Staff satisfaction with internal products and services from the } \\
\text { management system }\end{array}$ & Larry McClellan & Steve Einan \\
\hline $\begin{array}{l}\text { 3.3 Battelle leadership and management promote effective business } \\
\text { operations }\end{array}$ & Tom Baranouskas & Steve Einan \\
\hline 3.3.1 Research to support staff labor ratio & Greg Tumer & Steve Einan \\
\hline 3.3.2 Average cost per research FTE & Greg Turner & Steve Einan \\
\hline $\begin{array}{l}3.3 .3 \mathrm{DOE} \text { 's evaluation of overall Contractor performance in the } \\
\text { business management functional areas }\end{array}$ & Larry McClellan & Mark Coronado \\
\hline
\end{tabular}

business management functional areas 


\begin{tabular}{|c|c|c|}
\hline 4. COMMUNITY RELATIONS & Mike Schwenk & Joe Wiley \\
\hline $\begin{array}{l}\text { 4.1 Battelle will continue/establish partnerships with local and } \\
\text { regional organizations to enhance science, mathematics and } \\
\text { technology education reform efforts in schools }\end{array}$ & Mike Schwenk & Steve Einan \\
\hline $\begin{array}{l}\text { 4.1.1 The impact of Laboratory-sponsored programs for teachers of } \\
\text { science, mathematics and technology education in partner school } \\
\text { districts }\end{array}$ & Jeff Estes & Steve Einan \\
\hline $\begin{array}{l}\text { 4.2 Battelle will put technology to work in the Tri-cities and Pacific } \\
\text { Northwest to create and sustain a diversified and strong economy }\end{array}$ & Mike Schwenk & Bob Stewart \\
\hline $\begin{array}{l}\text { 4.2.1 Number of primary sector jobs created within the local area over } \\
\text { the five fiscal years beginning with FY } 1998 \text { and ending with FY } 2002\end{array}$ & Mike Schwenk & Bob Stewart \\
\hline $\begin{array}{l}4.33 \text { Battelle will serve the communities to further enhance the } \\
\text { Laboratory's status as a valued corporate citizen of the Northwest } \\
\text { region }\end{array}$ & Penny Phelps & Steve Einan \\
\hline 4.3.1 Successfully deploy a community volunteerism program & Katie Larson & Steve Einan \\
\hline $\begin{array}{l}\text { 4.3.2 The percentage increase in the hiring rate of minorities in mid- } \\
\text { level professional feeder job groups }\end{array}$ & Kevin Knox & Steve Einan \\
\hline $\begin{array}{l}\text { 4.3.3 Successful deployment of a campaigns to increase awareness of } \\
\text { Laboratory capabilities applicable to issues and industries of regional } \\
\text { significance }\end{array}$ & Kathryn Lang & Steve Einan \\
\hline
\end{tabular}


FY 1999 Performance Evaluation Agreement Distribution List For The Pacific Northwest National Laboratory

DOE-AMT/STP/STO/MET

NAME

RF Christensen

CE Collantes

MA Coronado

TL Davis

SR Einan

JK Erickson

RA Pressentin

CR Richins

RM Rosselli

DE Trader

JK Turner

JW Wiley

DOE-RL

\section{NAME}

JK Absher

JD Bauer

LK Bauer

GM Bell

KA Benguiat

$\mathrm{R}$ Cruz

KR Ensign

L Erickson

OA Farabee

DG Ogg

CA Hansen

EW Higgins

JE Kinzer

PM Knolimeyer

PW Kruger

AE Lorenze

ND Moorer

AQ Murphy

JE Ollero

LL Piper

KK Randolph

JE Rasmussen

RP Saget

DJ Sansotta

SM Sandlin

JL Spracklen

RR Tibbatts

SJ Veitenheimer

JD Wagoner
MSIN

K8-50

K8-50

K8-50

K8-50

K8-50

K8-50

K $8-50$

K8-50

$\mathrm{K} 8-50$

K $8-50$

K8-50

$\mathrm{K} 8-50$

MSIN

A7-50

A1-61

HO- 12

A5-52

R3-78

A1-55

A7-88

A7-80

R3-79

A5-52

S7-41

A5.58

S7-50

A5-11

A5-54

A7-72

A5- 11

A7-29

A5-18

A7-50

A7-75

A5-15

G6-52

A6-36

H0-12

A6-35

A7-89

A5-55

A7-50
DOE-HQ

NAME

PE Bayer

MA Krebs

AG Joseph

JM LaBarge

AA Patrinos

JS Walker

AM Zerega
ADDRESS

F-240

U.S. Department of Energy

19901 Germantown Road

Germantown, MD 20874-1290

7B-058

Forrestal Building

1000 Independence Ave SW

Washington D.C. 20585-0118

3F-043

Forrestal Building

1000 Independence Ave SW

Washington D.C. 20585-0118

$3 \mathrm{~F}-077$

Forrestal Building

1000 Independence Ave SW

Washington D.C. 20585-0118

G-165

U.S. Department of Energy 19901 Germantown Road Germantown, MD 20874-1290

Room 1157

U.S. Department of Energy 20400 Century Boulevard

Germantown, MD 20874

$3 \mathrm{H}-051$

Forrestal Building

1000 Independence Ave SW

Washington D.C. 20585.0118 
PNNL

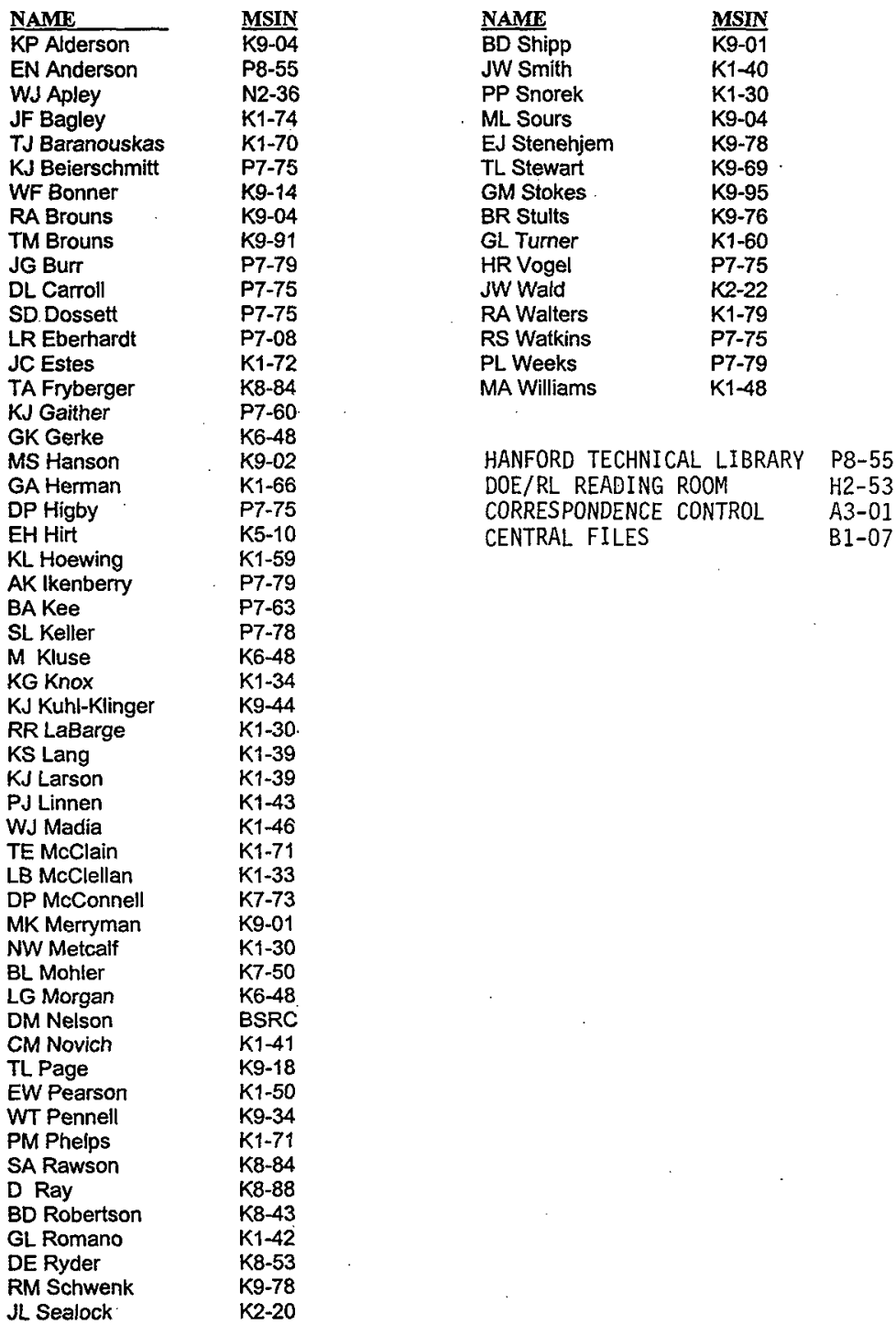

